\title{
Sound encoding in mutant mice with disrupted action potential generation
}

\author{
PhD Thesis \\ For the award of the degree \\ Doctor rerum naturalium \\ In the Sensory and Motor Neuroscience Program \\ at the Georg August University Göttingen \\ Faculty of Biology
}

submitted by

Gulnara Yamanbaeva

from

Salym, Russia

Göttingen, May 2017 


\section{Examination committee}

PD Dr. Nicola Strenzke (Supervisor, Reviewer, Member of the thesis committee) Department of Otolaryngology University Medical Center Göttingen

Prof. Dr. Siegrid Löwel (Reviewer, Member of the thesis committee) Department of Systems Neuroscience University of Göttingen

Prof. Dr. Tim Gollisch (Member of the thesis committee)

Department of Ophthalmology

University Medical Center Göttingen

Prof. Dr. Jochen Staiger (Member of extended committee)

Department of Neuroanatomy

University Medical Center Göttingen

Prof. Dr. Alexander Gail (Member of extended committee)

Sensorimotor Group

German Primate Center, Göttingen

Prof. Dr. Martin Göpfert (Member of extended committee)

Department of Cellular Neurobiology

University of Göttingen

Date of oral examination: $21^{\text {st }}$ of August 2017 


\section{Declaration}

Hereby I ensure that this thesis has been written independently and with no other sources and aids than quoted.

Gulnara Yamanbaeva

Göttingen, May 2017 


\section{Contents}

List of Figures $\quad$ v

List of Abbreviations $\quad$ vii

Summary $\quad$ ix

1 Introduction $\quad 2$

1.1 Sound encoding in peripheral nervous system 2

1.2 IHC ribbon synapse structure 4

1.3 Otoferlin mutant mice $\quad 7$

1.4 Tryptophan-rich basic protein (Wrb) knockout mouse $\quad 7$

1.5 IHC ribbon synapse exocytosis $\quad 8$

1.6 Anteroventral cochlear nucleus cells 9

1.7 Response properties of auditory nerve fibers $\quad 10$

$\begin{array}{ll}\text { 1.7.1 Spontaneous spikes activity } & 10\end{array}$

1.7.2 Tuning curves and frequency selectivity 11

$\begin{array}{ll}\text { 1.7.3 Sound - evoked responses } & 11\end{array}$

1.8 AMPA receptors in spiral ganglion neuron $\quad 12$

1.9 PSD - MAGUK proteins at neuronal synapses 13

1.10 AMPA receptors lateral organization and mobility 14

1.11 AMPA receptors in spiral ganglion neurons 16

1.12 PSD-95 deficient mice 18

1.13 Action potential generation in neurons $\quad 18$

1.14AIS structure and function $\quad 19$

1.14.1 Plasma membrane AIS region $\quad 20$

1.14.2 Submembrane AIS region $\quad 22$

1.14.3 Cytoplasmic AIS region 24

1.15 AP generation in spiral ganglion neurons 24

1.16 Quiverer mutant mice $\quad 25$

2 Materials and Methods 27

2.1 Animals 27

2.2 ABR measurement 27

2.3 Single unit extracellular recordings from ANFs and Cochlear nucleus neurons $\quad 29$

$\begin{array}{ll}\text { 2.3.1 Surgical approach } & 29\end{array}$

2.3.2 ANFs and cochlear nucleus neurons identification 30 
2.3.3 Acoustic system and signal processing $\quad 30$

2.3.4 Stimulus and response measurements 31

2.4 Immunohistochemistry 33

2.4.1 IHC ribbon synapse number 33

2.4.2 AMPAR subclusters number and distance from presynaptic active zone 33

2.4.3 PSD-95 expression and localization in SGNs 34

2.4.4 PSD-93 expression in PSD-95//- and PSD-95+/+SGNs 34

2.4.5 SAP-102 expression in SGNs 34

2.5 STED microscopy 34

2.6 Intellicage $\quad \mathbf{3 5}$

2.6.1 Transponder injection $\quad 35$

2.6.2 Intellicage setup 36

2.7 Data analysis 37

3 Results 39

3.1 Auditory phenotype of $\boldsymbol{W r}_{\boldsymbol{r}} \boldsymbol{b}^{\mathrm{fl} / \mathrm{fl}: \mathrm{Cr}^{A} \text { mice }} \mathbf{3 9}$

3.1.1 WRB disruption causes progressive hearing impairment in mice, observed

in strongly impaired ABRs $\quad 39$

3.1.2 Impaired sound encoding in $\mathrm{Wrb}^{\mathrm{fl} / \mathrm{fl}}$ : $\mathrm{Cre}^{\mathrm{A}} \mathrm{SGNs} \quad 40$

3.2 Sound encoding in PSD-95\%- mice 42

3.2.1 ABRs in PSD-95\%- mice 42

3.2.2 Disruption of PSD-95 entails reduction of spike generation in SGNs 43

3.2.3 Impaired AP generation in PSD-95/- SGNs compensated in $\mathrm{CN}$ neurons

3.2.4 Microscopy studies of the IHC ribbon synapses in PSD-95-/-mice 49

3.3 Auditory phenotype of $\mathbf{Q v}^{3} \mathrm{~J}$ mutant mice $\quad 57$

3.3.1 ABRs in $\mathrm{Qv}^{3}$ mutant mice $\quad 57$

3.3.2 Sound encoding in $\mathrm{Qv}^{3} \mathrm{~J}$ mutant mice $\quad 58$

3.3.3 Partial compensation in Qv $\mathrm{v}^{3 \mathrm{~J}}$ mutant globular bushy cells $\quad 60$

3.3.4 Full compensation in $\mathrm{Qv}^{3 \mathrm{~J}}$ mutant stellate cells 61

3.4 Sound perception in Otof ${ }^{1515 T / I 515 T}$ mice $\quad 63$

4 Discussions $\quad 65$

4.1 PSD-95 and synaptic AMPA receptors in sound encoding $\quad 65$

4.1.1 Reduction of ABR wave I amplitude in PSD-95\%- mice 65

4.1.2 Impaired sound encoding in PSD-95/- afferent IHC ribbon synapses 65

4.1.3 Immunohistochemical, confocal and STED microscopy studies of AMPA

receptor $\quad 67$

4.1.4 Central compensation of SGNs synaptic deficit in AVCN neurons 68

4.2 Impaired sound encoding in $\mathrm{Qv}^{3 \mathrm{~J}}$ mutant mice $\quad 68$

4.3 Auditory synaptopathy phenotype of $\mathrm{WRB}^{\mathrm{fl} / \mathrm{fl}}: \mathrm{Cre}^{\mathrm{A}}$ mice $\quad 70$ 
4.4 Impaired gap detection in Otof ${ }^{1515 T / 1515 T}$ mice

References

Acknowledgements

92

Curriculum Vitae

List of Publications 


\section{List of Figures}

\begin{tabular}{|c|c|}
\hline Figure 1 & Human ear structure \\
\hline Figure 2 & Organ of Corti (A) and IHC (B) innervated by SGNs \\
\hline Figure 3 & AMPA receptors and PSD-95 in SGN \\
\hline Figure 4 & Action potential \\
\hline Figure 5 & Voltage-gated sodium channels at AIS \\
\hline Figure 6 & ABR waves sources \\
\hline Figure 7 & Mouse preparation for the $\mathrm{ABR}$ recording \\
\hline Figure 8 & $\begin{array}{l}\text { Surgical approach for SGN and Cochlear nucleus neurons } \\
\text { single unit recording }\end{array}$ \\
\hline Figure 9 & $\begin{array}{l}\text { Representative examples illustrating the analysis of sound } \\
\text { evoked response measurements }\end{array}$ \\
\hline Figure 10 & Intellicage setup under laptop computer control \\
\hline Figure 11 & Degraded ABRs in $\mathrm{Wrb}^{\mathrm{fl} / \mathrm{fl}}: \mathrm{Cre}^{\mathrm{A}}$ mice \\
\hline Figure 12 & Sound encoding in SGNs of $\mathrm{WRB}^{\mathrm{fl} / \mathrm{fl}}: \mathrm{Cre}^{\mathrm{A}}$ mice \\
\hline Figure 13 & ABRs in PSD-95 ${ }^{-/-}$and wild type mice \\
\hline Figure 14 & Sound encoding in PSD-95 $5^{--}$and wild type SGNs \\
\hline Figure 15 & $\begin{array}{l}\text { Sound encoding in PSD-95 } 5^{-/-} \text {and wild type globular and } \\
\text { stellate cochlear nucleus cells }\end{array}$ \\
\hline Figure 16 & $\begin{array}{l}\text { Preliminary immunofluorescence analysis of IHC ribbon } \\
\text { synapses number }\end{array}$ \\
\hline Figure 17 & PSD-95 expression in SGNs \\
\hline Figure 18 & $\begin{array}{l}\text { Triple staining for CtBP2 (ribbon), GluA2/3 (AMPAR } \\
\text { subunits) and PSD-95 in PSD-95 } 5^{+/+} \text {and PSD-95 }{ }^{-/-} \text {SGNs }\end{array}$ \\
\hline Figure 19 & STED microscopy of AMPA receptors in PSD-95 ${ }^{-/-}$SGNs \\
\hline Figure 20 & $\begin{array}{l}\text { Analysis of AMPAR subclusters in PSD-95 }{ }^{-/-} \text {and PSD-95 } \\
\text { SGNs }\end{array}$ \\
\hline Figure 21 & PSD-93 expression in PSD-95 ${ }^{-/-}$and PSD-95 ${ }^{+/+}$SGNs \\
\hline Figure 22 & $\begin{array}{l}\text { STED imaging of SAP-102 expression at SGNs of C } 57 \mathrm{Bl} / 6 \\
\text { mouse at P14 }\end{array}$ \\
\hline Figure 23 & ABRs in $\mathrm{Qv}^{3 \mathrm{~J}}$ mutant and wild type mice \\
\hline Figure 24 & Sound encoding in $\mathrm{Qv}^{3 \mathrm{~J}}$ mutant and wild type SGNs \\
\hline Figure 25 & $\begin{array}{l}\text { Sound encoding in } \mathrm{Qv}^{3 \mathrm{~J}} \text { mutant and wild type globular bushy } \\
\text { cells }\end{array}$ \\
\hline Figure 26 & Sound encoding in $\mathrm{Qv}^{3 \mathrm{~J}}$ mutant and wild type stellate cells \\
\hline
\end{tabular}




\section{List of Abbreviations}

ABR

AIS

AMPA

ANF

AnkG

AP

AVCN

CAM

Cav

$\mathrm{CF}$

CtBP2

$\mathrm{CV}$

$\mathrm{dB}$

DLG

EPSC

FSL

GluR

GUK

IHC

ISI

$\mathrm{Kv}$

LTP

mEPSC

$\mathrm{Nav}$

NF-186

NMDA

NrCAM

$\mathrm{OHC}$

PDZ

PSD

PSD-MAGUK

RRP

SAP
Auditory brainstem response

Axon initial segment

$\alpha$-amino-3-hydroxy-5-methyl-4-isoxazolepropionic acid

Auditory nerve fiber, same as SGN

Ankyrin-G

Action potential

Anterior ventral cochlear nucleus

Cell adhesion molecules

Voltage-gated calcium channel

Characteristic frequency

C-terminal binding protein 2

Coefficient of variation

Decibel

Disc-large homolog

Excitatory post-synaptic current

First spike latency

Glutamate receptor sub-unit, the same as GluA2

Guanylate kinase

Inner hair cell

Inter spike interval

Voltage-gated potassium channel

Long-time potentiation

Miniature EPSC

Voltage-gated sodium channel

Neurofascin 186

Glutamate receptors-N-methyl-D-aspartate

Neuronal cell adhesion molecule

Outer hair cell

PSD-95/Disc large/Zona occludens 1

Postsynaptic density

Post-synaptic density-membrane associated guanylate kinase proteins

Ready releasable pool

Synapse - associated protein 
SGN

$\mathrm{SH} 3$

SPL

SR

TARP

TRC40

Vglut3
Spiral ganglion neuron, same as ANF

Src - homology 3

Sound pressure level

Spontaneous firing rate

Transmembrane AMPA regulatory protein

Transmembrane-recognition complex

Vesicular glutamate transporter 


\section{Summary}

Challenging tasks like sound localization or speech recognition are impossible without reliable and temporally precise neuronal sound encoding. The neuronal code must accurately preserve signal properties such as intensity and timing. Thus, electrophysiological recordings from single spiral ganglion neuron provide a detailed picture how auditory sensory information is encoded. The analysis of the response pattern of the cochlear nucleus cells gives insight into the auditory systems primary processing after receiving sensory information encoded at peripheral synapses. Studying the response patterns of spiral ganglion neurons and cochlear nucleus cells after mutations and deletions of different proteins of the pre- and postsynaptic sides of the inner hair cell ribbon synapse helps to reveal the role of these proteins in synaptic transmission and sound encoding.

Starting from presynaptic side of inner hair cell ribbon synapse, we first studied Wrb protein to reveal its role in the insertion of the tail-anchored protein otoferlin which is essential for IHC exocytosis (Chapter 3.1). Wrb-deficient mouse inner hair cells had a normal number of spiral ganglion neurons, $\mathrm{Ca}^{2+}$ channels, and membrane-associated synaptic vesicle, but had less ribbon-associated vesicles. In vivo electrophysiological recordings from postsynaptic spiral ganglion neurons revealed impaired synaptic vesicles replenishment. In vivo data from spiral ganglion neurons show a use-dependent phenotype in response to acoustic stimulation. Therefore, Wrb protein is critical for hearing, probably due to its role in regulating otoferlin expression and localization (Chapter 4.3).

Next, otoferlin mutant mice were studied to reveal a role of the otoferlin in inner hair cell exocytosis (Chapter 3.4), postsynaptic sound encoding and sound perception assessed in a psychophysiological gap and acoustic threshold detection experiments. During prolong stimulation, inner hair cells exocytosis from Otof ${ }^{515 T / 1515 T}$ mice was severely reduced, indicating a role of otoferlin in synaptic vesicles reformation. To study sound perception in Otof ${ }^{1515 T / 515 T}$ mutant mice, we performed psychophysiological behavioral experiments for the detection of silent gaps in noise and thresholds sensitivity. The threshold sensitivity was not affected in Otof ${ }^{1515 T / 1515 T}$ mutant mice, while the gap detection was impaired. The gap detection impairment was attributed to the stronger adaptation of acoustically evoked spiral ganglion neuron spike rates, as well as delayed recovery of the sound onset response in Otof $515 T / 1515 T$ spiral ganglion neurons. A similar mechanism might underlie the speech comprehension 
difficulties in human patients carrying the same mutation. We therefore suggested that tests for sound adaptation and temporal coding (e.g. gap detection) should be more commonly used in clinical settings in order to detect deficits which are not related to sound sensitivity (Chapter 4.4).

Two postsynaptic auditory phenotypes were studied in this thesis: quivering $\mathrm{Qv}^{3 \mathrm{~J}}$ mutant mice (Chapter 3.3) and PSD-95/-mice (Chapter 3.2).

In $\mathrm{Qv}^{3 \mathrm{~J}}$ mutants a gene coding for $\beta I V$-spectrin is mutated. $\beta I V$-spectrin is important for the proper clustering of voltage-gated sodium channels at the axon initial segments, where action potentials are generated. The mutation caused impaired action potential generation in spiral ganglion neurons reflected in a reduction of firing rates and moderately elevated auditory brainstem response thresholds (Chapters 3.3 and 4.2).

Auditory function of PSD-95 $5^{-/}$mice was studied to reveal the role of PSD-95 in AMPA receptor expression level and clustering at the postsynaptic membrane of spiral ganglion neuron, as well as understanding how possible impairments may affect synaptic transmission and sound encoding. PSD-95 ${ }^{-/}$mice showed reduced firing rates, delayed action potential generation as well as a lack of accuracy of coding assessed in the analysis of first spike latencies. Immunohistochemical studies together with confocal and STED microscopies revealed a reduced number of AMPA receptors subclusters at the PSD-95 ${ }^{-/-}$spiral ganglion neurons postsynaptic membrane (Chapters 3.2 and 4.1). 


\section{Introduction}

\subsection{Sound encoding in peripheral nervous system}

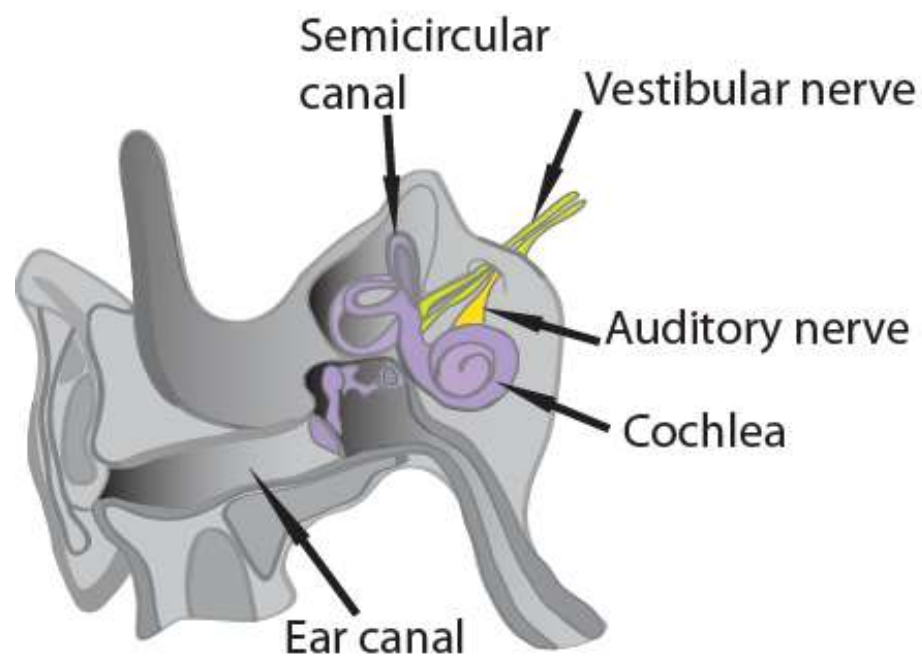

Figure 1. Human ear structure

Acoustic signals are first mechanically collected by the external and middle ear. The external ear channels the energy of the incoming acoustic wave onto the tympanic membrane. The middle ear connects the tympanic membrane with the oval window via three small ossicles, namely malleus, incus and stapes (Fig.1). The vibration of the tympanic membrane and ossicle chain is then transmitted into the fluid (the perilymph) in the cochlea through oval window. The tiny mechanical devices in the middle ear function as a lever system to match the low air impedance to high impedance of the inner ear fluid so that the energy not being reflected away (Geisler, 1998; Schnupp, 2011). At these stages, the external and middle ear together work as linear mechanical transducers which transform acoustic vibration of air molecules into travelling waves of the inner ear fluid, unless the middle ear muscles are activated by feedback mechanisms to attenuate the high intensity sound reaching the cochlea (Hüttenbrink, 1989).

In the inner ear, the mechanical propagation of travelling waves in the cochlear duct is detected by a sensory epithelium, the organ of Corti, resting on the basilar membrane. The travelling wave is decomposed along the cochlear axis into different frequency components due to the tonotopic properties of the basilar membrane and inertial mass of the fluid (Robles and Ruggero, 2001). The basal part is most sensitive to stimulation by high frequency sounds 
while the apex region analyzes low frequency sounds. Thus, the basilar membrane functions as a Fourier analyzer for frequency decomposition of sound signal. The organ of Corti harbors two type of hair cells, outer hair cells (OHCs) and inner hair cells (IHCs). IHCs form one row and $\mathrm{OHCs}$ three rows along the cochlear tonotopic axis. The OHCs non-linearly amplify the vibration of basilar membrane (Ashmore, 2008; Dallos et al., 2008), while the IHCs are the genuine sensory cells transmitting the mechanical vibration to spiral ganglion neurons (SGNs) via ribbon synapses (Ciuman, 2011). Vibration-driven deflection of IHC stereocilia leads to the opening or closing of mechanotransduction channels on hair bundles, and the resulting cation influx generates the receptor potential of the IHCs membrane. At active zones of IHCs, voltage gated $\mathrm{Ca}^{2+}$ channels (Cav) controls $\mathrm{Ca}^{2+}$ signals for triggering neurotransmitter release (Brandt et al., 2005; Frank et al., 2010a). Glutamate release into the synaptic junction between IHCs and the peripheral axon of the SGNs binds to ionotropic a-amino-3-hydroxy-5-methyl4-isoxazolepropionate (AMPA) type receptors, generating neural spikes that propagate in the SGNs (Glowatzki and Fuchs, 2002; Fuchs et al., 2003). In complement to the frequency analyzer function of the basilar membrane, the synaptic junction between IHC and SGN is specialized for high fidelity temporal processing (Moser et al., 2006; Parsons, 2006). The cell bodies of SGNs lie in a bony structure, the modiolus of the cochlea. The central axons of spiral ganglion neurons comprise auditory nerve fibers (ANFs), which then project to the cochlear nucleus through internal auditory meatus. Those fibers then branch to innervate many different types of cells throughout the cochlear nucleus. Each IHC contacts 8-20 afferent fibers (Spoendlin, 1969, 1975; Kiang et al., 1982), making parallel channels sending information to the central nervous system (Fig.2). 
A

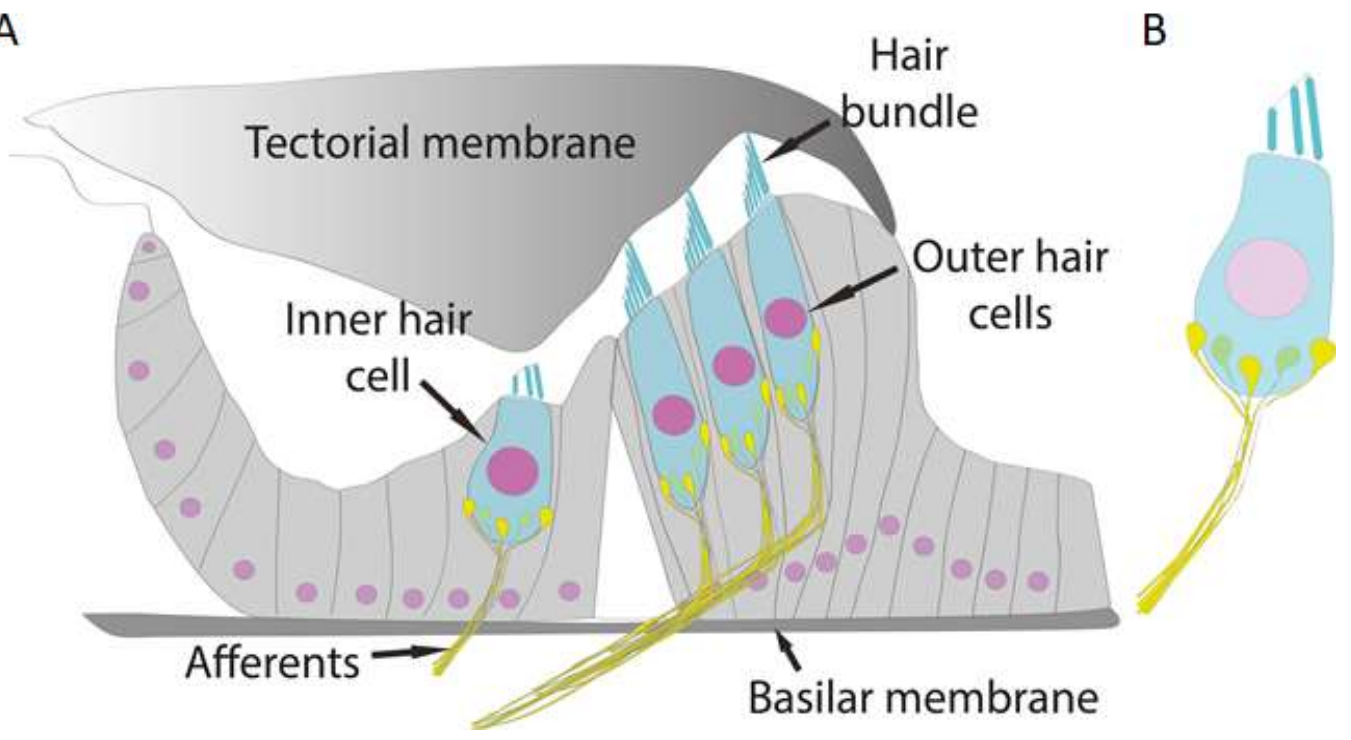

Figure 2. Organ of Corti (A) and IHC (B) innervated by SGNs

\subsection{IHC ribbon synapse structure}

Sound encoded in the inner ear by IHCs forming ribbon synapses with 8-20 myelinated auditory nerve fibres (SGNs) type I (Spoendlin, 1969, 1975; Kiang et al., 1982). Encoding of acoustic stimuli with high fidelity requires synaptic transmission to be both reliable and temporally precise. To provide such remarkable temporal fidelity and precision, IHC ribbon synapses have to be highly specialized in their molecular composition and structure. Understanding the structure/function relationship highlight the central questions of auditory science, such as sound encoding and sound perception (Nouvian et al., 2006; Meyer and Moser, 2010; Safieddine et al., 2012; Wichmann and Moser, 2015).

The IHC synapse is characterized by the presence of a large electron-dense presynaptic structure, the synaptic ribbon, that organizes synaptic active zones and tethers synaptic vesicles (Meyer and Moser, 2010; Safieddine et al., 2012; Wichmann and Moser, 2015). Most synaptic ribbons are anchored at the active zone to plasma membrane and opposed to the postsynaptic site. Approximately $5 \%$ of the ribbons are "floating", not anchored and probably reflect ribbon's turnover (Khimich et al., 2005; Jing et al., 2013). Ribbons vary in shape, size and number between different species, tonotopic localization, developmental stage, and different active zones of one cell (Merchan-Perez and Liberman, 1996; Lenzi and von Gersdorff, 2001; Moser et al., 2006; Matthews and Fuchs, 2010), likely reflecting structural adaptation to the specific needs in the synaptic sensory coding. Before the onset of hearing (P14 for mice) IHCs 
contain a large number of ribbons with small size (Sobkowicz et al., 1982) after the onset of hearing ribbons have ellipsoid shape and are observed in smaller number (10-20, (Sobkowicz et al., 1982; Khimich et al., 2005).

Ribbon - associated synaptic vesicles are tethered in a monolayer on the ribbon (Lenzi et al., 1999) representing only a tiny fraction of all synaptic vesicles. There at least three vesicle fractions which might be morphologically distinguished at the IHC ribbon synapse: (1) membrane-proximal vesicles, (2) ribbon-associated vesicles, and (3) free cytosolic synaptic vesicles (Lenzi et al., 1999, 2002; Schnee et al., 2005).

The main structural components of the ribbon and/or the anchorage of the ribbon to the active zone include RIBEYE (Schmitz et al., 2000; Zenisek et al., 2003), Bassoon (Khimich et al., 2005) and piccolino (Regus-Leidig et al., 2013, 2014).

RIBEYE is the major structural component of the ribbon (Schmitz et al., 2000; Magupalli et al., 2008). RIBEYE is composed of two major domains: the A domain is unique in structure and assembles the synaptic ribbon, and the B domain which is almost identical to the transcription repressor CtBP2 encoded by the same gene but with a different transcription initiation site (Schmitz et al., 2000). The B domain is thought to be involved in tethering of synaptic vesicles to the ribbon.

Bassoon, a large cytomatrix scaffold protein, is localized at the active zone at the base of the ribbon (Khimich et al., 2005; Frank et al., 2010a; Jing et al., 2013). Deletion of bassoon (Altrock et al., 2003) prevents anchoring of the ribbons to the presynaptic membrane (Khimich et al., 2005). The loss of ribbons at the active zones leads to the reduction of the readily releasable pool (RRP) at IHC (Buran et al., 2010a), which results in hearing impairment in mutant mice, suffering of desynchronized afferent synaptic transmission (Khimich et al., 2005; Buran et al., 2010a; Frank et al., 2010a; Jing et al., 2013). The loss of bassoon also affected the insertion of the $\mathrm{Ca}^{2+}$ channels at the active zones (Frank et al., 2010a). Taken together, the loss of bassoon and ribbons causes an auditory synaptopathy characterized by intact cochlear amplification but abnormal ABRs.

Piccolo, a homolog of bassoon, is expressed at conventional synapses (Altrock et al., 2003). Its short isoform piccolino is expressed at IHCs (Regus-Leidig et al., 2013, 2014). The short isoform lacks a large C-terminal part and binding sites for, e.g. bassoon or RIM (RegusLeidig et al., 2013), predicting different roles of piccolino and bassoon at the IHC ribbon structure. 
At conventional synapses, the exocytic machinery is controlled by the neuronal SNARE proteins syntaxin 1, SNAP-25 and synaptobrevin 1 (Jahn and Fasshauer, 2012). At photoreceptor ribbon synapses, SNAREs are fully present and function (Brandstätter et al., 1996). However, IHCs exocytosis appears to be insensitive to neurotoxic and genetic ablation of neuronal SNAREs (Nouvian et al., 2011). Thus, the role of the syntaxin 1, SNAP-25 and synaptobrevin 1 and 2 remains to be questionable. Some studies detected SNARE mRNAs and proteins in the sensory epithelium and IHCs (Safieddine and Wenthold, 1999; Uthaiah and Hudspeth, 2010; Nouvian et al., 2011), but immunofluorescence imaging in mouse IHCs have not detected neither SNAP-25, synaptobrevin 1-3, nor syntaxin 1 (Nouvian et al., 2011). Moreover, in mature IHCs such SNARE regulators as synaptotagmins 1-3 (Beurg et al., 2010; Reisinger et al., 2011) and complexins (Strenzke et al., 2009; Uthaiah and Hudspeth, 2010) were absent. Synsptotagmin 7 is the $\mathrm{Ca}^{2+}$ sensor for slow secretion of large dense core vesicles from endocrine cells, which is expressed in IHCs (Safieddine and Wenthold, 1999) and involved in exocytosis of hippocampal neurons (Virmani, 2003). Mutations in synaptotagmin 7 do not seem to affect IHCs exocytosis (Beurg et al., 2010). IHC specific homolog of synaptotagmin is multi-C2 domain protein otoferlin (Roux et al., 2006; Beurg et al., 2008; Dulon et al., 2009; Pangrsic et al., 2010) playing a central role for IHC exocytosis.

Otoferlin mutations cause deafness or temperature-sensitive hearing impairment in humans (Yasunaga et al., 1999; Varga et al., 2006), rodents and mice (Roux et al., 2006; LongoGuess et al., 2007; Schwander et al., 2007; Strenzke et al., 2016). Otoferlin is mostly but not exclusively found at synaptic vesicles, endosome like structures and the active zone membrane (Roux et al., 2006; Strenzke et al., 2016). Otoferlin is required for correct vesicular fusion and replenishment (Roux et al., 2006; Pangrsic et al., 2010; Strenzke et al., 2016; Vogl et al., 2016a). It is acting as a $\mathrm{Ca}^{2+}$ sensor in IHCs(Roux et al., 2006; Johnson and Chapman, 2010). IHC RRP exocytosis is disrupted in the absence of otoferlin (Roux et al. 2006). Furthermore, besides its role in exocytosis, otoferlin was recently suggested to play a role in vesicles endocytosis due to its interaction with AP-2 which found to be expressed in IHCs (Duncker et al., 2013; Jung et al., 2015). AP-2 participates in clatrin-mediated endocytosis via binding to clatrin-coated vesicles (Keyel et al., 2008; Boucrot et al., 2010). Further investigation to reveal the role of AP-2 in IHC endocytosis and importance of its interaction with otoferlin is required. 


\subsection{Otoferlin mutant mice}

One of the otoferlin mutant mouse models 'pachanga' carries a point mutation in otoferlin (Schwander et al., 2007). Pachanga mice showed impaired sustained IHC exocytosis while fast exocytosis reflecting RRP depletion was not affected (Pangrsic et al., 2010).

Otoferlin knockout mice Otof ${ }^{/-}$displayed a reduction in a short tethers connecting synaptic vesicles with the active zone membrane(Vogl et al., 2015) supported the idea that otoferlin plays a role in synaptic vesicles replenishment at IHCs.

Several missense mutations in otoferlin (Pro1987Arg, Glu1700Gln and Ile1573Thr) resulted in age-progressive hearing loss in humans (Varga et al., 2003; Chiu et al., 2010; Yildirim-Baylan et al., 2014). These patients were not tested for speech perception, auditory temporal processing, auditory fatigue and temperature sensitivity. Therefore, to reveal the role of otoferlin in synaptic sound encoding, Strenzke et al. (2016) generated a novel otoferlin mouse mutant model which carries p.Ile515Thr point mutation (in NP_001274418) and demonstrated intermediate hearing impairment. Human patients with the p.Ile515Thr mutation demonstrate mild low-frequency hearing loss, speech comprehension below the $10^{\text {th }}$ percentile in quiet and noise condition and impaired ABRs (Varga et al., 2006). The hearing impairment in Otof ${ }^{515 T / 1515 T}$ mice depicts the phenotype found in human patients, except for the temperature sensitivity (Strenzke et al., 2016).

\subsection{Tryptophan-rich basic protein (Wrb) knockout mouse}

The transmembrane-recognition complex (TRC40) pathway is important for the insertion of the tail-anchored proteins into membranes. Otoferlin as a tail-anchored protein is inserted into the endoplasmic reticulum via TRC40 pathway that has been studied in yeast and mammalian cell lines in culture (Simpson et al., 2010; Denic et al., 2013; Yamamoto and Sakisaka, 2015). The membrane insertion of tail-anchored proteins is distinct of translation and includes (1) recognition by TRC40 (Favaloro et al., 2008) (2) caging to the TRC receptors Wrb (Vilardi et al., 2011) and calcium-modulating cyclopholin ligand (Yamamoto and Sakisaka, 2015) on the endoplasmic reticulum membrane and (3) unbinding from TRC in an ATPdependent manner and insertion into the target membrane (Bozkurt et al., 2009). Recent studies in mice and zebrafish showed the fundamental importance of the TRC40 pathway in sensory function. For example, genetic deletion of the calcium-modulating cyclophilin ligand (Bryda 
et al., 2012) in sensory hair cells caused a loss of hair cells and deafness in mice. Moreover, the zebrafish WRB mutant (pinball wizard, pwi (Amsterdam et al., 2004)) displayed impaired visual and hair cell functions(Gross et al., 2005). Vogl et al. (2016) investigated the role of the TRC40 pathway in sensory IHCs of zebrafish and mice. The study was focused on the effect of disruption of Wrb protein on otoferlin biosynthesis and function.

$\mathrm{Wrb}^{\mathrm{fl} / \mathrm{fl}}: \mathrm{Cre}^{\mathrm{A}}$ mice were generated as described in Vogl et al (2016). In brief, these mice are conditional Wrb knockouts, generated by flanking exons two to four by loxP sites through homologous recombination ( $\mathrm{Wrb}^{\mathrm{fl} / \mathrm{fl}}$ ). To achieve IHC-specific Cre recombination, $\mathrm{Wrb}^{\mathrm{fl} / \mathrm{fl}}$ mice were then crossed with the mice expressing Cre- recombinase under control of the vesicular glutamate transporter (Vglut3) promoter, which expression is specific for IHCs (Obholzer et al., 2008a). Vglut3-Cre transgenic mouse line, in which Cre-recombinase (but without additional Vglut3) was expressed under the control of the transgenic Vglut3 promoter (Jung et al., 2015) was named $\mathrm{Wrb}^{\mathrm{fl} / \mathrm{fl}}: \mathrm{Cre}^{\mathrm{A}}$ mice.

\subsection{IHC ribbon synapse exocytosis}

IHC exocytosis relies on stimulus-secretion coupling by Cav1.3 channels (Platzer et al., 2000; Brandt et al., 2003, 2005). Cav1.3 channels cluster at the ribbon-occupied active tones of IHCs (reviewed in Wichmann and Moser 2015; Nouvian et al. 2006). Mouse cochlear IHCs contain approximately $80 \mathrm{Ca}^{2+}$ channel per active zone. There are two hypotheses about $\mathrm{Ca}^{2+}$ channels control of exocytosis: a microdomain hypothesis suggested by Robert's and Fettiplace's groups and nanodomain control hypothesis proposed by Moser's group (Brandt et al., 2005). The microdomain hypothesis suggests that exocytosis is controlled by calcium domains which have micromolar concentration and micrometer size. Alternatively, experiments on stimulus-secretion coupling in mouse IHCs suggested that exocytic fusion of a given RRP is controlled only by one or few nearby $\mathrm{Ca}^{2+}$ channels (Brandt et al., 2005) nanodomain hypothesis of exocytosis control. Released into the synaptic cleft glutamate neurotransmitter activates AMPA-type glutamate receptors internalized at the postsynaptic membrane (Matsubara et al., 1996).

Patch-clamp recordings of membrane capacitance of IHCs allowed to discriminate at least 2 components of the IHC exocytosis: the first kinetic component which mediates exocytosis at extremely high rates but saturates within a few milliseconds (Moser and Beutner, 2000a; Spassova et al., 2004; Rutherford and Roberts, 2006), and the second kinetic component 
which typically triggered by prolonged, strong depolarizing steps (tens of $\mathrm{ms}$ to $\mathrm{s}$ in duration (Nouvian et al., 2006)).

RRP size correlates with the number of afferent synapses and varies along the tonotopic axis of the cochlea (Schnee et al., 2005; Meyer and Moser, 2010), as well as it correlates with the auditory brainstem response (ABR) wave I amplitude reflecting the compound action potential of a synchronously activated SGNs (Khimich et al., 2005). In addition, RRP depletion and replenishment is thought to mediate a short-term adaptation and recovery from it in SGNs (reviewed in Nouvian et al., 2006).

The sustained, second kinetic component of IHC exocytosis remains to be more complicated to describe. It has been debatable whether sustained, slow kinetic component of exocytosis represents simply the serial refilling of the RRP or/and parallel exocytosis at extra synaptic fusion sites. Schnee et al. (2005) proposed that there are three kinetic components of exocytosis in turtle IHCs. They suggested that the second kinetic component could be attributed to the exocytic turnover of the ribbon-associated vesicle population, whereas vesicle re-supply of the ribbon would come thereafter. However, there are several lines of evidence arguing for a significant contribution of ribbon-independent and at least in part parallel extra synaptic exocytosis to the sustained component of IHC exocytosis. First, a preserved sustained exocytosis in the IHCs that lack $90 \%$ of their synapse-associated ribbons (Khimich et al., 2005). Second, the presence of the docked vesicles at the extra synaptic stretches of the plasma membrane (Lenzi et al., 1999, 2002). And third, $\mathrm{Ca}^{2+}$ unchanging flash photolysis induced extensive fast exocytosis which by far exceeds fusion of the RRP, suggesting the presence of many fusion-competent vesicles outside the active zone (Beutner et al., 2001). Taken together, most evidences support the hypothesis that sustained IHC exocytosis (the second kinetic component) represents both the serial refilling of vesicles at the active zones and the parallel extra synaptic turnover of synaptic vesicles (Nouvian et al., 2006).

\subsection{Anteroventral cochlear nucleus cells}

Study the functional organization of the cochlear nucleus is essential for comprehension of the auditory brainstem processing. The cochlear nucleus is divided into dorsal and ventral parts (reviewed in Cant and Benson 2003). The ventral cochlear nucleus is divided by the auditory nerve into anterior (AVCN) and posterior divisions. In the AVCN there are three principal morphological cell types: globular bushy cells spherical bushy cells and stellate or 
multipolar cells. Electrophysiologists classified AVCN units in vivo based on their temporal response properties to acoustic stimuli exhibited in specific post-stimulus time histogram (PSTHs). Based on electrophysiological classification, AVCN units were termed primary-like, primary-like with notch, chopper and onset units (Oertel et al., 2011). Intracellular labelling of cochlear nucleus neurons combined with extracellular in vivo recordings revealed relation between electrophysiological PSTH types and morphologically defined types of neurons (Cant and Benson, 2003). Spherical bushy cells have primary-like response pattern, globular bushy cells - primary-like with notch, and stellate cells - chopper patterns.

Stellate cell dendrites run along the path of SGNs (Oertel et al., 2011). Each multipolar neuron contacted by numerous bouton synapses from only a few SGNs. Depolarization of their membrane emits regularly timed APs, which in response to the acoustic stimulation produce chopper type PSTH with regular firing pattern.

Bushy cells receive multiple inputs from just a few SGNs, which envelop their terminal processes around the entire soma (Nayagam et al., 2011). Because bushy cells contacted by axosomatic auditory nerve inputs by way of powerful endbulb of Held synapses (Rothman et al., 1993), each ANF input trigger an AP in the postsynaptic neuron. In response to the toneburst stimulation spherical bushy cells produce primary-like PSTH, and globular bushy cells exhibit primary-like PSTH with a notch (Roos and May, 2012a; Typlt et al., 2012).

\subsection{Response properties of auditory nerve fibers}

There are a number of responses properties of mouse spiral SGNs, which were analysed previously (Taberner and Liberman, 2005a), including spontaneous rates (SRs), tuning curves (TCs), response adaptation, as well as the relation between SR and these response characteristics.

\subsubsection{Spontaneous spikes activity}

Spontaneous firing rate (SR) of ANFs was studied in 1961 by Gacek and Rasmussen (Gacek and Rasmussen, 1961) which found that cat's SGNs fire spontaneously in a stochastic manner. Different SGNs innervating one IHC may vary in SRs. It is most probably that in cats spontaneous firing activity of SGNs correlated with the morphology (diameter of the nerve fiber) and location of the afferent fibers innervating IHC. High SR fibers mostly connect the pillar side of IHCs and tend to have more mitochondria and larger axon diameter whereas low SR fibers tend to innervate the modiolar side of IHCs and they are smaller in diameter and have 
lower number of mitochondria (Liberman, 1982; Liberman and Oliver, 1984). Presynaptic mechanisms may also contribute to the SGNs heterogeneity: SGNs with different SR have also been shown to receive input from presynaptic active zones occupied by synaptic ribbons that vary in size and complexity (Merchan-Perez and Liberman, 1996). Functionally, high SR fibers have lower activation thresholds and narrower dynamic range while low SR fibers have higher acoustic thresholds and wider dynamic range (Taberner and Liberman, 2005a). While Liberman initially classified cat ANFs into low- (<0.5 spike/s), medium- (0.5 -1 18) and high (>18) - SR fibers, the separation into these groups is less distinct in the mouse. Nevertheless, mouse SGNs still demonstrate SR heterogeneity, ranging from 0 to 129 spikes/s (Taberner and Liberman, 2005a). The source of heterogeneity in SGNs spontaneous activity is still not clear (Grant et al., 2010; Liu et al., 2014; Davis and Crozier, 2015a). There are presynaptic, postsynaptic mechanisms or efferent modulation may contribute to it. Unfortunately, the special segregation into modiolar/abneural ribbon synapses is not exact and there are no known molecular markers for low/high SR fibers.

\subsubsection{Tuning curves and frequency selectivity}

The frequency selectivity of SGNs is relied on the frequency decomposition of acoustic signals along the tonotopic axis of basilar membrane. The passive basilar membrane responses have a broad tuning. Following nonlinear amplification by OHCs has a sharp tuning tip around characteristic frequency (CF) for each SGN. Active amplification can be perturbed with application of ototoxic drugs into the cochlea or noise trauma resulting in a change of SGN tuning curves (Sewell, 1984; Kiang et al., 1986; Müller and Smolders, 2005). Thus, SGN acoustic responses may detect $\mathrm{OHC}$ amplification problem.

\subsubsection{Sound - evoked responses}

In response to brief pure tones, SGNs generate a train of APs. Adaptation of the spike rate is remarkable characteristic of the SGN response (Kiang et al., 1965). A typical SGN response to tone bursts includes four stages:

(1) at the onset of stimulation, the firing rate reaches a maximum for the time constant of approximately $0.65 \mathrm{~ms}$ of the tone (Westerman and Smith, 1984a).

(2) after the transient response the discharge rate gradually adapts to the steady-state rate.

(3) after the end of the stimulation, the spike rate drops sharply to levels lower than SR. 
(4) at the last stage, the spike rate gradually recovers to the spontaneous discharge level.

The time course of adaptation has multiple exponentially-decaying components in different timeframes (Westerman and Smith, 1984a; Yates et al., 1985a). The time course of adaptation can be defined by fitting single-exponential curve to the post-stimulus time histogram (PSTH). Different components of adaptation can be revealed depending on the stimulus duration and bin size used to reconstruct PSTH for quantifying adaptation. For instance, PSTH bin sizes smaller than $1 \mathrm{~ms}$ emphasize on rapid spike rate adaptation during stimulus onset, as well as another slower short-term adapting component with a time constant of approximately $10 \mathrm{~ms}$ at $50 \mathrm{~ms}$ stimulus duration in mouse SGNs (Buran et al., 2010a). Since IHC receptor potential does not demonstrate a similar decay in response to tone burst stimulation (Russell and Sellick, 1978; Palmer and Russell, 1986), and the reduction in calcium current (Hudspeth and Lewis, 1988; Moser and Beutner, 2000a) and AMPA receptors desensitization in postsynaptic side (Goutman and Glowatzki, 2007a) are not essential, adaptation is most likely rely on synaptic transmission, e.g., via RRP depletion (Furukawa and Matsuura, 1978; Moser and Beutner, 2000a; Goutman and Glowatzki, 2011).

Several biological processes may contribute to origination of those different adapting components. For example, vesicles replenishment and diffusion due to the neurotransmitter release (Furukawa and Matsuura, 1978; Moser and Beutner, 2000a; Nouvian et al., 2006; Goutman and Glowatzki, 2007b) as well as kinetics of glutamate neurotransmitter binding to AMPA receptors, or refractoriness of SGNs spiking. Short-term adaptation is suggested to have presynaptic origin, reflecting the depletion of RRP of vesicles (Moser and Beutner, 2000a; Singer and Diamond, 2006). Following recovery from short-term adaptation reflects the replenishment of vesicles (Spassova et al., 2004). Therefore, the synaptic vesicle pool dynamics can be inferred from SGN responses.

\subsection{AMPA receptors in spiral ganglion neuron}

Fast synaptic transmission between the IHCs and the non-branched dendrites of the type I myelinated primary SGNs mediated by AMPA receptors at the postsynaptic terminus, activated by excitatory glutamate release. It has been debated whether this neurotransmitter may also act via activation of another type of ionotropic glutamate receptors-N-methyl-Daspartate (NMDA) receptors. In 1992 S. Safieddine and M. Eybalin checked co-expression of 
NMDR-1 and GluR1-4 mRNAs in SGNs of rat and ginea pig cochleae using a non-radioactive in situ hybridization technique. AMPA/kainate receptor oligoprobe labeling of GluR2 and GluR3 subunits of was very intense, whereas GluR1 and GluR4 mRNAs were not seem to be expressed in SGNs. Additionally, type I SGNs do not seems to express kainate-preferring subunits GluR5 and GluR6. A weak labelling of GluR4 probes was observed in ring-shaped glial cells, surrounding SGNs type I in the spiral ganglion and in glial cells of the osseous spiral lamina. NMDAR1 oligoprobe labeling was moderate, and it has been suggested that only a subpopulation of SGNs express functional NMDA receptors (Safieddine and Eybalin, 1992). Functional NMDA receptors were also expressed in the immature (before hearing onset) SGNs type I of rat cochleae day 5-7 (Zhang-Hooks et al., 2016).

In 2002 E. Glowatzki and P. Fuchs showed that excitatory postsynaptic currents (EPSCs) in SGN postsynaptic boutons are mediated by AMPA receptors. They performed whole-cell tight-seal recordings of postsynaptic currents from afferent boutons of SGNs of P713 rat cochleae. Application of CNQX antagonist on AMPA/kainate receptors completely and reversibly blocked EPSCs. In addition, they tested the effect of the application of cyclothiazide, which reduces the desensitization of AMPA receptors but not kainate receptors. Cyclothiazide prominently reduced the rate of the decay of the EPSCs and had a little effect on the time of its rise. Based on these findings, it is possible to conclude that the EPSCs of SGNs were mediated by AMPA receptors, with no participation of NMDA receptors, and minor or no role of kainate receptors (Glowatzki and Fuchs, 2002).

\subsection{PSD - MAGUK proteins at neuronal synapses}

Post-synaptic density-membrane associated guanylate kinase proteins (PSDMAGUKs) are scaffolding proteins, which target, anchor and clusters receptors and channels to subcellular sites of excitatory glutamate ergic synapses (Elias et al., 2006a; Gardoni et al., 2009). The multi-domain disc-large homolog (DLG) or PSD-MAGUK proteins include the following domains: three PDZ (PSD-95/Disc large/Zona occludes 1) domains, a src homology 3 (SH3) domain and a C - terminal guanylate kinase (GUK) domain. DLG has four different homologs, described in vertebrates: synapse - associated protein (SAP)90/PSD-95, SAP102, SAP97/hDLg and capsin -110/PSD-93. It has been shown that in central synapses PSD-95 regulates AMPA receptor surface diffusion and density through its association with 
stargazin (Schnell et al., 2002a) and thus participates in modifying synaptic strength, or plasticity (Opazo et al., 2011) .In the present thesis I studied a role of PSD-95 for the synaptic sound encoding and AMPA receptor clustering at IHC ribbon synapses.

\subsection{AMPA receptors lateral organization and mobility}

It is commonly accepted that the number of AMPA receptors at the postsynaptic density controls efficiency of the glutamatergic synapses. The efficiency of synaptic transmission might be determined not only by number of AMPA receptors in synapse (Lisman and Raghavachari, 2006), but also by the density of AMPA receptors in subdomains and their distribution (Chen et al., 2007). Another aspect which determines synaptic transmission is the lateral positioning or distribution of AMPA receptors across the face of the synapse (MacGillavry et al., 2011). The probability of receptor activation strongly depends on its alignment with presynaptic release site. Additionally, even in the single synapse the receptor pattern might be actively modulated, e. g. AMPA receptors might exchange in and out of synapses within seconds to minutes (Makino and Malinow, 2009). The single - molecule tracking method using fluorescent quantum dots has helped to clarify that the lateral positioning of at least some antibody-labeled receptors is constantly changing (Triller and Choquet, 2008).

AMPA receptor distribution (Fig.3) and its dynamic control relies on interaction with MAGUK proteins, and particularly with PSD-95, which interacts with AMPA receptors via subunits of auxiliary transmembrane (Elias et al., 2006b) AMPA regulatory proteins (TARPs). The acute knockdown of PSD-95 decreases synaptic AMPA receptor clustering and generation of AMPA- mediated currents (EPSCs) while overexpression of PSD-95 increases it (Elias et al., 2006a; Schlüter et al., 2006). It has been suggested that those alterations in the AMPA receptor number depends on changes in the PSD-95 "slots", which indicate that PSD has limited capacity to hold receptors (Opazo et al., 2011).

Additionally, not only the number of PSD-95 slots, but their affinity to TARPs might play a critical role in retaining of AMPA receptors within the PSD. Such affinity can be regulated by activity-dependent phosphorylation of the TARP stargazin by CaMKII $\left(\mathrm{Ca}^{2+/}\right.$ calmodulin-dependent protein kinase II (Opazo et al., 2010). 
Studying the mechanisms of activity-dependent modifications in synaptic strength, a phenomenon known as synaptic plasticity is important for revealing the molecular basis of learning and memory. During long-time potentiation (LTP), when activity of synapse is persistently increases based on previous activity, extra synaptic AMPA receptors are highly mobile (50-80\% mobile fraction (Borgdorff and Choquet, 2002). The mobile extra synaptic AMPA receptors can enter, scan and exit synapses within around $2 \mathrm{~s}$ (Opazo et al., 2011). Such high mobility is needed to facilitate recovery from synaptic depression due to AMPA receptors desensitization during high frequency stimulation (Opazo et al., 2010). During LTP extra synaptic AMPA receptors redistribute to the synaptic site. The surface redistribution of AMPA receptors is likely due to diffusional trap mechanisms (Opazo et al., 2010). During LTP, increased anchoring of diffusing AMPA receptors at synaptic surface might be due to increase in affinity of AMPA receptors to existing 'slots' or involve a new 'slots' at synapses. Later it has been revealed that synaptic AMPA receptors stabilization is mainly based on interactions within a protein tripartite complex composed on PSD-95, stargazin and AMPA receptors.

Almost half of synaptic AMPA receptors are packed and stabilized in clusters of about $80 \mathrm{~nm}$ wide and include about 20 receptors each (so-called in this thesis 'subclusters', or nanodomains according Constals et al. (2015)). The other half is highly mobile within the synaptic site (Nair et al., 2013). The AMPA receptor subclusters are tightly bind by stargazin (Tomita, 2004; Cais et al., 2014) and stabilizes it at the synaptic membrane through binding of its C-terminus to PDZ domain-containing of PSD-95 or other MAGUKs. Constals et al. (2015) showed that stabilization of AMPA receptors depend on their glutamate-triggered conformational changes (open, closed and desensitized states (Constals et al., 2015a)). Using single-molecule tracking method it has been shown (Constals et al., 2015a) that desensitized AMPA receptors have increased mobility compare to closed or open ones due to less affinity/avidity for stargazin. This desensitization induced increase in AMPA receptor removal (20-30\%) from subclusters and synaptic sites without overall modification of the AMPA receptor subcluster organization (Constals et al., 2015a). Higher mobility of desensitized AMPA receptors is necessary for the faster recovery from glutamate-induced high-frequency short-term depression, occurring due to AMPA receptors desensitization. Thus, increased mobility of desensitized AMPA receptors allows rapid turnover of AMPA receptors at the glutamate synaptic sites required for the fast synaptic transmission. 


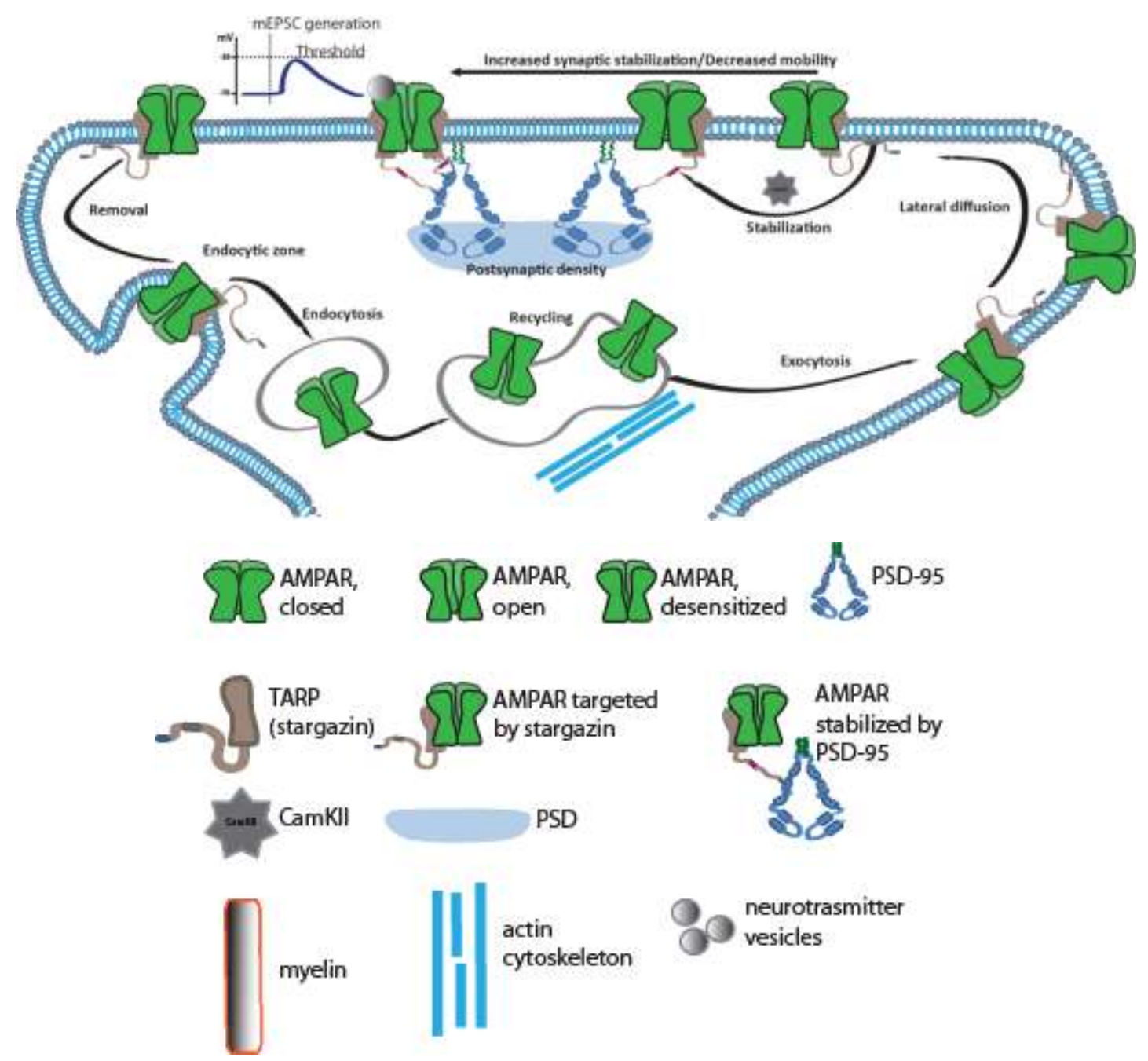

Figure 3. AMPA receptors and PSD-95 in SGN (modified from Opazo et al. 2012; Angonno and Huganir 2012; Jones and Svitkina 2016, and Hsu et al. 2014 )

\subsection{AMPA receptors in spiral ganglion neurons}

The previous chapter considered that in hippocampal neurons the synaptic strength may be dynamically regulated by changes in the postsynaptic AMPA receptors surface and its recycling in response to the glutamate release. In cultured auditory neurons glutamate agonists and antagonists alter surface and total number of GluA2 subunits (glutamate receptors main subunit in SGNs) (Chen et al., 2007). In this study Chen et al. found that in response to application of glutamate agonists (20 microM AMPA, NMDA or glutamate for 10 min) surface GluA2 was reversibly decreased (by 55-60\%) when compared with application of artificial 
perilymph. Application of glutamate receptors antagonists alone, D-(-)-2-amino-5phosphonovaleric acid (APV, 50 microM, a selective inhibitor of NMDA-induced surface GluA2 removal) and 6,7-dinitroquinoxaline-2,3-dione (DNQX, 20 microM, a selective blocker of AMPA-induced surface GluA2 removal) did not produce a significant reduction of surface GluA2, but each could partially (40-50\%) reduce agonist-induced removal of surface GluA2 receptors.

Further on, Chen et al. (2007) showed that the previous finding in cultured auditory neurons may be relevant to transmission of acoustic information in vivo. ABR thresholds and impact of sound-evoked changes on surface AMPA receptors in SGNs were studied in CBA/CaJ mice at 6-8 age of weeks (Chen et al., 2007). After 2-6 min of 10-min broad-band acoustic-noise exposure (1-40 kHz, $116 \mathrm{~dB}$ sound pressure level), ABRs were measured and then cochleae were homogenated for biotinylation of all cochlear surface proteins and further extraction for western blot analysis. Surface AMPA receptors decreased to $49 \%$ after 2 min of noise exposure compare to cochlea without noise exposure and recovered to $64 \%$ at $20 \mathrm{~min}$, and to $91 \% 1 \mathrm{~h}$ after noise. The decrease of surface AMPA receptor in vivo following to noise exposure correlated with the recovery of ABR thresholds to sound stimuli. This is consistent with the idea that the number of postsynaptic AMPA receptors in SGNs plays a role in regulation of sensitivity of cochlear neurons to acoustic stimuli. Infusion of APV and DNQX glutamate receptors antagonists blocked neuronal responses to the acoustic stimuli, whereas infusion of APV antagonist of NMDA receptors alone revealed no acute effects on ABR thresholds. These findings once more confirmed a major role of AMPA receptors in cochlear neurotransmission (Glowatzki and Fuchs, 2002; Chen et al., 2007).

Rapid regulation of synaptic efficiency of auditory neurons may have several roles. First, it could be one of the sources of heterogeneity of the synaptic response range to transmitter release from inner hair cells (Liberman, 1982; Grant et al., 2010). Second, it can contribute to a stable spontaneous discharge rate of cochlear afferent neurons. Finally, during continuous high-intensity acoustic stimulation regulation of expressed AMPA receptors may reduce excitotoxicity in auditory neurons (Chen et al., 2009).

Studying AMPA receptors recycling in auditory neurons is important for revealing the role of AMPA receptors in regulating the synaptic strength and modulating synaptic 
neurotransmission. Even subtle changes in synaptic efficiency may lead to alteration in the response characteristics of auditory neurons, making it an advantageous model to investigate synaptic neurotransmission and sound encoding.

\subsection{PSD-95 deficient mice}

PSD-95 knockout (PSD-95 ${ }^{-/}$) mice lack PSD-95 protein expression due to genetic deletion of the guanylate -kinase domain of PSD-95 (Abbas et al., 2009). They have lifelong and juvenile-like ocular dominant plasticity which characterized by experience-dependent cortical plasticity in the primary visual cortex V1, induced by monocular deprivation (Huang et al., 2015a) and increased number of AMPA-silent synapses. The silent synapses are excitatory glutamatergic synapses containing on the postsynaptic membrane NMDA-type but not AMPA-type glutamatergic receptors, thought to be immature (Isaac et al., 1995; Liao et al., 1995). It has been shown by Huang et al. (2015) that PSD-95 ${ }^{-/-}$mice have disrupted experience- dependent maturation of silent synapses. Thus, PSD-95 is required for experience - dependent reduction of silent synapses. The prevention of silent synapse maturation leads to abolished termination of the critical period for juvenile-like ocular-dominant plasticity in pyramidal neurons of V1 (Huang et al., 2015b). In addition, PSD-95 mice showed preserved ocular dominance plasticity in the visual cortex after somatosensory cortex stroke which was absent in wild type (Greifzu et al., 2016). This finding indicates that an increased number of AMPA-silent synapses preserves ocular dominance plasticity either in healthy brain or in another experimental paradigm of cortical plasticity, such as long-range influence on primary visual cortex V1 - plasticity after somatosensory cortex stroke (Greifzu et al., 2016).

\subsection{Action potential generation in neurons}

The dendrites of a nerve cell receive stimulus that causes sodium channels to open (Fig.4). The sufficient opening drives the intracellular potential from $-70 \mathrm{mV}$ to $-55 \mathrm{mV}$. After reaching the action potential threshold, more voltage-gated sodium channels open. The sodium influx drives the intracellular membrane potential up to about $+30 \mathrm{mV}$. Described processes called depolarization. When the peak potential of around $+40 \mathrm{mV}$ is reached, the sodium channels close and potassium channels open. The slower kinetics of the potassium channels allows sufficient time to reach a positive potential which is prerequisite for the action potential (AP). 


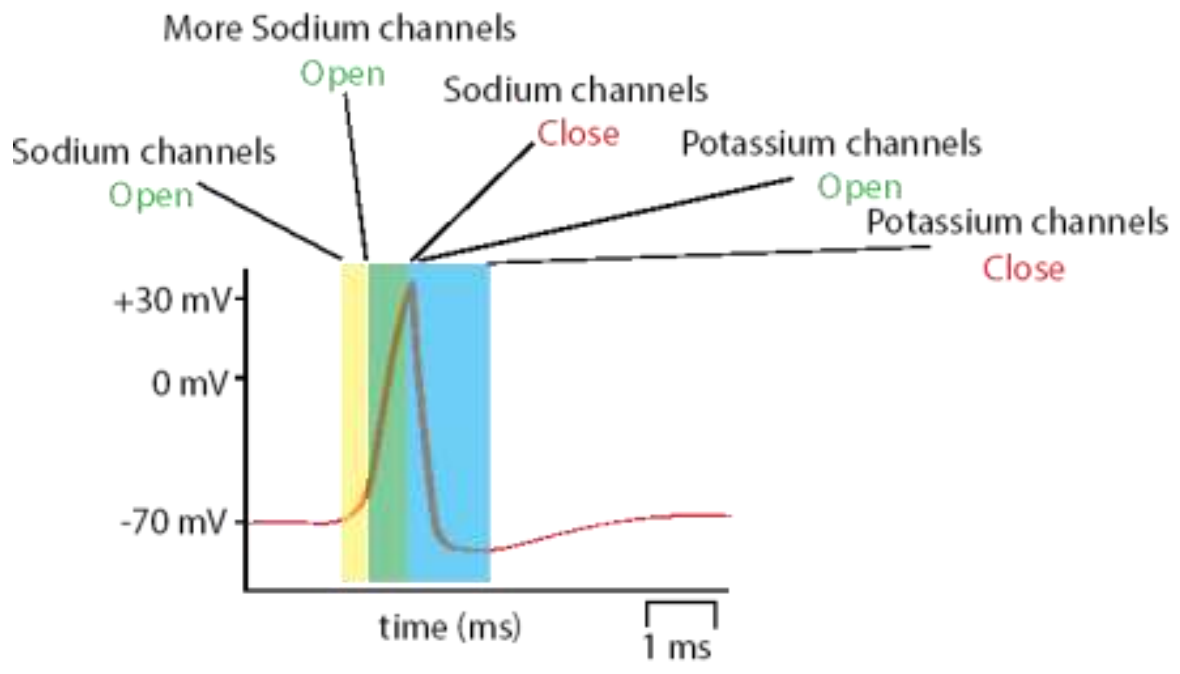

Figure 4. Action potential

When potassium channels are opened the membrane begins to repolarize back toward its resting potential. Commonly, the repolarization overshoots the resting potential to about $90 \mathrm{mV}$. This process called hyperpolarization and prevents a neuron from prematurely firing of the AP or retrograde AP transmission. After hyperpolarization, sodium-potassium pumps bring the membrane back to the resting potential of $-70 \mathrm{mV}$.

\subsection{AIS structure and function}

Based on localization, function, and molecular composition, the AIS cytoskeleton has two parts: submembrane and cytoplasmic (Jones and Svitkina, 2016). The cytoskeletal components include ankyrin-G (AnkG), BIV-spectrin, and actin filaments (Fig.5). The cytoplasmic cytoskeleton consists of microtubules, actin filaments, and neurofilaments (Jones and Svitkina, 2016). AIS has two main functions: (1) to integrate synaptic inputs and to initiate AP generation and (2) to ensure neuronal polarity function. The AIS polarity function serves as a diffusion barrier to restrict the mobility of plasma membrane components and to prevent their migration from the axonal domain to the somatodendritic domain, and as intracellular selective filter allowing transport of organelles and molecules between these two domains through the cytoplasm (Jones and Svitkina, 2016).

The AIS layers or regions include (Fig.5) the plasma membrane (outermost surface), submembrane cytoskeleton (middle layer), and inner AIS shaft (cytoplasmic region). These 
layers are organized by the multimodal scaffolding protein AnkG acting as a master organizer of the AIS (Fig.5).

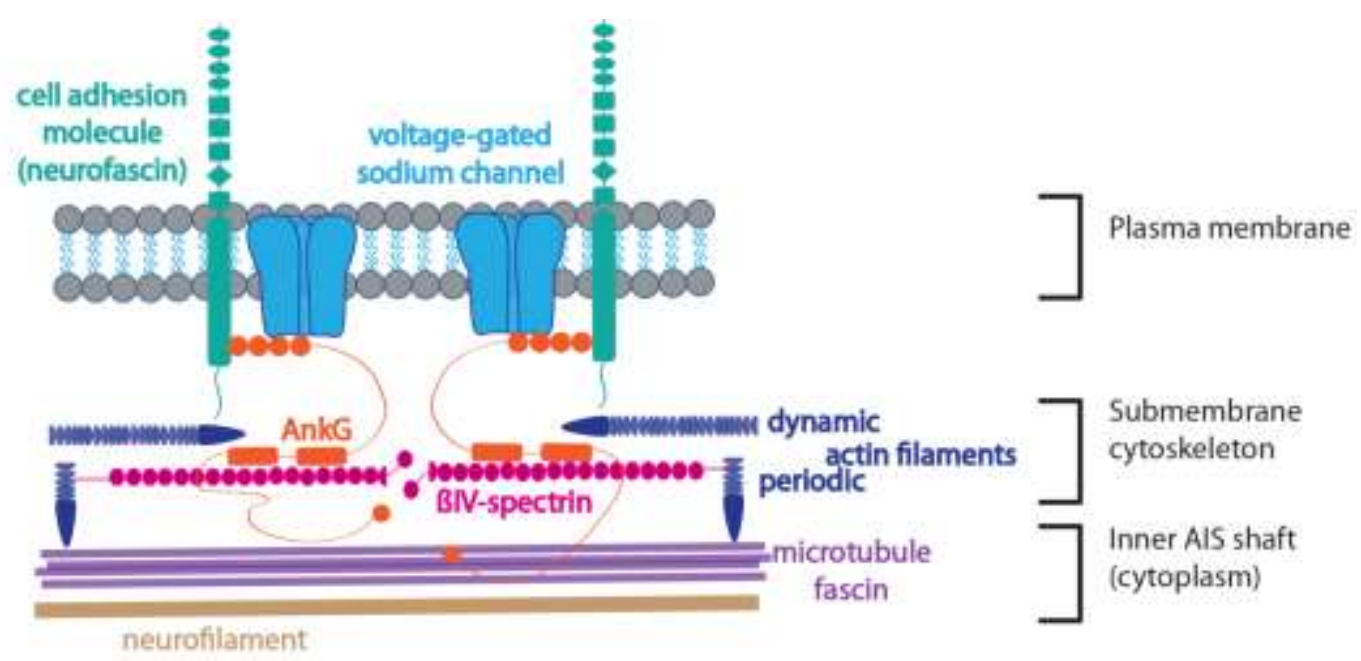

Figure 5. Voltage-gated sodium channels at AIS (modified from Jones and Svitkina 2016)

\subsubsection{Plasma membrane AIS region}

The plasma membrane of the AIS is enriched with specialized transmembrane proteins (including voltage-gated ion channels) and specific cell adhesion molecules (CAMs, Fig.5). Voltage-gated ion channels allow the unique electrical properties of the AIS and nodes of Ranvier (Zhou et al., 1998; Ho et al., 2014) and include voltage-gated sodium (Nav), potassium $(\mathrm{Kv})$, and calcium (Cav) channels. High densities of Nav channels are required for AP initiation (Kole et al., 2008).

\section{Sodium channels at AIS}

Various sodium channel subtypes have been described to be expressed at the AIS, but the major Nav subtypes include Nav1.1, Nav1.2, and Nav1.6 channels (Boiko et al., 2003; Hu et al., 2009; Leterrier et al., 2011) Those channels were expressed at the AIS of motoneurons, retinal ganglion cells, and cortical pyramidal cells, respectively (Brackenbury et al., 2008, 2010; Brachet et al., 2010). It has been indicated in many studies that mutations in Nav channels are involved in development of various neurological and psychiatric disorders. For instance, de novo heterozygous mutations in Nav1.1 causes Dravet Syndrome, a form of severe 
myoclonic childhood-onset encephalopathy, in which various epileptic phenotypes are seen (Claes et al., 2001). Missense mutations in Nav1.1 (Volkers et al., 2011; Xu et al., 2012), Nav1.2 (Touma et al., 2013), and Nav1.6 (Oliva et al., 2014) showed implication into the numerous forms of genetic epilepsies. Dysfunction of Nav was also linked to genetic autism spectrum disorders (Weiss et al., 2003). Nav1.1 testing for genetic epilepsies is applied in the clinic (Hirose, 2013) and disruptions in this isoform of Nav have been identified in sporadic autism (O’Roak et al., 2012) and familial hemiplegic migraine (Cestele et al., 2013). Mutations in the Nav1.2 is highly associated with genetic autism (Sanders et al., 2012). Mutations in SCN8A the gene encoding Nav1.6 causes motor deficits in human and mice (Trudeau, 2006). In summary, because of wide diversity of polymorphisms revealed for Nav channels, particular contribution of each channel subtype into development of psychiatric disorders is still necessary(Hsu et al., 2014).

\section{Potassium channels at AIS at plasma membrane}

Potassium channels at the AIS modulate AP initiation (Pan, 2006; Lorincz and Nusser, 2008; Johnston et al., 2010) through suppression of neuronal excitability by counteracting Nav channels either actively or passively as a shunt (Dodson et al., 2002; Goldberg et al., 2008; Shah et al., 2008). Several types of Kv channels have been identified at the AIS: Kv1.1, Kv1.2, Kv7.2 (KCNQ2), and Kv7.3 (KCNQ3). Unlike Kv7.2 and Kv7.3, Kv1.1 and Kv1.2 do not contain AnkG- binding motifs and instead bind to the synaptic scaffolding protein PSD-93 (Ogawa and Rasband, 2008). Kv1 channels are critical for shortening APs (Kole et al., 2007; Shu et al., 2007). Kv7 channels are known to set the resting potential and through this play a role in controlling Nav activation (Battefeld et al., 2014).

\section{Calcium channels at AIS plasma membrane}

Voltage-gated calcium (Cav) channels contribute to the modulation of the AP at AIS in various ways (Yamada and Kuba, 2016). Cav2.3 and Cav3 activated at relatively lower thresholds and facilitate AP generation by enhancing after depolarization (Bender and Trussell, 2009). Cav2.1 and Cav2.2 exhibit higher activation thresholds and suppress AP generation and promote AP repolarization by augmenting the bypass conductance via activation of $\mathrm{Ca}^{2+}$ activated $\mathrm{K}^{+}(\mathrm{BK})$ channels (Yu et al., 2010). 


\section{Neurofascin at AIS at plasma membrane}

In addition to ion channels, the L1 CAMs neurofascin 186 (NF-186) and neuronal cell adhesion molecule (NrCAM) clustered at the AIS via interaction with AnkG (Fig.5 (Bennett and Baines, 2001a)). CAMs at the AIS can contribute to the interaction of the submembrane cytoskeleton with the extracellular matrix (Jones and Svitkina, 2016) or other cells. For instance, NF-186 hippocampal neurons attract components of the AIS extracellular matrix (e.g. brevican (Hedstrom et al., 2007; Frischknecht and Seidenbecher, 2012). Disruption of NF186 in mice results in AIS disintegration, Purkinje cell dysfunction and impairment of motor learning (Zonta et al., 2011).

\subsubsection{Submembrane AIS region}

The submembrane cytoskeleton is composed of actin filaments, AnkG (the master organizer of the AIS), and BIV-spectrin (Fig.5, (Jones and Svitkina, 2016)). The submembrane cytoskeleton is important for AIS polarity function.

\section{Ankyrin-G at AIS submembrane}

AnkG may be considered as AIS master organizer of the AIS. Two neuron-specific large AnkG isoforms, $270 \mathrm{kDa}$ and $480 \mathrm{kDa}$, localize particularly at AIS and along the distal axon in nodes of Ranvier (Kordeli et al., 1995). AnkG clustered at the proximal axon initially, involves almost all other AIS proteins to the plasma membrane and functions within all layers of the AIS (Bennett and Baines, 2001b; Leterrier et al., 2015). This multiple role in AIS organization based on domain constitution of AnkG playing various roles in interaction with other AIS parts: membrane-binding domain at N-terminus, spectrin-binding domain, serinerich domain, and C-terminal domain (Mohler et al., 2002). Through its membrane-binding domain, AnkG associates with plasma membrane region of AIS and through spectrin-binding domain with submembrane region (Fig.5). The C-terminal tail projects into the inner AIS shaft, where it is may interact with other partners (Leterrier et al., 2015), e.g. microtubules (Bennett and Baines, 2001a). AnkG depletion in neurons leads to impaired formation of the AIS and nodes of Ranvier, and AnkG deficiency contributes to development of several neurological diseases, such as epilepsy, schizophrenia, bipolar disorder, autism spectrum disorder, 
Alzheimer's disease (Buffington and Rasband, 2011; Hsu et al., 2014). Severe ataxia was found in mice lacking AnkG in their cerebellum (Jenkins and Bennett, 2001). Such neurological disorders are likely based on the loss of voltage-gated sodium channels and impaired AP generation (Zhou et al., 1998; Komada and Soriano, 2002).

\section{Spectrins at AIS submembrane}

Spectrin molecules typically form $\alpha \beta$-heterotetramers included two $\alpha$ and two $\beta$ subunits that shaped in flexible rod structures 150-200 nm in length (Jones and Svitkina, 2016). A typical $\alpha$-spectrin consists of one incomplete spectrin repeat at the N-terminus, twenty complete repeats of spectrin, a Src homology 3 (SH3) domain and C-terminal domain including two EF-hand motifs, one of which is $\mathrm{Ca}^{2+}$-binding motif. A typical $\mathrm{B}$-spectrin includes $\mathrm{N}$ terminal actin-binding domain, sequenced by 16 tandem full spectrin repeats, an incomplete $17^{\text {th }}$ spectrin repeat, a variable specific domain, and C-terminal plekstrin homology $(\mathrm{PH})$ domain (Fig.5). B-spectrin interacts with AnkG through its spectrin repeats 4-15 (Yang et al., 2007) and with actin filaments through their $\mathrm{N}$-terminal actin-binding domains, but ankG and actin do not bind to the alpha-spectrin subunit of spectrin molecule (Jones and Svitkina, 2016). There are five different genes encoding $\beta$-spectrins in mammals, but only BIV-spectrin is specifically localized at the AIS and nodes of Ranvier in mature neurons (Berghs et al., 2000; Bennett and Baines, 2001a), where it interacts with Nav through its binding to AnkG 480/270 (Jenkins and Bennett, 2001; Komada and Soriano, 2002). Genetic removal of multiple BIVspectrins in mice results in reduced clustering of ankG and Nav at AIS and nodes of Ranvier. Mice carrying this mutation exhibit tremors and contraction of hindlimbs (Komada and Soriano, 2002). There are six isoforms of alternatively spliced gene encoded BIV-spectrins:

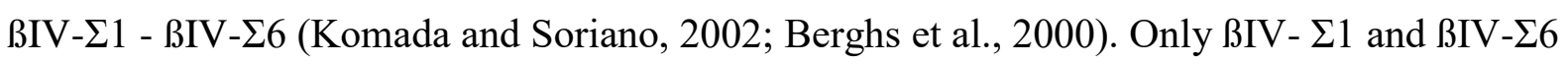
specifically expressed in at the AIS and nodes of Ranvier of the peripheral and central nervous system (Berghs et al., 2000; Lacas-Gervais et al., 2004). Selective depletion of $\beta I V-\Sigma 1$ isoform from neurons causes AIS and nodal loss due to the absent binding to actin interacting with actin-binding domain which exclusively present only in this B-spectrin isoform (Lacas-Gervais et al., 2004). A truncated isoform of $\beta I V-\Sigma 6$, which misses the N-terminus and the first 10 repeats of spectrin, demonstrated specific role in Nav channels clustering at the AIS and nodes of Ranvier (Uemoto et al., 2007). Due to the tight interaction between AnkG and BIV-spectrin, 
impaired $\beta$-spectrin expression or function may contribute to several psychiatric disorders (Hsu et al., 2014). Chromosome de novo microdeletion in genes encoding for BIV-spectrin caused autism and spherocytosis combined phenotype in patient (Griswold et al., 2011). In mice, mutation in BIV-spectrin causes auditory and motor neuropathies, resulting in the autosomal recessive quivering phenotype (Parkinson et al., 2001). There are two $\alpha$-spectrin genes in mammals: $\alpha$ I-spectrin (in erythrocytes) and $\alpha$ II-spectrin (ubiquitous), both have a variety of isoforms resulted from alternative splicing (Riederer et al., 1986). It is still unclear whether $\alpha$ spectrins are present at AIS.

\subsubsection{Cytoplasmic AIS region}

The cytoplasmic AIS region contains neurofilaments, microtubules, and actin filaments (Fig.5). These major cytoskeletal filaments play different roles in neuronal morphology, integrity and function (Luo, 2002; Barnes and Polleux, 2009; Kapitein and Hoogenraad, 2011).

\subsection{AP generation in spiral ganglion neurons}

Mouse IHCs are innervated by myelinated unbranched bipolar SGNs type I, where excitatory presynaptic glutamate release triggers AP generation. Bipolar SGNs are different from other neurons and do not have a classical AIS, instead postsynaptic heminode (Liberman, 1980; Hossain et al., 2005; Kim and Rutherford, 2016a).

Each SGN in cats and mice has a postsynaptic heminode located 20-40 $\mu \mathrm{m}$ from its presynaptic active zone on an IHC (Liberman, 1980; Hossain et al., 2005). Voltage-gated ion channels have been identified in SGNs (Oak and Yi, 2014; Davis and Crozier, 2015b) and distribute at different parts of rat SGNs (Kim and Rutherford, 2016b). High-voltage-activated $\mathrm{Kv} 3.1 \mathrm{~b}$ strictly clustered at nodes and heminodes, and Kv2.2 localized at the juxtaparanodes and further expressed centrally along the first internode. Nav1.1 clustering partly overlapped Nav1.6 and AnkG at the spike-initiating heminodes. Kv7.2 and Kv7.3 channels expressed at heminodes, nodes, internodes, and the unmyelinated synaptic terminal segments (Kim and Rutherford, 2016).

It has been considered in the previous chapter that APs in the axons initiated by voltagegated ion channels enriched at the AIS. Therefore, the question about topography of the spike generation in SGNs relied on the question about distribution of the ion channels in it. Based on 
evidences about voltage-gated ion channels topography at SGNs, Kim and Rutherford (2016) concluded that the SGN heminode exhibits molecular-anatomical specializations of the AIS and proposed as a preferred site of AP initiation.

\subsection{Quiverer mutant mice}

The autosomal recessive mouse mutation quiveriring $(\mathrm{Qv})$ produces ataxia with hind limb paralysis, deafness and tremor. Six spontaneously mutated alleles have been identified: $\mathrm{Qv}^{\mathrm{J}}, \mathrm{Qv}^{2 \mathrm{~J}}, \mathrm{Qv}^{3 \mathrm{~J}}, \mathrm{Qv}^{3 \mathrm{~J}}, \mathrm{Qv}^{4 \mathrm{~J}}$, and $\mathrm{Qv}{ }^{\ln 2 \mathrm{~J}}$ (Bronson et al., 1992). Quivering mice carrying a lossof-function mutation in the mouse BIV-spectrin gene (SPNB4) show impaired ion channels clustering in myelinated nerves resulting in auditory and motor neuropathies (Parkinson et al., 2001). The severity of phenotype is correlated to the length of BIV-spectrin loss: Qv (81\% of wild type peptide length), $\mathrm{Qv}^{2 \mathrm{~J}}(65 \%), \mathrm{Qv}^{3 \mathrm{~J}}(86 \%), \mathrm{Qv}^{4 \mathrm{~J}}(53 \%)$, and $\mathrm{Qv}{ }^{\text {Ind2J }}$ (19\%) (Parkinson et al., 2001; Bronson et al., 1992). The severity of auditory phenotype in quivering mutant mice correlates with loss of peptide length (or lack of expression, in $Q v^{\ln 2 J}$ ): $Q v^{2}<\mathrm{Qv}^{4 J}<\mathrm{Qv}^{\operatorname{lnd} 2 J}$.

In Qv mutants ABR wave I (representing responses from the SGNs) was broadened and delayed, and ABR wave II (representing responses from AVCN neurons) was strongly reduced. In $\mathrm{Qv}^{4 \mathrm{~J}}$ and $\mathrm{Qv}^{\text {Ind2J }}$ mutants $\mathrm{ABR}$ waves were reduced in amplitude, latencies were prolonged and, except wave I, which was sometime poorly formed, other waves were absent.

Immunohistochemical studies of $\mathrm{Qv}^{\ln 2 \mathrm{~J}}$ mice revealed a disruption of the voltage-gated sodium and potassium channels localization at the AIS and nodes of Ranvier. Finally, single unit extracellular recordings from cochlear nucleus neurons was performed in Qv4J mutants to explain severely reduced acoustically evoked ABR wave II amplitude indicating central deafness (Kopp-Scheinpflug and Tempel, 2015a). There were slightly increased acoustically stimulated neuronal response thresholds, but neither the spontaneous nor sound - evoked firing rates were reduced compare to the wild type littermates. However, cochlear nucleus neurons showed severely reduced accuracy of the AP generation, as well as impaired phase locking to the sinusoidal amplitude modulations, calculated as vector strength (Chapter 2.3.4 of "Materials and Methods"). First spike latencies of sound-evoked spiking were significantly longer, and a jitter was significantly increased indicating impaired temporal encoding. Based on these data, Kopp-Scheinpflug and Tempel (2015) proposed that the loss of phase-locking to the stimulus on the single neuron level disrupts the synchronized response of neuronal 
population which leads to the reduced summation of the extracellular field potentials so they can no longer be detected by the ABR electrode. Therefore, the loss of temporal precision rather than loss of threshold sensitivity is responsible for the reduced ABR wave II and consequent waves in this mutant (Kopp-Scheinpflug and Tempel, 2015).

$\mathrm{The}_{\mathrm{Qv}}{ }^{3 \mathrm{~J}}$ allele contains a single-base insertion (InsT6786) that produces a frameshift at amino acid G2209 and a new 49-amino-acid extension with no homology to previously described peptides. This is a single loss-of-function point mutation affecting the C-terminal region of BIV-spectrin (Parkinson et al., 2001). An in vivo study of granule cell function in the dentate gyrus of $\mathrm{Qv}^{3 \mathrm{~J}}$ mutants revealed their reduced ability to generate APs and decreased network excitability (Winkels et al., 2009). Auditory function of these mutant mice was not yet investigated. 


\section{Materials and Methods}

\subsection{Animals}

The following mouse lines were used in the studies covered in this thesis:

1) C57BL/6 mice 14-15 days old.

2) PSD-95 ${ }^{-/}$and PSD-95 ${ }^{+/+}$mice aged between P14 and 6 to 12 weeks. PSD-95 KO mice were generated as described previously (Yao et al., 2004). PSD-95 ${ }^{+/+}$littermates served as a control. 3) BIV-spectrin $\mathrm{Qv}^{3 \mathrm{~J}}$ mutants and wild type littermates aged between 6 and 12 weeks. These mutants have a single loss-of-function point mutation in mouse gene SPNB4 affecting the Cterminal region of BIV-spectrin (Parkinson et al., 2001).

4) $\mathrm{WRB}^{\mathrm{fl} / \mathrm{fl} l}: \mathrm{Cre}^{\mathrm{A}}$ mice and their wild type littermates aged between P14 and P23. Mice were generated as described previously (Vogl et al., 2016b). Wild type littermates were used as a control.

4) Otof ${ }^{515 T / 1515 T}$ mice were generated by targeted mutagenesis of a genomic vector and homologous recombination in mouse embryonic stem cells (Strenzke et al., 2016). Mice aged between 4 to 50 weeks old.

All experiments complied with national animal care guidelines and were approved by the University of Göttingen Board for animal welfare and the animal welfare office of the state of Lower Saxony.

\subsection{ABR measurement}

ABRs represent synchronized neuronal activity along the auditory pathway in response to sound onset. The SGNs and auditory brainstem nuclei of it generate responses, reflected in ABR waves (Fig.6). All ABR recordings were performed by Nadine Hermann and Stefan Thom.

To perform ABR measurement animals between 6 and 12 weeks old were administered with ketamine (125 mg/kg, i.p) and xylazine (2.5 mg/kg, i.p.) as anaesthetic. To record data three subcutaneous needles were used, (+) underneath the pinna, (-) on the vertex and one as a common ground near the legs on the back (Fig.7). To generate and present the stimulus and to acquire and process data TDT III System was used (Tucker-Davis-Technologies). Acoustic 
pressure levels are presented in AB SPL RMS (tonal stimuli) or dB SPL peak equivalent (PE, clicks).

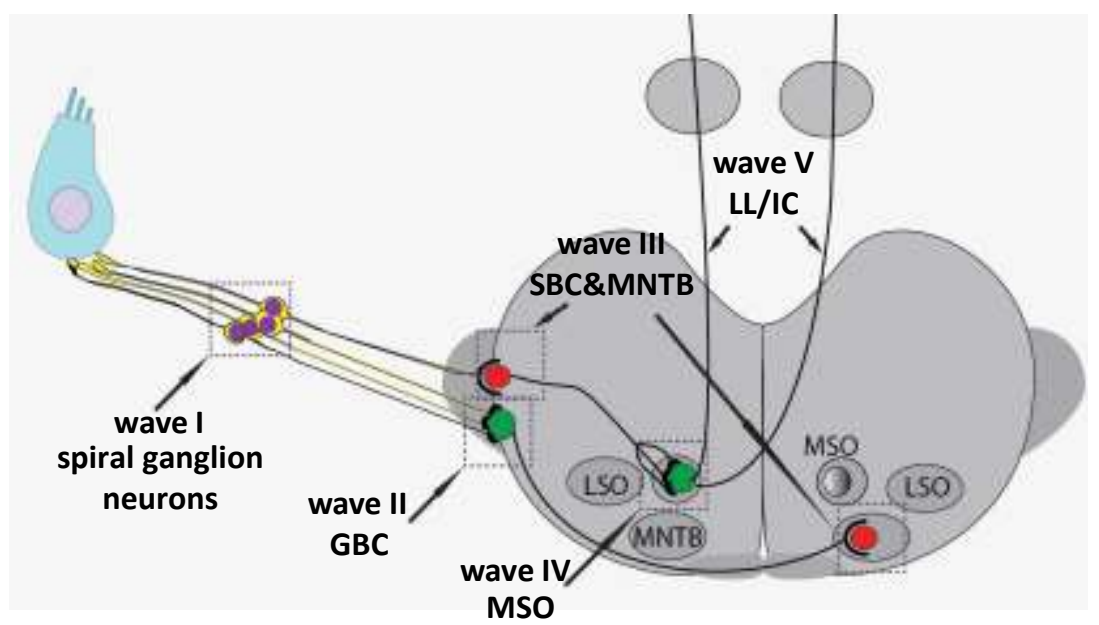

Figure 6. ABR waves sources: wave I - SGN; wave II - globular bushy cells; wave III spherical bushy cells and medial nucleus of the trapezoid body; wave IV - medial superior olive; wave V - lateral lemniscus and inferior colliculus (Strenzke, unpublished)

Acoustic pressure levels are calibrated with 1/4" Brüel and Kjaer microphone (D 4039, Brüel and Kjaer GmbH). With the help of JBL 2402 speaker 10 ms plateau with $1 \mathrm{~ms} \cos 2$ rise/fall tone bursts or $0.03 \mathrm{~ms}$ clicks were introduced at $20 \mathrm{~Hz}$ ipsilateral in free field.

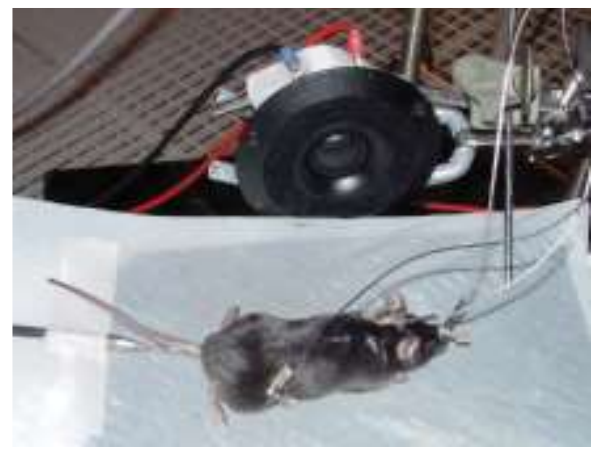

Figure 7. Mouse preparation for the ABR recording. Anesthetized mouse with needle electrodes, inserted subcutaneously. JBL 2402 loudspeaker placed near the left ear (Photo provided by Nicola Strenzke)

Amplifier of a custom design was utilized for the amplification of the (+) and (-) needles difference potential, with a $20 \mathrm{~ms}$ sample of $50 \mathrm{kHz}$ and offline filter $(300-3000 \mathrm{~Hz}$ for Automated Auditory Brainstem Response). To determine hearing threshold visual inspection was utilized based on lowest intensity of the stimulus to evoke response waveform that is reproducible. 


\subsection{Single unit extracellular recordings from ANFs and Cochlear nucleus neurons}

\subsubsection{Surgical approach}

To analyze the encoding of sound in individual ANFs single unit recordings were

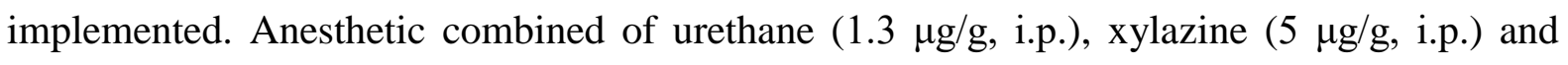
buprenorphine $(0.1 \mu \mathrm{g} / \mathrm{g}$, i.p. $)$ was administered to the animals. Heating pad of a custom design was used to maintain animal temperature at $36.5^{\circ} \mathrm{C}$. Animal was placed in a double-walled chamber that was sound proof with $33{ }^{\circ} \mathrm{C}$ ambient temperature. Procedures for surgery and recording were performed as per description (Taberner and Liberman 2005, Jing et al., 2013).
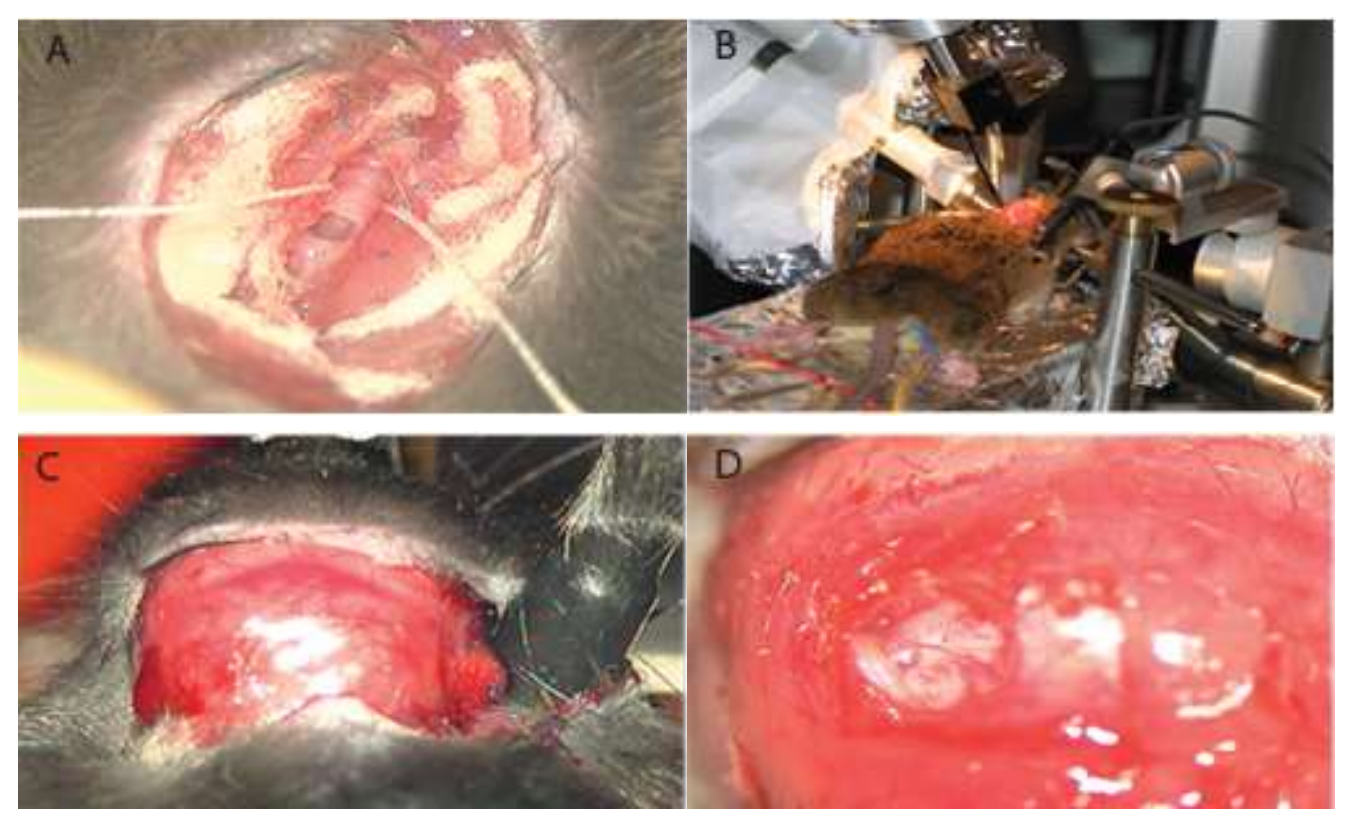

Figure 8. Surgical approach for SGN and Cochlear nucleus neurons single unit recording (Photos provided by Anna Gehrt)

A - Tracheostomy.

$\mathrm{B}-$ Positioning at the stereotaxic system.

C - Exposed occipital bone.

D - Partially removed cerebellum exposed superior semicircular canal with reference point (dark spot at the bone).

Tracheostomy was performed on the animal (Fig.8A), removal of cartilaginous ear canals was performed before placing the animal in a stereotactic apparatus of custom design (Fig.8B). Moist cotton was used to plug contralateral ear canal (Fig.8C). Occipital approach was used to expose the cochlear nucleus with cerebellum partially removed (Fig.8D). 1\% methylene blue and $2 \mathrm{M} \mathrm{NaCl}$ filled glass microelectrodes were inserted in $4 \mu \mathrm{m}$ steps utilizing 
EXFO Burleigh Inchworm micromanipulator at the time of noise burst stimulation, with ANFs' entry zone into cochlear nucleus area being targeted. AVCN posterior region was avoided as a target, due to high concentration of spherical bushy cells, which possess responding pattern similar to ANFs.

\subsubsection{ANFs and cochlear nucleus neurons identification}

Noise bursts at $50 \mathrm{~ms}$ intervals introduced at $80 \mathrm{~dB}$ were used to identify soundresponsive neurons. To distinguish between primary cochlear nucleus units and SGNs, electrode position was utilized (interior auditory meatus, submerged beyond $1 \mathrm{~mm}$ depth below the cochlear nucleus surface) as well as SGNs primary-like response characteristics to $50 \mathrm{~ms}$ tone bursts administered at suprathreshold presented at their characteristic frequency. Irregular firing pattern typical for SGNs was confirmed by over 0.5 value for the inter-spike intervals of adapted responses variation coefficient (Taberner and Liberman, 2005b).

Verification of the proper electrode position was performed succeeding the experiment, by aspirating the cochlear nucleus to expose interior auditory canal and the ANF. The higher probability for the defective classification of the unit type was more likely to take place during low firing rates (e.g. in WRB knockouts), resulting in response patterns that were less clear. Data was evaluated against the depth criterion (to be lowered $>900 \mathrm{~mm}$ below cochlear nucleus surface).

\subsubsection{Acoustic system and signal processing}

Tucker-Davis Technologies TDT Systems III were used to generate the acoustic stimuli After the adjustment of sound pressure level using PA5 attenuator (Tucker-Davis Technologies), ED-1 speaker was used to deliver the sound (Tucker Davis Technologies), and a close-field probe of a custom design was positioned near the left ear canal opening. Bandpass was filtered (300-3000 Hz) and extracellular signals amplified with the help of ELC-03XS amplifier (NPI Electronics). Once sound-evoked spiking activity was detected on the audio monitor and connected oscilloscope (TDS2004B, Tektronix), analog-to-digital multifunction processor (RX6, Tucker-Davis Technologies) was used to record the signals at $24414 \mathrm{~Hz}$ sampling rate. Custom written MATLAB Software was used to control the recording and presentation of the stimulus. All the data were analyzed offline through the spike detection routine based on N. Strenzke routines. The quality of spike sorting was rated subsequently and 
in most cases double-checked by independent observer (N. Strenzke) blinded to the strain and genotype.

\subsubsection{Stimulus and response measurements}

At first, without any stimuli present, the spontaneous firing rate for each identified sound responsive unit was measured in a $10 \mathrm{~s}$ interval. An additional 10 or $20 \mathrm{~s}$ recording interval was added, when spontaneous rate was less than 10 or $2 \mathrm{~Hz}$ respectively. Afterwards, automatically adapting algorithm was employed, designed to define the best threshold and $\mathrm{CF}$ for each unit, that varied sound pressure levels and frequencies of $15 \mathrm{~ms}$ tone bursts systematically. Sequential probability test with $\mathrm{p}=0.03$ (Wald 1947) was applied to define whether statistical significance was reached and acquired spike rate was equivalent to the threshold rate $(S R+20 \mathrm{~Hz})$ or it was comparable with the spontaneous rate or if the measurement had to be repeated. To reach the precision of $1 \mathrm{~dB}$, original $16 \mathrm{~dB}$ step size was halved every time threshold was crossed. Similarly, to achieve CF with $1 / 32$ octave precision, original 1 octave frequency step was halved for frequencies near the best frequency to determine the thresholds.

For sound evoked responses characterization, $50 \mathrm{~ms}$ tone bursts at $\mathrm{CF}\left(2.5 \mathrm{~ms} \cos ^{2}\right.$ rise /fall, repetition rate at $8 \mathrm{~Hz}$ ) were used (Fig.9A).

Forward masking paradigm (Frank, Rutherford et al. 2010) was used to measure recovery from adaptation, in which $100 \mathrm{~ms}$ tone burst (Masker, $30 \mathrm{~dB}$ above threshold, at $\mathrm{CF}$ ) was succeeded by a $15 \mathrm{~ms}$ tone burst (Probe) which was presented at the same stimulus level and frequency as the masker (Fig.9C). Several randomly ordered intervals between 4 to 256 ms were used to separate the probe and masker. Each interval was repeated 30 times and stimulus trials were presented at a rate of $2 \mathrm{~Hz}$.

25 tone bursts per level were used to measure rate-level functions, with a range between $20 \mathrm{~dB}$ below and $50 \mathrm{~dB}$ above threshold (Fig.9D). $5 \mathrm{~dB}$ steps were used to randomly generate sequence of stimulus levels. Over a fixed window between stimulus onset and stimulus offset the number of spikes was counted for each stimulus trial. For each level spike counts were then averaged and a rate-level function was generated. They were fitted utilizing five-parameter model (Sachs and Abbas, 1974; Sachs et al., 1989a; Taberner and Liberman, 2005b). The fitting was done using lsqcurvefit function in Matlab, which solves nonlinear curve-fitting problem in least-square sense. Computing root mean square error $(<20$ spikes/s) was used to 
assess the goodness of fit. Dynamic range was defined as the sound pressure levels range where rate-level function displayed rate increase between $10 \%-90 \%$ of the spontaneous and maximum rate difference (Fig.9D). ANFs dynamic ranges calculation was based on the model fitted rate-level functions. To analyze signal detection, standard derivation of the rate across trials for each level was also computed and smoothed using a moving average filter.

To measure ANFs ability for amplitude modulated tones encoding, amplitude modulated by a half wave rectified modulator sinusoid $(500 \mathrm{~Hz})$ transposed tones with $\mathrm{CF}$ carrier frequency were presented (Fig.9 E). The time - varying amplitude of the carrier wave was increased in $5 \mathrm{~dB}$ steps every $2 \mathrm{~s}$. Synchronization index (SI) (Goldberg and Brown 1969) or vector strength was calculated as described (Fig.4 F).
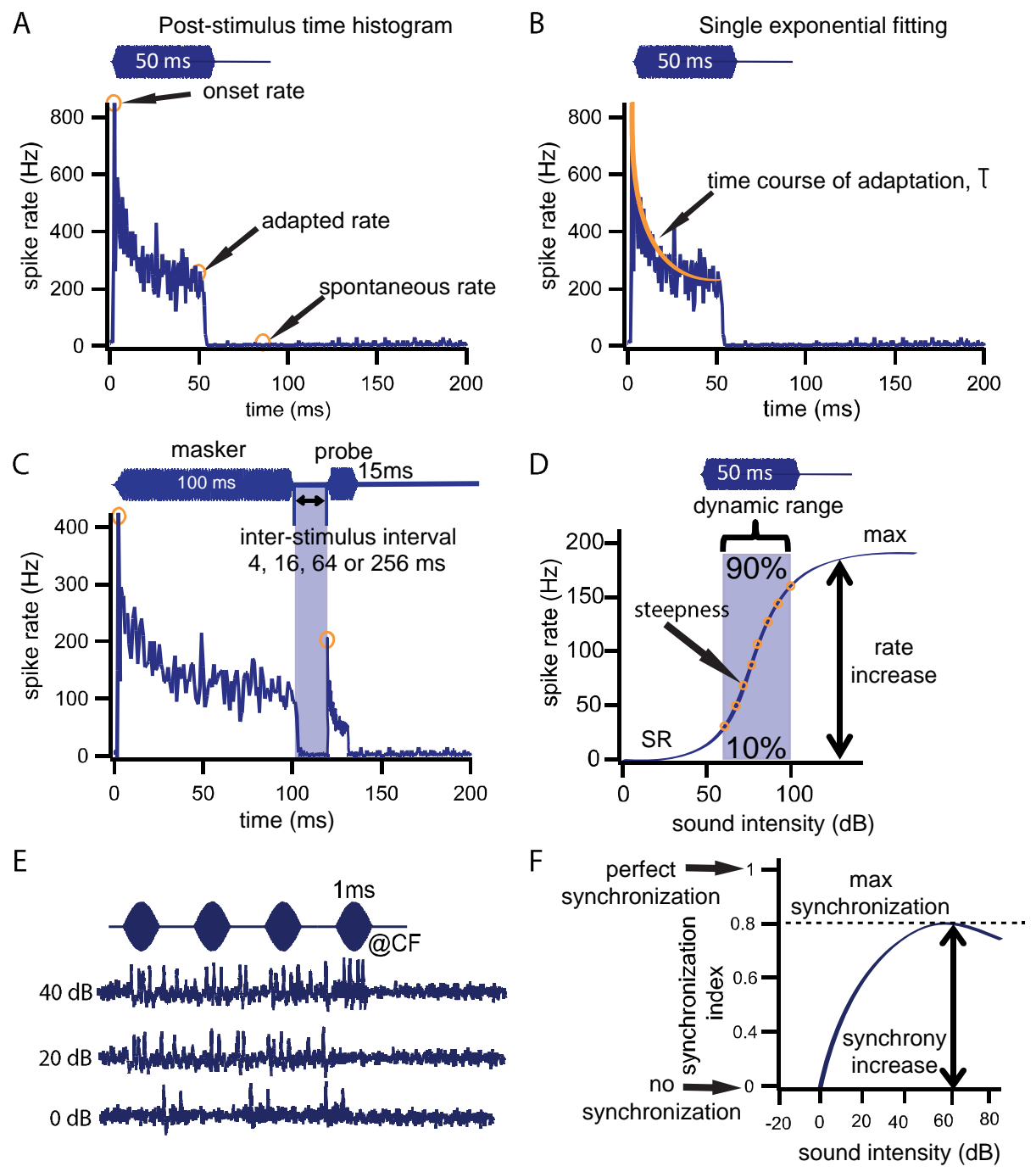

Figure 9. Representative examples illustrating the analysis of sound evoked response measurements 
A - Poststimulus time histogram, obtained after $50 \mathrm{~ms}$ tone burst stimulation at CF 30 $\mathrm{dB}$ above the threshold. Primary-like type of PSTH is one of the criterion for ANF identification. B - single-exponential fitting of each recorded PSTH is used to define $\tau$ time course of response adaptation.

C - Recovery from forward-masking stimulation. Following $100 \mathrm{~ms}$ tone burst stimulation at CF $30 \mathrm{~dB}$ above the threshold, probe stimulation is presented after various silent intervals (4, 16, 64 and $256 \mathrm{~ms})$. Onset responses to masker and probe analyzed further to estimate recovery from depression.

D - Rate level function to $50 \mathrm{~ms}$ tone bursts at CF $20 \mathrm{~dB}$ below up to $50 \mathrm{~dB}$ above threshold $5 \mathrm{~dB}$ steps. Steepness and dynamic range (the range of intensities over which the spike rate increased from $10 \%$ to $90 \%$ of the evoked rate).

E - Phase-locking to amplitude-modulated tones.

F - Synchronization index (or vector strength, a measure of phase locking to amplitude modulation) for a range of intensities.

\subsection{Immunohistochemistry}

To study morphological changes in the IHC ribbon synapses, mouse cochleae were dissected after animal was sacrificed. The dissected organ of Corti was fixed in 4\% PFA during 10 min on ice. Immunostaining and confocal microscopy was performed mostly as described Khimich et al. (2005).

\subsubsection{IHC ribbon synapse number}

Presynaptic major ribbon protein RIBEYE (1:200, mouse, BD Bioscience) was costained with postsynaptic AMPAR protein GluA2/3 (1:100, rabbit, Chemicon). The number of colocalized puncta was counted to determine the number of IHC ribbon synapses. Secondary antibodies Alexa 488 (1:200, goat anti rabbit, MoBiTec) and Alexa 546 (1:200, goat anti mouse, MoBiTec) were used to image stained proteins with a confocal microscope (Leica SP5, 63xobjective).

\subsubsection{AMPAR subclusters number and distance from presynaptic active zone}

Organs of Corti of PSD-95 ${ }^{-/-}$and their wild type littermates were dissected, fixed and stained with primary antibodies as described above. To achieve greater resolution to study the 
morphology of AMPAR cluster, STED microscopy was performed to image IHC ribbon synapses.

\subsubsection{PSD-95 expression and localization in SGNs}

Combination of 3 primary antibodies was used to address the question about the expression and localization of PSD-95 protein in SGNs: PSD-95 (1:200, mouse, Sigma Aldrich), GluA2/3 (1:100, rabbit, Chemicon) and CtBP2 (1:150, goat, Abcam). Secondary antibodies STAR 580P (1:200, donkey anti rabbit, Abberior), STAR 635P (1:200, donkey anti mouse, Abberior) were used to image PSD-95 and GluA2/3 with STED microscope and Alexa 488 (1:200, donkey anti goat, MoBiTec) to image ribbon with confocal microscope.

\subsubsection{PSD-93 expression in PSD-95 $/ /-$ and PSD-95 ${ }^{+/+}$SGNs}

The scaffolding MAGUK protein PSD-93 was stained with a monoclonal antibody against PSD-93 (1:200, mouse; University of California, Davis/National Institutes of Health NeuroMab) together with GluA2/3 (1:100, rabbit, Chemicon). Secondary antibodies STAR 580P (1:200, goat anti mouse, Abberior) and STAR 635P (1:200, goat anti rabbit, Abberior) were used to image structures with STED microscope.

\subsubsection{SAP-102 expression in SGNs}

C57B1/6 mice of age P14 were used to study the question about expression of SAP-102 in mouse SGNs. SAP-102 primary monoclonal antibodies (1:100, mouse; University of California, Davis/National Institutes of Health NeuroMab) were combined with GluA2/3 AMPA receptor subunits antibodies (1:100, rabbit, Chemicon). Secondary antibodies STAR 580P (1:200, goat anti mouse, Abberior) and STAR 635P (1:200, goat anti rabbit, Abberior) were used to image synapses with STED resolution.

\subsection{STED microscopy}

2D STED microscopy was used to image IHC ribbon synapses with resolution $80 \mathrm{~nm}$ in $\mathrm{X}, 80 \mathrm{~nm}$ in $\mathrm{Y}$ and $200 \mathrm{~nm}$ in Z dimensions. An Abberior STED microscope (Abberior Instruments 2-color STED 775 QUAD Scanning) with a 100x magnification and immersion oil were used to image stained IHC ribbon synapses. The system is based on an Olympus IX83 microscope (4-color LED illumination source and a monochrome wide field camera) equipped with the Abberior QUAD scanner (Scan field: $>80 \times 80 \mu \mathrm{m}$, Line frequency: $2 \mathrm{kHz}$ ). The STED 
system has two pulsed excitation laser sources with wavelengths of 594 and $640 \mathrm{~nm}$ and a pulsed STED laser of $775 \mathrm{~nm}$.

Analysis of STED microscopy images was performed in an aim to reveal the question about a possible impairment of AMPA receptors cluster arrangement. I used Imaris software and performed the analysis blinded to the genotype of the animals. Two algorithms were applied depending on imaging approaches: (1) for a big stack of many imaged synapses, I applied a custom-written algorithm, named Autoregressive Motion; (2) for singly imaged synapses (in intention to reduce bleaching and image particularly oriented synapse) I applied an algorithm named MarkByHand integrated into Imaris Image Analysis Software (http://www.bitplane.com/imaris/imaris). Both custom algorithms were implemented by Gerhard Hoch and both have similar analysis settings but differ in the area of analysis. With both algorithms, fluorescent spots of a diameter of about $100 \mathrm{~nm}$ for AMPA receptor nanoclusters or of $300 \mathrm{~nm}$ for IHC ribbons were automatically detected. The algorithm applies Gaussian filtered versions of the original image for background subtraction. A "Quality" filter implemented in Imaris which represents the fluorescence intensity at the center of the spots, was used to analyze the singly imaged synapses. Further thresholding allowed manual adjustment and detection of spots. Spots with lower intensity values could be identified by moving the yellow inclusive region to the left. Both algorithms allowed to identify the centers of mass of individual AMPA receptor nanoclusters and ribbons. Imaris tools were then used to measure distances from each nanocluster to the center of the mass of the nearest ribbon (Fig.20A). For the quantification of the number of AMPA receptor nanoclusters per synapse and the measurement of the distances from each nanocluster to the ribbon, we considered only the synapses with one ribbon per AMPA receptors cluster.

\subsection{Intellicage}

Operant conditioning in the "Audiobox" (Auditory Box IntelliCage System, TSE Systems GmbH; Fig. 10) was carried out essentially as described ín de Hoz \& Nelken, 2014. The experiments had been started by Elisabeth Auge.

\subsubsection{Transponder injection}

Otof ${ }^{515 T / 1515 T}$ mutant mice and their wild type littermates were injected with transponder after they achieved age of 4 weeks. Mice were briefly anesthetized with isoflurane and 
buprenorphine $(0.1 \mu \mathrm{g} / \mathrm{g}$, i.p.). Transponder was injected subcutaneously on the back. Animal was placed back to the cage to recover after anesthesia.

\subsubsection{Intellicage setup}

The Audiobox serves both as a living area for the experimental animals and as their testing platform (de Hoz and Nelken, 2014a). Mice were kept in groups of 5-10 animals. The Audiobox consists of two compartments connected by a long tube (Fig.10A). The first compartment included two normal mouse cages connected by tubes. Those cages served as a home cage with a free access to food and wheels for running. The second compartment of the Audiobox, the "corner" (Fig.10B), had water access in the bottles placed inside a soundattenuated box (Fig.10C). The corner has two ports where mouse may access water by nosepoking, "nose-poke". For the presentation of sound stimuli, a loudspeaker is positioned directly above the corner. There is also an air valve in the ceiling of the corner allowing punishment by air puffs.

Each entrance of a mouse into the corner, a "visit", was detected by an antenna located at its opening that recognizes the injected transponder. The start of the visit was defined by the detection of the implanted transponder and the activation of a heat sensor located within the corner. The end of the visit was defined when the same transponder was not detected anymore and the heat sensor was no longer activated. Visits to the drinking corner, nose-pokes to the sliding door to the water bottle, and drinking were automatically registered by the system for each mouse. Sound stimulus presentation, opening and closing of the doors giving access to the water bottles, and air puff punishment were computer controlled according to the experimenter's settings for each mouse. There was no interference by humans except for weekly cleaning and re-filling of water bottles.

Thus, the Audiobox system recognizes specific mouse that visits the corner and therefore can select the stimulus to be presented and air puff punishment or water reward accordingly and collect data on the number and duration of visits, nosepokes and licks for each mouse and stimulus setting.

In the gap detection experiment, mice were conditioned to attempt to drink water only when continuous broadband noise was present. When the noise was interrupted by $90 \mathrm{~ms}$ silent gaps, access to the water bottles was denied and drink attempts were punished by air puffs (1 Bar air pressure). After reaching > 30\% discrimination performance, we first achieved 
generalization to varying gap durations and then in the experimental phase introduced shorter gaps in a total of $8 \%$ of the trials.

In the threshold detection experiment mice were conditioned to attempt to drink only in silence. When the silence was interrupted by $80 \mathrm{~dB}$ noise burst, access to the water bottles was denied and drink attempts were punished by air puffs (1 Bar air pressure). After reaching $>30 \%$ discrimination performance, first achieved generalization to varying gap durations and then in the experimental phase other sound intensities were introduced in a total of $8 \%$ of the trials.
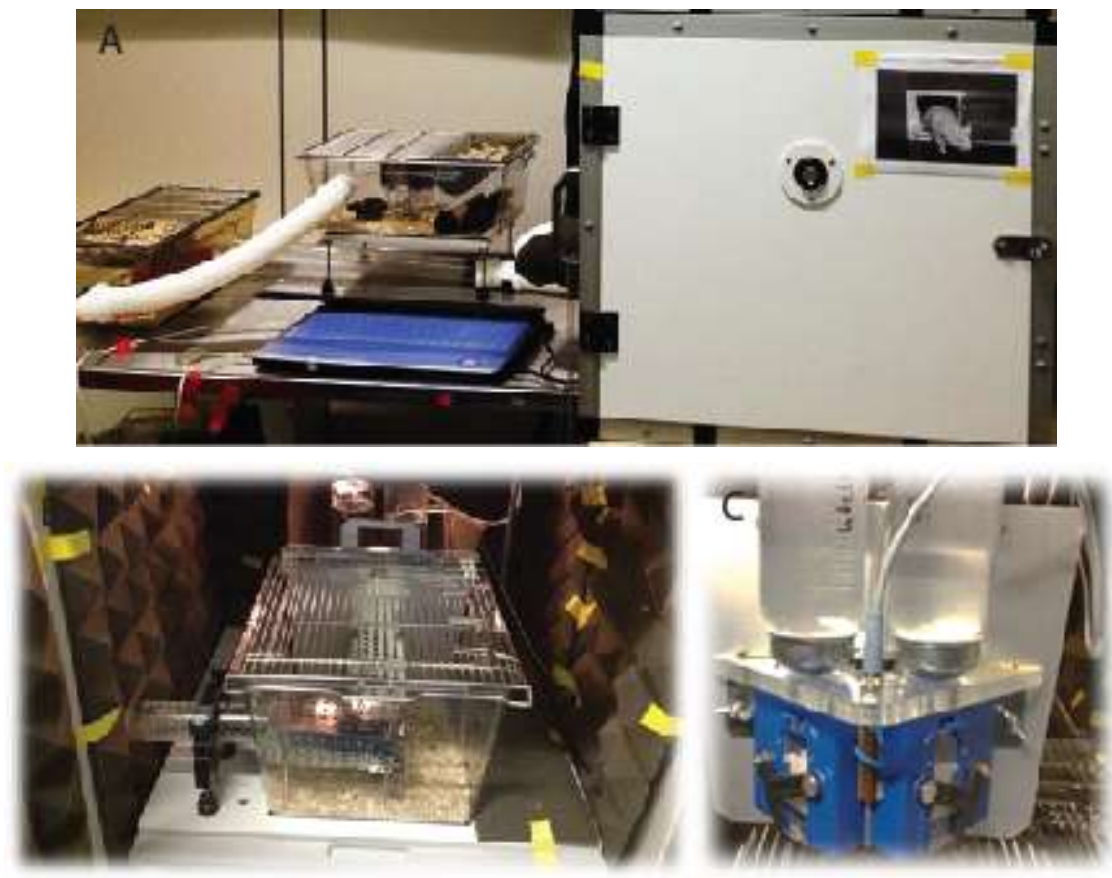

Figure 10. Intellicage setup under laptop computer control (Photos provided by Elisabeth Auge)

A - Two cages, connected with tube, one has a running wheel and another a "house", where mice can hide, sleep or play. Both cages have feeders.

B - One cage connected to the sound-proof box, where mice have access to the water.

$\mathrm{C}$ - Water bottles in the corner with transponder detector.

\subsection{Data analysis}

Data analysis was performed using Matlab (Mathematics), Igor Pro (Wavemetrics), ImageJ software (Fiji) (http://rsb.info.nih.gov/ij/), Imaris 7.6.5 and Statistica 13.2. For comparing two groups, unpaired, two-tailed t-test were used if the samples passed normality 
test (Jarque-Bera test). In all other cases, the non-parametric unpaired, two-tailed MannWhitney test was used. For comparing multiple samples, one-way ANOVA followed by Dunn's tests were used. Means are expressed as mean \pm SEM, unless specified otherwise. Significance is shown as follows: $* \mathrm{p}<0.05, * * \mathrm{p}<0.01, * * * \mathrm{p}<0.001$ and n.s. (not significant). 


\section{Results}

\subsection{Auditory phenotype of $W r b^{t / f t}: C r e^{A}$ mice}

\subsubsection{WRB disruption causes progressive hearing impairment in mice, observed in strongly impaired ABRs}

$W_{r b}^{f f f f l}: \mathrm{Cre}^{A}$ mice were generated as described in the Appendix Supplementary Methods in Vogl et al (2016). In brief, these mice are conditional Wrb knockouts, generated by flanking exons two to four by loxP sites through homologous recombination $\left(\mathrm{Wrb}^{\mathrm{f} / \mathrm{fl}}\right)$. To achieve IHC-specific Cre recombination, $\mathrm{Wrb}^{\mathrm{fl} / \mathrm{fl}}$ mice were then crossed with the mice expressing Cre- recombinase under control of the vesicular glutamate transporter (Vglut3) promoter, which expression is specific for IHCs (Obholzer et al., 2008b; Ruel et al., 2008; Seal et al., 2008) and to some classes of neurons (El Mestikawy et al., 2011). Vglut3 - Cre transgenic mouse line, in which Cre-recombinase (but without additional Vglut3) was expressed under the control of the transgenic Vglut3 promoter (Jung et al., 2015) was named $\mathrm{Wrb}^{\mathrm{f} / \mathrm{fl} l: \mathrm{Cre}^{\mathrm{A}} \text { mice. }}$

ABRs were recorded for 3 age groups: group I: P14-17, II: P21-26; III: >29. Group I was analyzed in order to estimate early changes in auditory function right after hearing onset (P14), when auditory sensitivity is not yet fully mature. $\mathrm{Wrb}^{\mathrm{fl} / \mathrm{fl}}: \mathrm{Cre}^{\mathrm{A}}$ mice had strong, ageprogressive ABR impairment (Fig.11 A-A"). ABR wave I, which reflects SGN compound action potentials, was progressively reduced in $\mathrm{Wrb}^{\mathrm{fl} / \mathrm{fl}}: \mathrm{Cre}^{\mathrm{A}}$ mice. In a line with $\mathrm{ABR}$ wave $\mathrm{I}$ amplitude progressive reduction, ABR thresholds were progressively elevated (Fig.11B-B"). 

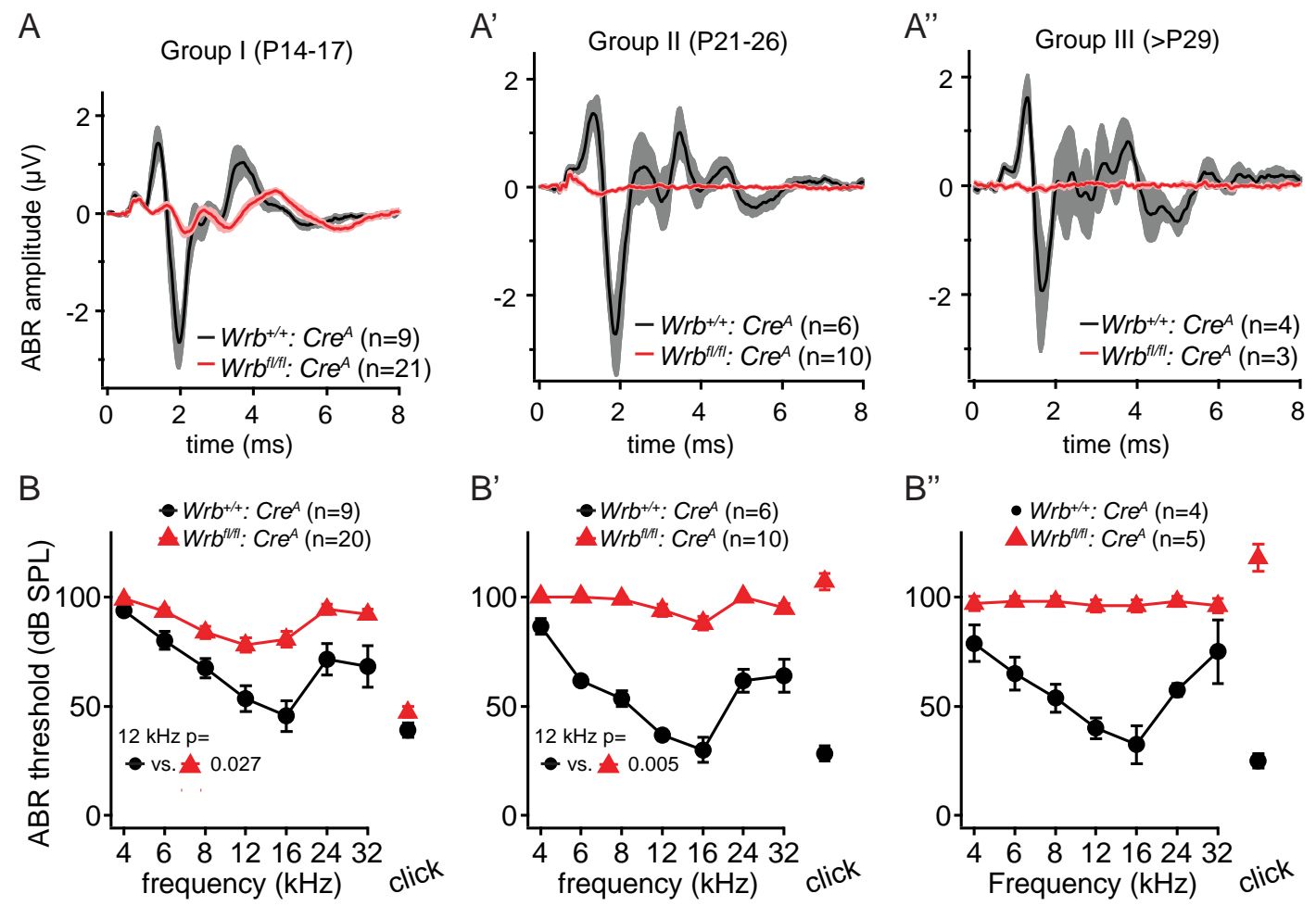

Figure 11. Degraded ABRs in $\mathrm{Wrb}^{\mathrm{fl} / \mathrm{fl}:}: \mathrm{Cre}^{\mathrm{A}}$ mice (adapted from (Vogl et al., 2016a)) $\mathrm{A}-\mathrm{A}^{\prime \prime}-$ Averages of ABRs in $\mathrm{Wrb}^{\mathrm{fl} / \mathrm{fl} l}: \mathrm{Cre}^{\mathrm{A}}$ (red traces, SEM pink) and $\mathrm{Wrb}^{+/+}: \mathrm{Cre}^{\mathrm{A}}$ (black traces, SEM grey) mice. ABRs were recorded for three separate age groups (A-A", as indicated in the graph) using $80 \mathrm{~dB}$ click at $20 \mathrm{~Hz}$ stimulation rate. $\mathrm{Wrb}^{\mathrm{f} / \mathrm{fl} l}: \mathrm{Cre}^{\mathrm{A}}$ mice demonstrated age-progressive reduction of ABR wave I.

$\mathrm{B}-\mathrm{B}^{\prime \prime}-\mathrm{ABRs}$ in $\mathrm{Wrb}^{\mathrm{fl} / \mathrm{fl}:}: \mathrm{Cre}^{\mathrm{A}}$ mice showed a progressive threshold increase, and $\mathrm{Wrb}^{+/+}: \mathrm{Cre}^{\mathrm{A}}$ mice had normal thresholds. Statistical comparison of the threshold at $12 \mathrm{kHz}$ was done by Kruskal-Wallis test, and p-values were taken from post hoc Dunn's multiple comparison test. Measurements in which no ABR was observed at the maximal available tone burst level (90 $\mathrm{dB})$ or click level $(120 \mathrm{~dB})$ scored as $100 \mathrm{~dB}$ threshold. Data is represented as means \pm SEM.

\subsubsection{Impaired sound encoding in $\mathrm{Wrb}^{\mathrm{f} / \mathrm{fl}}: \mathrm{Cre}^{\mathrm{A}} \mathrm{SGNs}$}

ABR wave I age-progressive reduction suggested SGN impaired synaptic sound encoding. Therefore, in vivo extracellular recording from individual SGNs were performed for P16-21 mice.

All recorded $W r b^{f l l f l}: \mathrm{Cre}^{\mathrm{A}}$ showed SRs lower than $20 \mathrm{~Hz}$, unlike in $\mathrm{Wrb}^{+/+}: \mathrm{Cre}^{\mathrm{A}} \mathrm{SGNs}$, where high SR fibers were readily found (Fig.12A). Tuning curves and acoustic thresholds were well preserved in $\mathrm{Wrb}^{\mathrm{fl} / \mathrm{fl}}: \mathrm{Cre}^{\mathrm{A}}$ mice (Fig.12B,C). Sound evoked responses of SGNs were better than in described earlier pachanga mutants (Pangrsic et al., 2010), giving an opportunity 
for detailed analysis of sound encoding, which was missing for otoferlin deficient mutants. Firing rates and latencies were studies in response to $50 \mathrm{~ms}$ tone burst stimulation at CF $30 \mathrm{~dB}$ above threshold. Tones were played at three different stimulus repetition rates $(2,5$ and $10 \mathrm{~Hz}$, Fig.12D-D'). Recorded PSTHs showed use-dependent reduction in onset and adapted firing rates of $\mathrm{Wrb}^{\mathrm{fl} / \mathrm{fl}}$ :Cre ${ }^{\mathrm{A}} \mathrm{SGNs}$ (Fig.12E). Spike rates were decreased when stimulation rates were increased. In line with the reduction of spike rates, median FSL was dramatically increased, as well as variance of FSL (standard deviation of FSL, or jitter) was enhanced (Fig.12F). This defined spike reduction and impaired synchrony of coding may likely explain strong ABR wave I reduction and high thresholds.
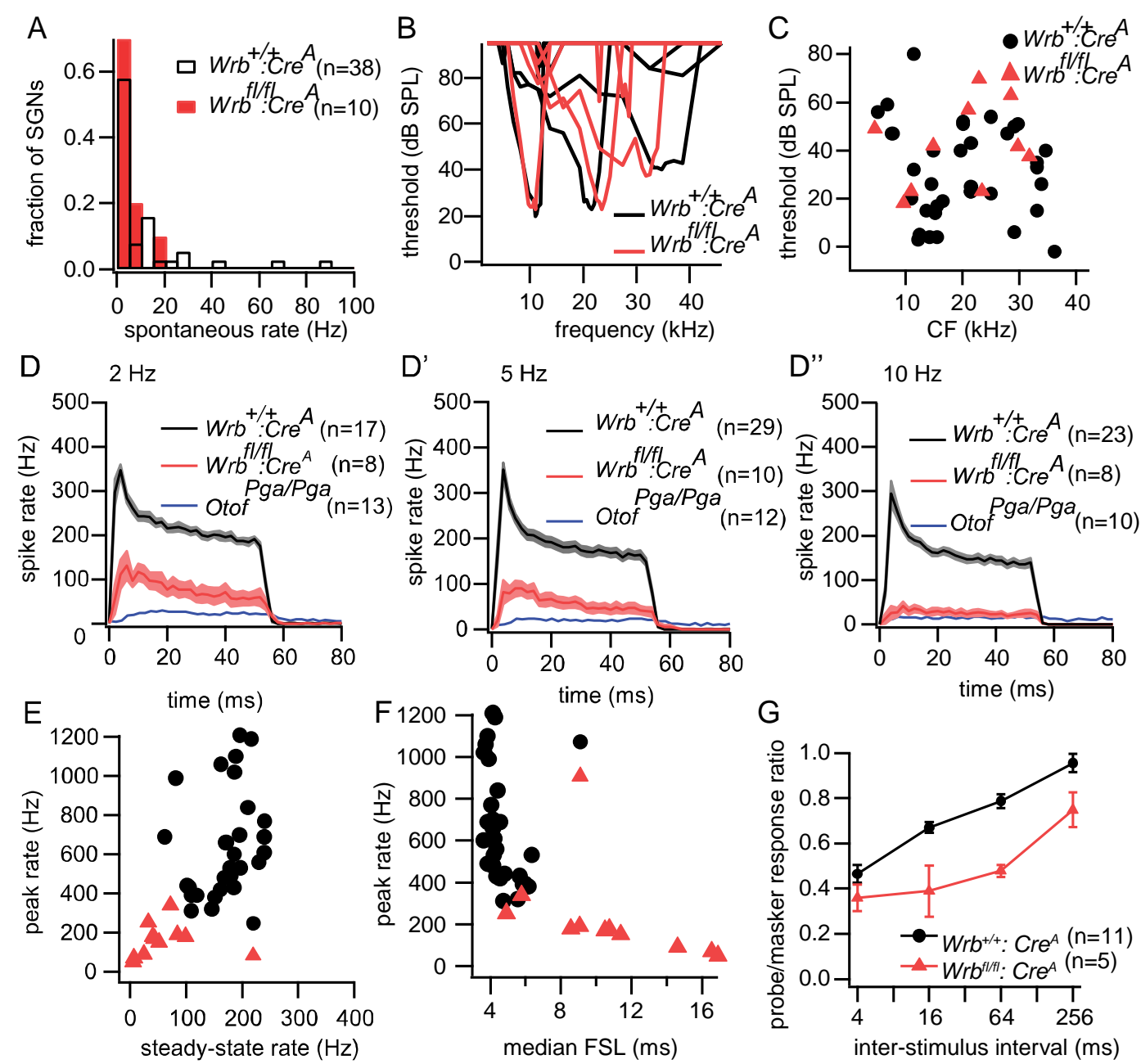

Figure 12. Sound encoding in SGNs of WRB ${ }^{\mathrm{fl} / \mathrm{fl}}: \mathrm{Cre}^{\mathrm{A}}$ mice (adapted from (Vogl et al., 2016a)

A - All recorded $\mathrm{Wrb}^{\mathrm{f} / \mathrm{fl} l}: \mathrm{Cre}^{\mathrm{A}}$ SGNs had SRs below $20 \mathrm{~Hz}(\mathrm{p}>0.05$, Kolmogorov-Smirnov test).

B - Well preserved tuning curves from $\mathrm{Wrb}^{\mathrm{fl} / \mathrm{fl}:}: \mathrm{Cre}^{\mathrm{A}}$ and $\mathrm{Wrb}^{+/+}: \mathrm{Cre}^{\mathrm{A}}$ SGNs indicating retained active cochlear amplification in spite disruption of Wrb in IHCs. 
$\mathrm{C}$ - Normal thresholds at the CF in $\mathrm{Wrb}^{\mathrm{fl} / \mathrm{fl} l}: \mathrm{Cre}^{\mathrm{A}}$ SGNs.

D-D" - Mean PSTH \pm SEM of $\mathrm{Wrb}^{\mathrm{fl} / \mathrm{fl}:}: \mathrm{Cre}^{\mathrm{A}}$ and $\mathrm{Wrb}^{+/+}: \mathrm{Cre}^{\mathrm{A}}$ SGNs in response to $50 \mathrm{~ms}$ tone bursts presented at CF, $30 \mathrm{~dB}$ above threshold at stimulus rates of $2 \mathrm{~Hz}(\mathrm{D}), 5 \mathrm{~Hz}$ (D'), or 10 $\mathrm{Hz}\left(\mathrm{D}^{\prime \prime}\right)$. While the general response pattern was preserved, spike rates were dramatically reduced in $\mathrm{Wrb}^{\mathrm{f} / \mathrm{fl} l}: \mathrm{Cre}^{\mathrm{A}} \mathrm{SGNs}$, especially at higher stimulus rates. SGN and $\mathrm{CN}$ neurons responses of Otof ${ }^{\text {Pga/Pga }}$ animals from Pangrsic et al (2010) were replotted for direct comparison.

$\mathrm{E}$ - Spike rates in response to sound onset and adapted rates were significantly reduced in $\mathrm{Wrb}^{\mathrm{fl} / \mathrm{fl} l}: \mathrm{Cre}^{\mathrm{A}} \mathrm{SGNs}$ (stimulus rate $5 \mathrm{~Hz}, \mathrm{p}<0.001$ ).

$\mathrm{F}-$ Median FSL following stimulus onset was greatly increased in $\mathrm{Wrb}^{\mathrm{f} / \mathrm{fl} l}: \mathrm{Cre}^{\mathrm{A}}$ SGNs compared to $\mathrm{Wrb}^{+/+}: \mathrm{Cre}^{\mathrm{A}}$ (stimulus rate $5 \mathrm{~Hz}, \mathrm{p}<0.001$ ).

$\mathrm{G}-100$-ms masker tone presented at $\mathrm{CF}, 30 \mathrm{~dB}$ above threshold was followed by silence intervals of variable duration and 15-ms probe tone (CF, $30 \mathrm{~dB}$ above threshold). In $\mathrm{Wrb}^{\mathrm{fl} / \mathrm{fl} l}: \mathrm{Cre}^{\mathrm{A}} \mathrm{SGNs}$, the response to the first $5 \mathrm{~ms}$ of the masker probe tone (shown as a fraction of the response to the first $5 \mathrm{~ms}$ of the masker) was strongly reduced. Data represents means \pm SEM.

To estimate recovery from synaptic depression and suggested impairment of vesicles replenishment of readily releasable pool of $\mathrm{Wrb}^{\mathrm{fl} / \mathrm{fl}}: \mathrm{Cre}^{\mathrm{A}}$ mice, forward masking stimulation was applied to SGNs. Spike rate adaptation of SGN is thought to reflect partial depletion of RRP, whereas recovery from adaptation might reflect RRP replenishment (Moser and Beutner, 2000b; Goutman and Glowatzki, 2007b; Frank et al., 2010b). Wrb ${ }^{\text {fl/fl }}: \mathrm{Cre}^{\mathrm{A}}$ SGNs showed slower recovery from adaptation. These results indicating that impaired sound encoding in $\mathrm{Wrb}^{\mathrm{fl} / \mathrm{fl}}: \mathrm{Cre}^{\mathrm{A}} \mathrm{SGNs}$ is due to reduced vesicle replenishment, which resulting in lower size of standing RRP.

\subsection{Sound encoding in PSD-95/- mice}

\subsubsection{ABRs in PSD-95\% ${ }^{-/}$mice}

ABRs were measured by Stefan Thom in order to detect a possible sound encoding impairment in PSD-95 ${ }^{-/}$mice. ABR wave I, which reflects responses of SGN, was significantly reduced in amplitude, indicating a sound encoding defect. No reduction or delay of following ABR waves was found (Fig.13A-C), and ABR thresholds were normal, suggesting that the 
peripheral sound encoding impairment in PSD-95 $5^{-/-}$mice was very mild and mostly compensated in the auditory brainstem.

A

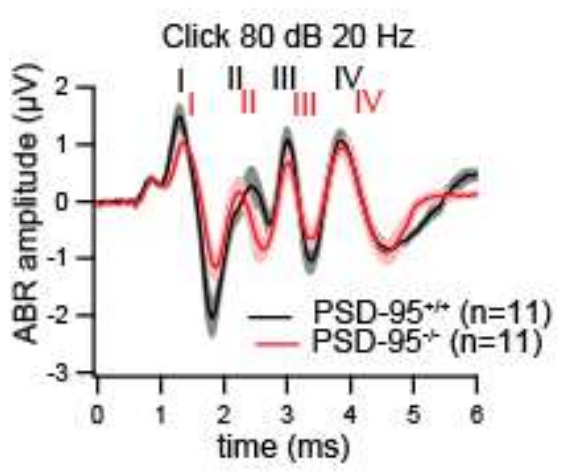

C

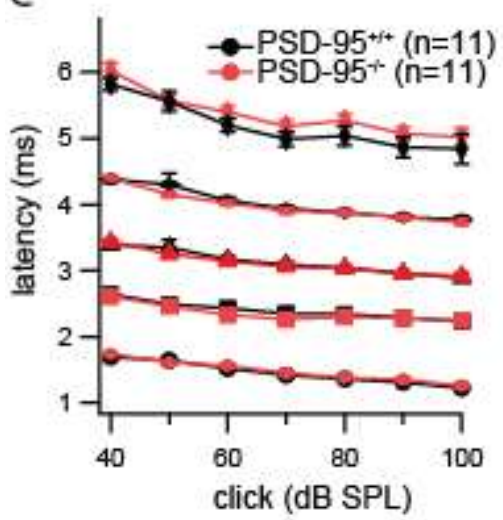

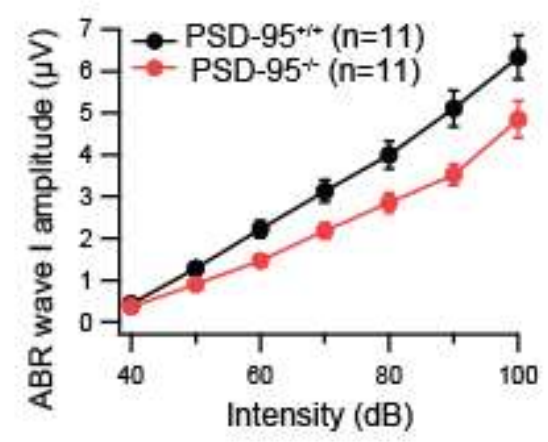

D

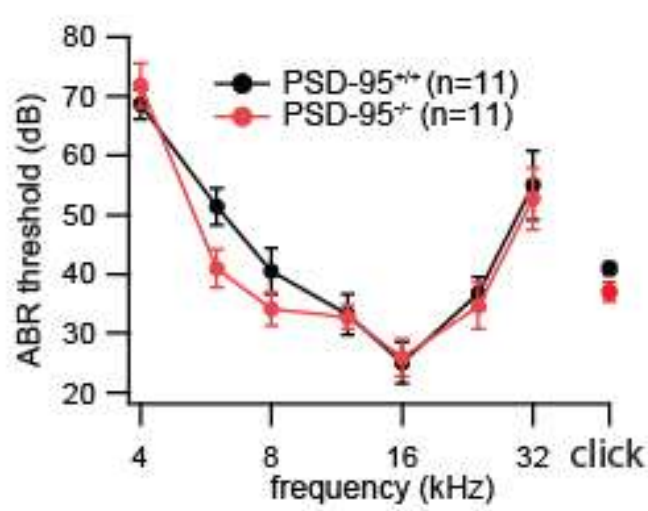

B

Figure 13. ABRs in PSD-95 ${ }^{-/-}$and wild type mice

A - ABRs to $20 \mathrm{~Hz}$ Click stimulation at $80 \mathrm{~dB}$. In PSD-95 ${ }^{-/-}$mice the first peak is reduced, but other peaks were mostly preserved, suggesting a mild synaptic deficit in SGN sound encoding and compensation of it in the auditory brainstem.

$\mathrm{B}-\mathrm{ABR}$ wave I amplitude is reduced in PSD-95 ${ }^{-/-}$mice.

$\mathrm{C}-\mathrm{ABR}$ wave latencies are normal in PSD-95 ${ }^{-/}$mice.

D - ABR thresholds of PSD-95 ${ }^{-/}$mice are normal across different frequencies.

\subsubsection{Disruption of PSD-95 entails reduction of spike generation in SGNs}

The primary mechanism underlying defined ABR distortions was possible to study by recording responses of single SGNs. Single unit extracellular recording in vivo recordings were performed to study impaired synaptic sound encoding in SGNs. Genotyping of PSD-95 mice was done by Man Ho Wang. 
Spontaneous discharge rates of SGNs were recorded in silence. PSD-95 $5^{-/-}$mice showed significantly lower SRs (Fig.14A).

The SGNs respond selectively to particular ranges of frequencies of sinusoidal stimuli that correspond to the cochlear tonotopic location of the inner hair cell they innervate. Thus, each SGN is tuned to certain characteristic frequency (CF, see chapter in Introduction). The threshold was defined as the minimum intensity of the stimulus level needed to trigger a spike rate exceeding spontaneous rate by $20 \mathrm{~Hz}$. A tuning curve can be obtained by plotting threshold as a function of stimulus frequency. Figure 14B shows representative ANF tuning curves of PSD-95 ${ }^{-/}$and PSD-95 wild type littermates of them. Defined thresholds were then plotted versus their CFs. PSD-95 ${ }^{-/}$SGNs have better preserved single unit thresholds.

SGNs fire trains of APs in response to $50 \mathrm{~ms}$ suprathreshold tone bursts applied at 30 $\mathrm{dB}$ above threshold at CF. These tone bursts were presented 200 times, and post-stimulus time histograms "PSTH" ( $0.5 \mathrm{~ms}$ binwidth) were constructed to display the time distribution of spike generation time in relation to the stimulus onset for each SGN. The typical PSTH of SGNs has a sharp onset response, which gradually adapts to the steady state rate. In addition, $50 \mathrm{~ms}$ tone bursts may vary in stimulation frequency $(2,5,10 \mathrm{~Hz})$. Figure $14 \mathrm{D}, \mathrm{E}, \mathrm{F}$ shows the significant reduction of spike rate in PSD-95 ${ }^{-/-}$SGNs at either slow $2 \mathrm{~Hz}$ stimulation, or faster $5 \mathrm{~Hz}$ and $10 \mathrm{~Hz}$. Figure $14 \mathrm{G}, \mathrm{H}$, I demonstrate that at each frequency of stimulation both peak and steady state rates were reduced. In PSD-95 $5^{+/+}$and PSD-95 ${ }^{-/}$SGNs peak and steady state rates were respectively (mean \pm SEM; p-value, Mann-Whitney U-test): $819.1 \pm 41.7$ vs $617.7 \pm 36.9$ and $255.1 \pm 9.7$ vs $180.1 \pm 10$ at $5 \mathrm{~Hz}$ stimulation ( $<<0.001$ ); $913.8 \pm 58.9$ vs $632.6 \pm 42.8$ and $303.2 \pm 13.8$ vs $181.1 \pm 10.5$ at $2 \mathrm{~Hz}$ stimulation ( $\mathrm{p}<0.001$ ); $574.4 \pm 50.5$ vs $403.5 \pm 38.4$ and $216.5 \pm 13.5$ vs $133.3 \pm 9.2$ at $10 \mathrm{~Hz}$ stimulation ( $\mathrm{p}=0.001)$.

No further decay of steady state spike rate of PSD-95 ${ }^{-/}$SGNs was observed during longer (100 ms tone burst $30 \mathrm{~dB}$ above threshold at CF) stimulation (Fig.14J).

The latency of sound onset responses of SGN was quantified as median first spike latency "FSL". In PSD-95"- SGNs onset responses were significantly delayed (Fig.14K, in PSD-95 $^{+/+}$vs PSD-95 ${ }^{-/-}$SGNs4.5 \pm 0.12 ms vs 5 \pm 0.2 , p=0.01, Mann-Whitney U-test).

Sound onset coding precision was estimated as the variance of FSL (jitter). In PSD-95'- jitter was significantly greater, indicating that sound encoding in SGNs of knockouts is less precise (Fig.14K). In PSD-95 ${ }^{+/+}$vs PSD-95/-, respectively (mean \pm SEM; p-value, MannWhitney U-test): $1.3 \pm 0.1 \mathrm{~ms}^{2}$ vs $1.7 \pm 0.2 \mathrm{~ms}^{2}(\mathrm{p}=0.05$ ). The time constant of adaptation of a 
spike rate was quantified by fitting a single exponential function to each recorded PSTH. The time course of adaptation in PSD-95 ${ }^{-/}$was significantly shorter (Fig.14M). In PSD-95 ${ }^{+/+}$vs PSD-95 ${ }^{-/-}$, respectively (mean \pm SEM): $6.3 \pm 0.5$ vs $3.9 \pm 0.4$. The strength of adaptation, quantified as peak-to-rate ratio, was not different (Fig.14M, in PSD-95 ${ }^{+/+}$vs PSD-95 ${ }^{-/-}$ respectively: $0.3 \pm 0.010 .3 \pm 0.01$.

Increase of stimulus level monotonically increases the discharge rate of SGNs (Sachs and Abbas, 1974). This correlation was studied in rate-level functions. The Sachs-Abbas model (Sachs et al., 1989b) was adapted into five parameter phemenological model by Taberner and Liberman (Taberner and Liberman, 2005a). This model fits the rate-level function and better approximates dynamic ranges. The dynamic range was defined as the range of intensities over which the spike rate increased from $10 \%$ to $90 \%$ of the evoked rate. Figure $14 \mathrm{~N}$ shows normal rate-level thresholds, but reduced maximal rates. No statistical significant difference was observed between dynamic ranges of PSD-95 ${ }^{-/-}$and wild types (Fig.14O): 16.6 $\pm 2.1 \mathrm{~dB}$ vs. 18.7 $\pm 1.9 \mathrm{~dB}$ in PSD-95 $5^{+/+}$vs. PSD-95 ${ }^{-/-}$respectively ( $\mathrm{p}=0.46$, $\mathrm{t}$-test). To estimate the slope of the rate-level function, the steepness was calculated the maximal increase of spike rate per $5 \mathrm{~dB}$ increase of the stimulus intensity. Figure 14P shows that PSD-95/- mice have significantly reduced steepness (Fig.14L): $18.5 \pm 1.4$ vs $14.2 \pm 1.4$ in PSD-95 ${ }^{+/+}$vs. PSD-95 ${ }^{-/-}$respectively ( $p=0.04$, Mann-Whitney U-test), which can be explained as a result of a decrease of spike rates.

The temporal precision of spike generation was assessed as ability to phase-lock. Phase locking was measured using transposed amplitude modulated $\mathrm{CF}$ tones, which were amplitude modulated by $500 \mathrm{~Hz}$ at different intensities ( $5 \mathrm{~dB}$ steps). PSD-95 $5^{-/-}$SGNs showed similar phase locking ability, estimated as SI (Fig. 14Q): $0.66 \pm 0.03 n=18$ vs. $0.62 \pm 0.03 n=23$ of PSD$95^{+/+}$vs. PSD-95 $5^{-/-}$respectively ( $\mathrm{p}=0.57$, Mann-Whitney U-test).

Forward-masking paradigm was applied to estimate synaptic depression and recovery from it. $100 \mathrm{~ms}$ CF masker tone burst was first presented, followed by another $15 \mathrm{~ms}$ probe tone separated by varying inter-stimulus intervals $(4,16,64$ and $256 \mathrm{~ms})$. To estimate recovery from forward masking, ratios between onset responses to probe and masker stimulation were calculated for various inter-stimulus intervals. For PSD-95 ${ }^{-/-}$there was no significant difference between probe-to-masker response ratios at various silence intervals (Fig14), where in PSD$95^{+/+}$vs PSD-95 ${ }^{-/-}$SGNs ratios at 4, 16, 64 and $256 \mathrm{~ms}$ silent intervals were respectively: $0.6 \pm 0.02$ vs. $0.5 \pm 0.01 ; 0.7 \pm 0.03$ vs. $0.7 \pm 0.02 ; 0.9 \pm 0.02$ vs. $0.8 \pm 0.03 ; 0.99 \pm 0.04$ vs. $0.99 \pm 0.04$, $(\mathrm{p}=0.27$, repeated measures ANOVA). 

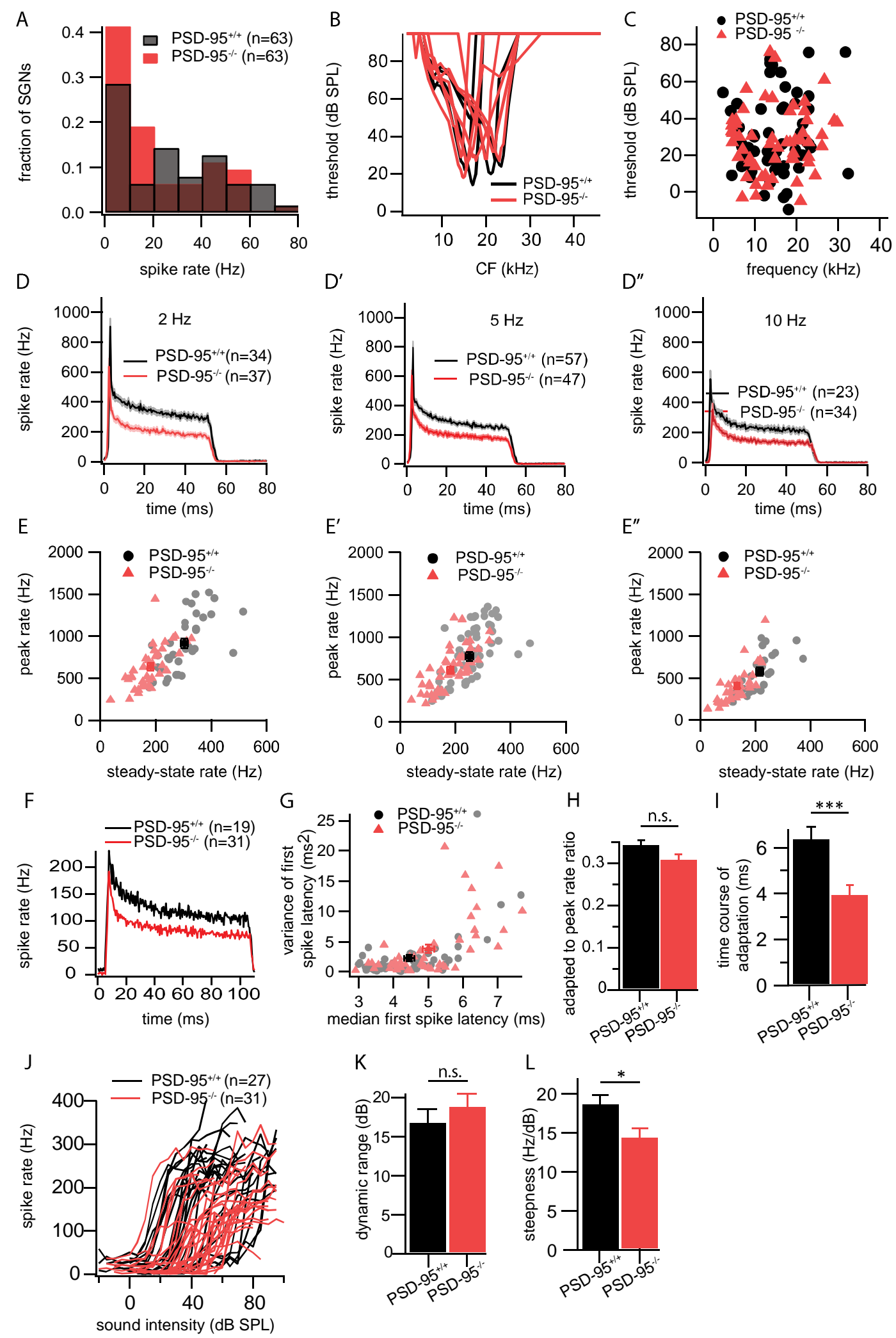

(Figure legend on the next page) 

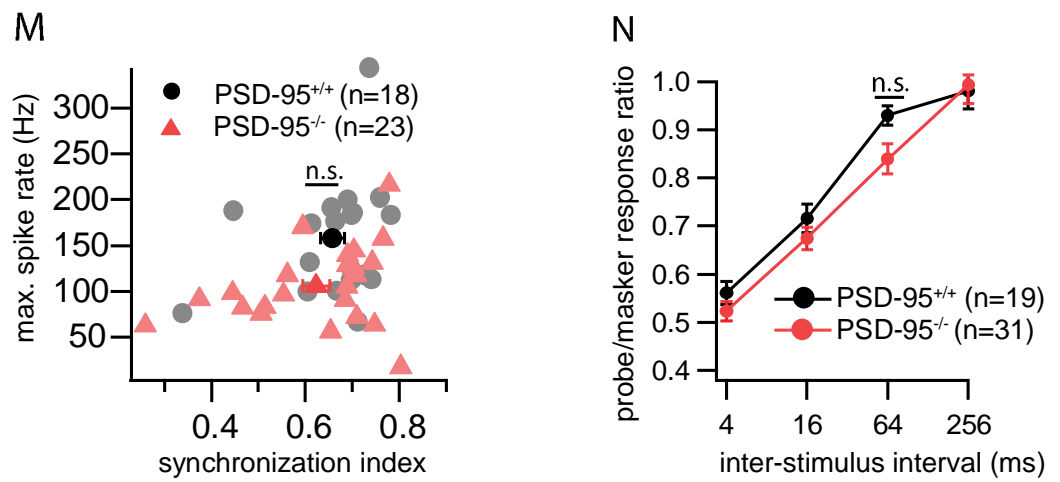

Figure 14. Sound encoding in PSD-95 ${ }^{-/}$and wild type SGNs

A - SR of SGNs, measured in silence. PSD-95 $5^{-/-}$mice have significantly reduced SRs ( $\mathrm{p}=0.02$, Kolmogorov - Smirnov test $)$.

B , C - Tuning curves and defined thresholds at CFs were well preserved in PSD- $95^{-/}$SGNs. D-D" - Mean PSTHs \pm SEM of PSD- $95^{+/+}$and PSD-95 ${ }^{-/-}$SGNs in response to $50 \mathrm{~ms}$ tone bursts presented at $\mathrm{CF}, 30 \mathrm{~dB}$ above threshold at stimulus rates 2, 5 and $10 \mathrm{~Hz}$. While general response pattern was well preserved, PSD-95 ${ }^{-/}$SGN showed reduced spike rates, especially at higher stimulus rates.

E-E" - Spike rates in response to sound onset. Peak rates in PSTH with 0.5 ms binwidth and steady-state rates averaged between 35 and $45 \mathrm{~ms}$ after stimulus onset were lower in PSD-95 ${ }^{-1}$ SGNs.

$\mathrm{F}-$ Mean PSTHs \pm SEM of PSD-95 ${ }^{+/+}$and PST-95 ${ }^{-/}$SGNs in response to $100 \mathrm{~ms}$ tone bursts presented at $\mathrm{CF} 30 \mathrm{~dB}$ above threshold at $5 \mathrm{~Hz}$ stimulus rate. $\mathrm{PSD}-95^{-1-} \mathrm{SGN}$ had reduced peak and adapted rates with no further spike decline at the end of long stimulation.

$\mathrm{G}$ - In a line with the reduction in spike rates, FSL following stimulus onset was increased compared to PSD- $95^{+/+}$at $5 \mathrm{~Hz}$ stimulation. PSD-95 ${ }^{-/-}$SGNs were also more variable in FSL indicated in greater jitter.

$\mathrm{H}$ - Adapted to peak rate ration, calculated from PSTHs at $5 \mathrm{~Hz}$ stimulation. The ratio estimates a strength of adaptation which was normal in PSD-95 ${ }^{-1-}$ SGNs.

I - Time course of adaptation, calculated after single exponential fitting to each recorded PSTHs at $5 \mathrm{~Hz}$ stimulation. Mean values showed significantly faster adaptation in PSD-95I- SGNs.

$\mathrm{J}$ - Rate-level functions, recorded in response to $50 \mathrm{~ms}$ tone burst presented $30 \mathrm{~dB}$ above threshold at CF. PSD-95 ${ }^{-1-}$ SGNs demonstrated normal rate-level function compare to PSD$95^{+/+}$SGNs.

$\mathrm{K}$ - Calculated from rate-level function dynamic range was not significantly different in PSD-95 ${ }^{-1-}$ SGNs. 
$\mathrm{L}$ - Calculated from rate-level function steepness necessary to estimate the slope of the function. In PSD-95 ${ }^{-/}$steepness was significantly reduced compared to PSD-95 ${ }^{+/+}$SGNs. M - Calculated SI plotted versus maximal spike rates. Phase-locking ability as an estimation of a temporal precision of a coding was assessed in SI. PSD-95 ${ }^{-/}$SGNs showed normal phase locking in response to transposed amplitude modulated CF tones.

$\mathrm{N}$ - Forward-masking experiment: a $100 \mathrm{~ms}$ masker $\mathrm{CF}$ tone, $30 \mathrm{~dB}$ above threshold was followed by silence intervals of variable duration and $15 \mathrm{~ms}$ probe tone $(\mathrm{CF}, 30 \mathrm{~dB}$ above threshold). PSD-95 ${ }^{--}$SGNs recovered from forward-masking stimulation normally.

\subsubsection{Impaired AP generation in PSD-95 ${ }^{-/-}$SGNs compensated in $\mathrm{CN}$ neurons}

Stellate (or multipolar, or chopper) cells are cells of the ventral cochlear nucleus (Oertel et al., 2011). They have dendrites which run parallel to the path of SGNs. Each stellate cell receives many inputs from only a few SGNs. Depolarizing current trigger, a train of APs in them. In response to tone burst stimulation stellate cells produce "chopper" PSTH with regular firing pattern. Despite impaired spike generation in PSD-95 $5^{-/-}$mice, stellate cells responses to the 50 ms tone burst stimulation at CF $30 \mathrm{~dB}$ above threshold were normal (Fig15A). In PSD$95^{+/+}$vs. PSD-95 ${ }^{-/-}$mice onset and steady-state rates were respectively (mean \pm SEM; $p$-value, Mann-Whitney U-test): $829.7 \pm 69.3$ vs. $678 \pm 95.3$ and $235.9 \pm 18.3$ vs. $223.7 \pm 28.3$ ( $\mathrm{p}=0.14$ and $\mathrm{p}=0.66$ respectively).

Globular bushy cells in anterior ventral cochlear nucleus receive multiple inputs from just a few SGNs, which wrap their terminal branches around the entire soma (Nayagam et al., 2011), the so-called modified endbulbs of Held. Globular bushy cells have primary-like PSTHs with a "notch" (Roos and May, 2012b). These cells preserve the temporal characteristics of the SGN input. As well as in stellate cells described above, in globular bushy cells impaired firing rate of SGNs in PSD-95 ${ }^{-/-}$was also compensated (Fig.15B). In PSD-95 wild types vs. PSD-95-

${ }^{1-}$ mice onset and steady-state rates were respectively (mean \pm SEM; p-value, Mann-Whitney Utest): $1154.67 \pm 45.68$ vs. $1053.2 \pm 69.59$ and $221.53 \pm 8.55$ vs. $217.79 \pm 19.28$ ( $\mathrm{p}=0.12$ and 0.7 respectively). 
A

B
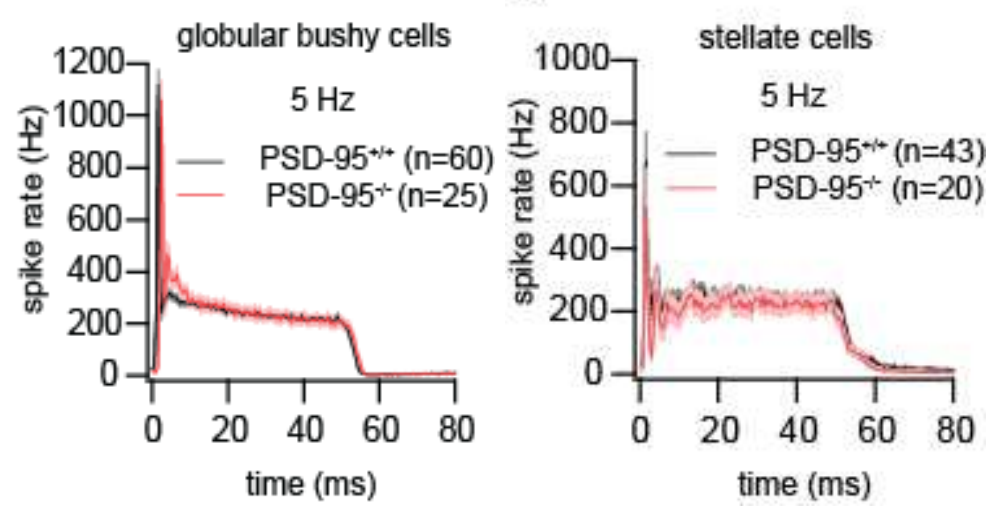

Figure 15. Sound encoding in PSD-95 ${ }^{-/}$and wild type globular and stellate cochlear nucleus cells

A - Globular bushy cells responses to $5 \mathrm{~Hz}$ stimulation of $50 \mathrm{~ms}$ tone burst $30 \mathrm{~dB}$ above threshold at CF (black and red traces - mean value, grey and pink traces - \pm SEM). PSD- $95^{-/-}$ bushy cells have normal spike rates, suggesting central compensation.

B - Stellate cells responses to stimulation, described above (black and red traces - mean value, grey and pink traces - \pm SEM). Both, peak and adapted spike rates were normal.

\subsubsection{Microscopy studies of the IHC ribbon synapses in PSD-95/-mice}

\section{IHC ribbon synapse counting in PSD-95/- SGNs}

Preliminary immunofluorescence analysis of IHC ribbon synapses number was done by Sangyong Jung. Organs of Corti of two mice at P14 were stained for IHC ribbons with CtBP2 and AMPARs of SGNs with GluA2/3 antibodies. 25 cells per genotype were analysed. Preliminary quantification suggests that PSD-95 $5^{-/}$have a normal number of IHC ribbon synapses at P14, which was in average 12.5 synapses per IHC (Fig.16).

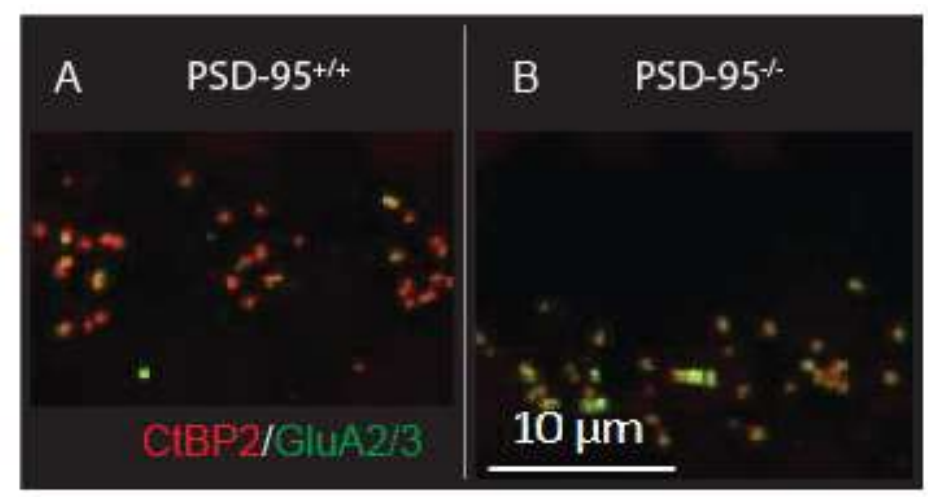

Figure 16. Preliminary immunofluorescence analysis of IHC ribbon synapses number 
A - Confocal imaging of IHC ribbon synapses: CtBP2 anti ribbon (red) and GluA2/3 anti AMPARs (green) in PSD-95 $5^{-/}$at the age P14.

B - The same immunostaining for ribbons and AMPARs at IHC ribbon synapses of PSD$95^{-1-}$, done in parallel. PSD-95 ${ }^{-{ }^{-}}$mice seems to have normal number of IHC ribbon synapses (12,5 per IHC).

\section{PSD-95 and AMPAR clusters arrangement in SGNs}

Immunostaining of PSD-95 in C57B1/6 mice of age P14 showed that it expressed in SGNs (Fig.17B). 2D STED imaging allowed to estimate the shape of PSD-95 cluster and its relation to the AMPAR cluster. It is appeared that PSD-95 (Fig.17 B, inset) organized in similar to AMPAR cluster shape.

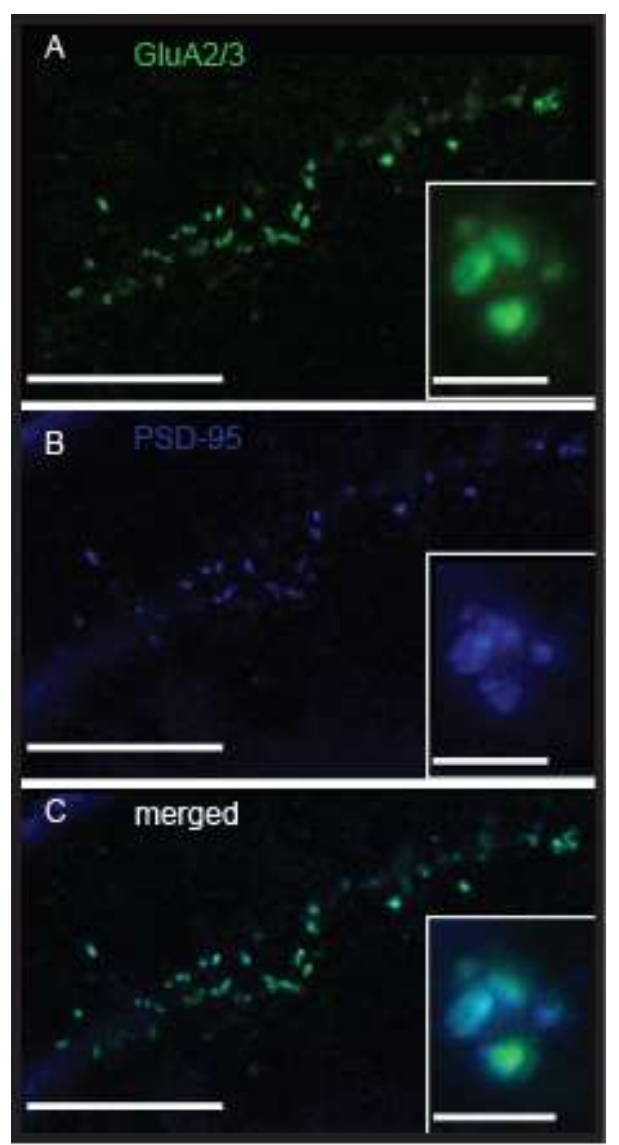

Figure 17. PSD-95 expression in SGNs

A - AMPARs subunits GluA2/3 stained in SGNs of C57Bl/6 mouse of P14 age (bigger panel); XY confocal imaging. AMPARs organized in clusters with ring-like shape (several clusters at the panel); 2D STED imaging, maximal projection of XYZ stack. 
B - PSD-95 expression at SGNs. STED image reveals similar to AMPARs shape of PSD-95 cluster (inset).

C -Merged images of PSD-95 and GluA2/3 subunits of AMPAR clusters colocalized in SGNs.

Scale bars: $10 \mu \mathrm{m}$ in big panels (confocal imaging, $\mathrm{XY}$ scanning) and $300 \mathrm{~nm}$ in insets (STED imaging, z-stack, maximum intensity projection of the entire synapse volume).

To estimate a relation between presynaptic ribbon and postsynaptic AMPARs and PSD-95, triple staining of PSD-95, CtBP2 anti ribbon and GluA2/3 glutamate receptor subunits anti AMPARs was performed for PSD-95-/-mice and their littermates of age 6 weeks (Fig.18A-A',', B-B','). Postsynaptic AMPARs and PSD-95 are superimposed to the presynaptic ribbon and organized in the ring-like shape clusters. PSD-95 is arranged within the AMPAR cluster. No expression of PSD-95 was observed in PSD-95-/- SGNs.

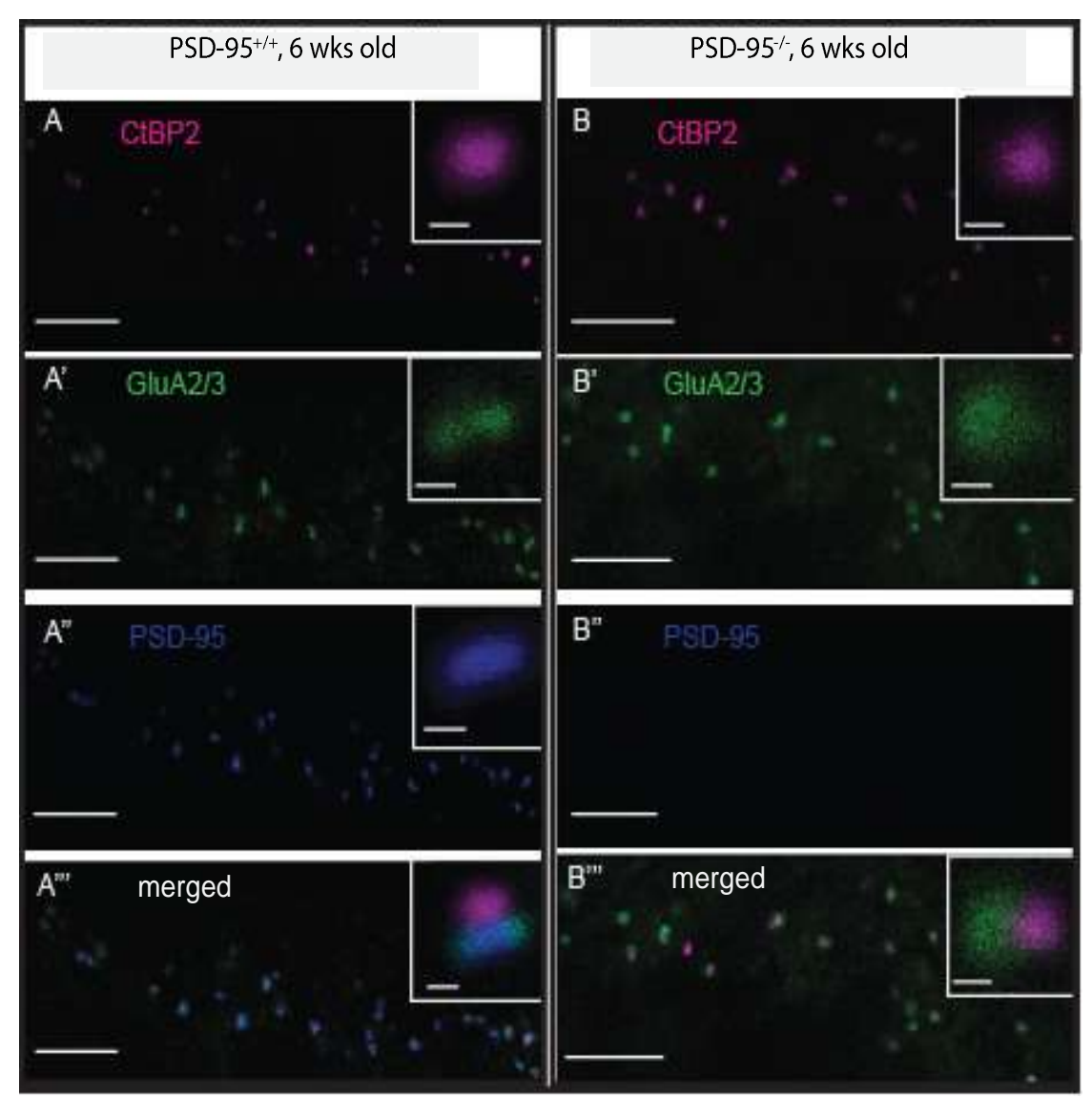

Figure 18. Triple staining for CtBP2 (ribbon), GluA2/3 (AMPAR subunits) and PSD-95 in PSD-95 $5^{+/+}$and PSD-95 ${ }^{-/}$SGNs. Preliminary data from 2 mice aged between 6 weeks 
A, B - Confocal imaging of CtBP2 stained in PSD-95 ${ }^{-/}$and littermate control SGNs (bigger panel) and 2D STED (insets).

A', B' - Confocal imaging of GluA2/3 subunits of AMPARs expressed in PSD-95 ${ }^{+/+}$(A') and PSD-95 ${ }^{--}\left(\mathrm{B}^{\prime}\right)$ SGNs (in bigger panels). 2D STED imaging of AMPARs indicated its possible reduction in PSD-95 ${ }^{--}$SGNs (in insets).

A", B" - Confocal imaging of PSD-95, expressed in PSD-95 ${ }^{+/+}$and absent in PSD-95 $5^{-1-}$ SGNs (in bigger panel).

A',", B", - Merged confocal imaging of CtBP2, GluA2/3 and PSD-95 in PSD-95 ${ }^{+/+}$and PSD-95 ${ }^{-1-}$ SGNs.PSD-95 and AMPAR clusters are super-imposed to the ribbon (bigger panel). 2D STED imaging of z-stack showed that PSD-95 is arranged within the AMPAR cluster (A",, in inset).

Scale bars: $10 \mu \mathrm{m}$ in big panels (confocal imaging, XY scanning) and $300 \mathrm{~nm}$ in insets (STED imaging, z-stack, maximum intensity projection of the entire synapse volume).

\section{Reduction of AMPAR subclusters number in PSD-95\%/- SGNs}

Analysis of relation of presynaptic CtBP2 (stained for ribbon) and postsynaptic GluA2/3 (stained for AMPARs) and PSD-95 in the previous chapter suggested a possible reduction of the AMPAR cluster in PSD-95 ${ }^{-/-}$SGNs. In addition, PSD-95 ${ }^{-/}$mice demonstrated reduced, delayed and less reliable spikes generation in SGNs, considered in the previous chapters. These findings raised a question, how AMPARs arranged in PSD-95-/- SGNs.

STED microscopy was done in order to reveal the AMPAR cluster organisation in PSD$95^{+/+}$and PSD-95 ${ }^{-/-}$IHC ribbon synapses. Such high resolution of STED imaging (Chapter 2.5) allowed to asses a nanocluster organization of AMPAR cluster and calculate a number of its subclusters and distance of each subcluster to the corresponding synaptic ribbon (Fig.20A).

For STED image analysis, the centres of mass of the synaptic ribbons and glutamate receptor subclusters was determined using algorithms implemented in Imaris/Matlab software. Experiments done for 2 age groups of PSD-95 ${ }^{-/}$and their littermates: P14 (1 mouse per genotype) and 6-8 weeks old (3 mice per genotype). There was no difference between these two age groups in number of AMPAR subclusters (Table1). Thus, further analysis was done for the pooled data. PSD-95 ${ }^{-/-}$SGNs showed significant reduction of the number of AMPAR subclusters in PSD-95 ${ }^{+/+}$vs PSD-95 ${ }^{-/-}$SGNs (Fig.20B), mean \pm SEM respectively: 7,3 $\pm 0,2$ vs 5,2 $\pm 0,5, \mathrm{p}<0.01$, Mann-Whitney U-test). 
Analysis of a distances from each detected AMPAR subcluster in synapse to the centre of the mass of corresponding synaptic ribbon was done for P14 PSD-95 ${ }^{-/-}$and their littermates (1 mouse per genotype). There was no difference in the distances of AMPAR subclusters from the centre of a mass of a ribbon in PSD-95 $5^{-/-}$and PSD-95 ${ }^{+/+}$SGNs (Fig.20C in PSD-95 ${ }^{+/+}$vs PSD-95 ${ }^{-/}$SGNs mean \pm SEM (nm) distances from each detected AMPAR subcluster to the corresponding synaptic ribbon respectively: $420 \pm 10$ vs. $441 \pm 20, p=0.92$, Mann-Whitney Utest).

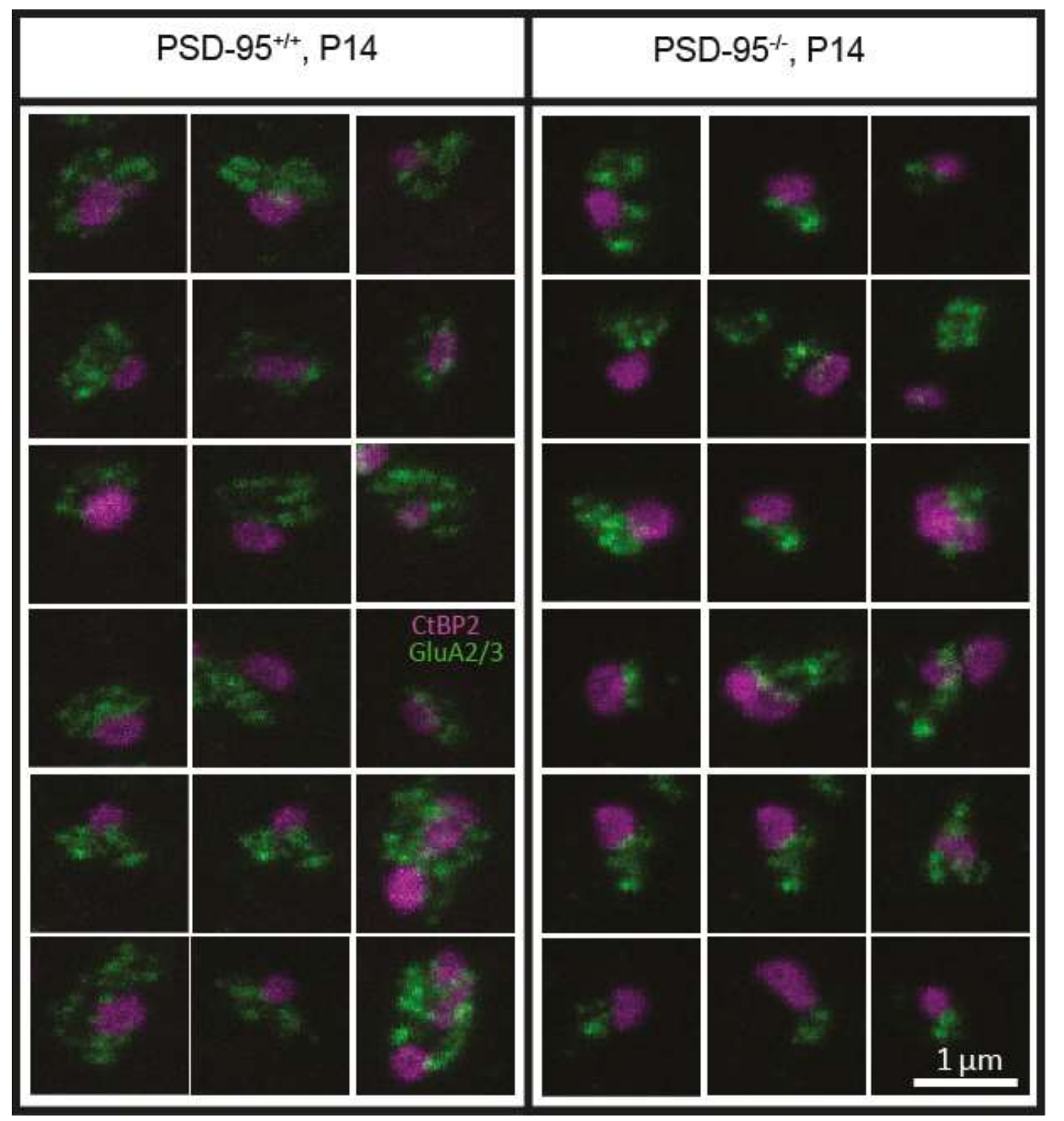

Figure 19. STED microscopy of AMPA receptors in PSD-95 ${ }^{-/}$and wild type SGNs. Data obtained

from P14 PSD-95 ${ }^{--}$mice and wild type littermate organs of Corti stained for CtBP2 (synaptic ribbons) and GluA2/3 (AMPA receptors). Each image is a maximum intensity projection of optical sections containing the entire synapse volume 


\begin{tabular}{|c|c|c|c|}
\hline \multicolumn{3}{|c|}{ Table 1 Quantification of AMPAR sub-clusters for the different age groups } \\
\hline $\begin{array}{c}\text { Number of AMPAR } \\
\text { sub-clusters in PSD- } \\
95^{-/-} \text {(mean } \pm \text { SEM) }\end{array}$ & $4,8 \pm 0,5$ & $6-8$ weeks old & Pooled data \\
\hline $\begin{array}{c}\text { Number of AMPAR } \\
\text { sub-clusters in PSD- } \\
95^{+/+} \\
(\text {mean } \pm \text { SEM) }\end{array}$ & $7,8 \pm 0,4$ & $7,2 \pm 0,2$ & $5,2 \pm 0,5$ \\
\hline $\begin{array}{c}\text { PSD-95 } \\
\text { analysed synapses }\end{array}$ & 24 & 89 & $7,3 \pm 0,2$ \\
\hline $\begin{array}{c}\text { PSD-95 } \\
\text { analysed synapses }\end{array}$ & & & 113 \\
\hline
\end{tabular}
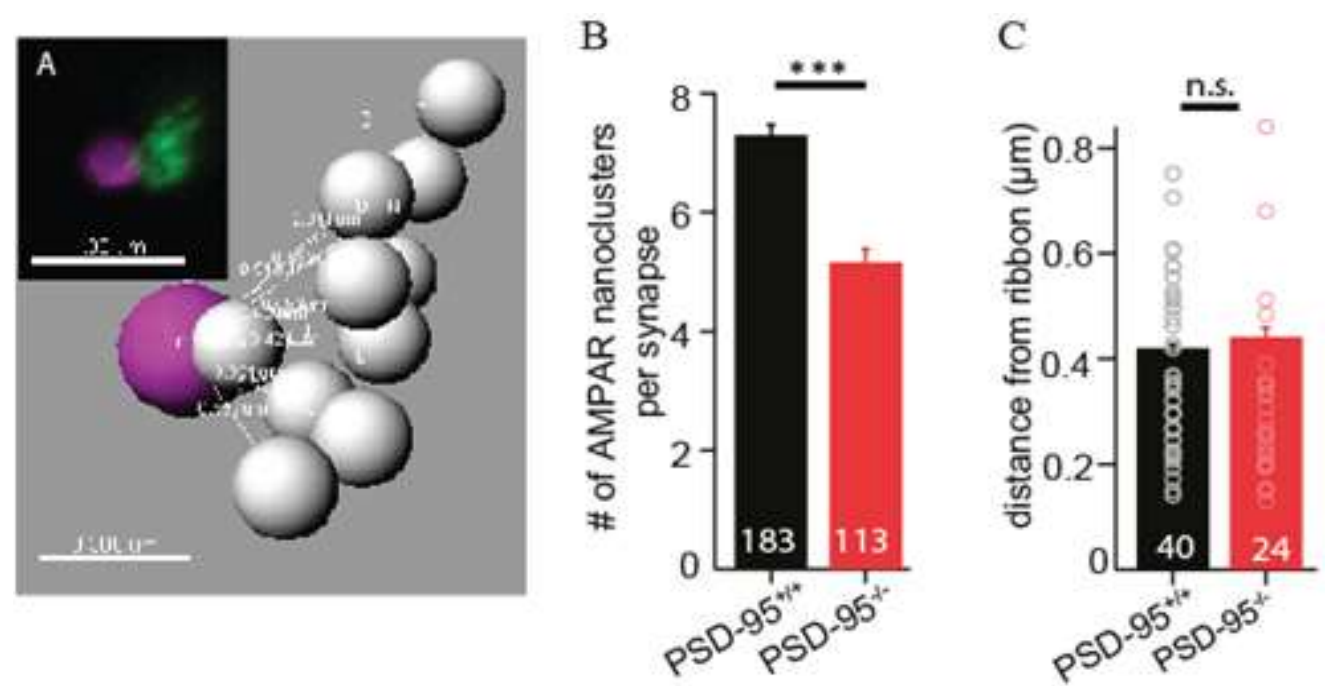

Figure 20. Analysis of AMPAR subclusters in PSD-95 ${ }^{-/}$and PSD-95 $5^{+/+}$SGNs

A - Imaris analysis of STED images of wild type IHC ribbon synapse.

B - Reduced number of AMPAR sub-clusters per IHC ribbon synapse in PSD-95 $5^{-1}$ synapses.

$\mathrm{C}$ - Distance between glutamate receptor subcluster and the ribbon is comparable between PSD-95 ${ }^{-/}$and PSD-95 ${ }^{+/+}$synapses. Averages of distances determined in individual synapses are shown as grey dots for PSD-95 $5^{+/+}$and pink - for the PSD-95 $5^{-/-}$SGNs. 


\section{PSD-93 and SAP-102 MAGUKs expression in SGNs}

Synaptic transmission in PSD-95 ${ }^{-/}$SGNs have very subtle impairment. Targeting of AMPA receptors might be regard to compensation with the other MAGUK proteins. Compensatory function of PSD-93 and SAP-102 MAGUKs was proposed in primary hippocampal cultures (Elias et al., 2006a) acutely knockdowned for PSD-95: in immature synapses (P10) PSD-95 deletion was compensated with SAP-102, and in mature synapses (>P11) - with PSD-93.

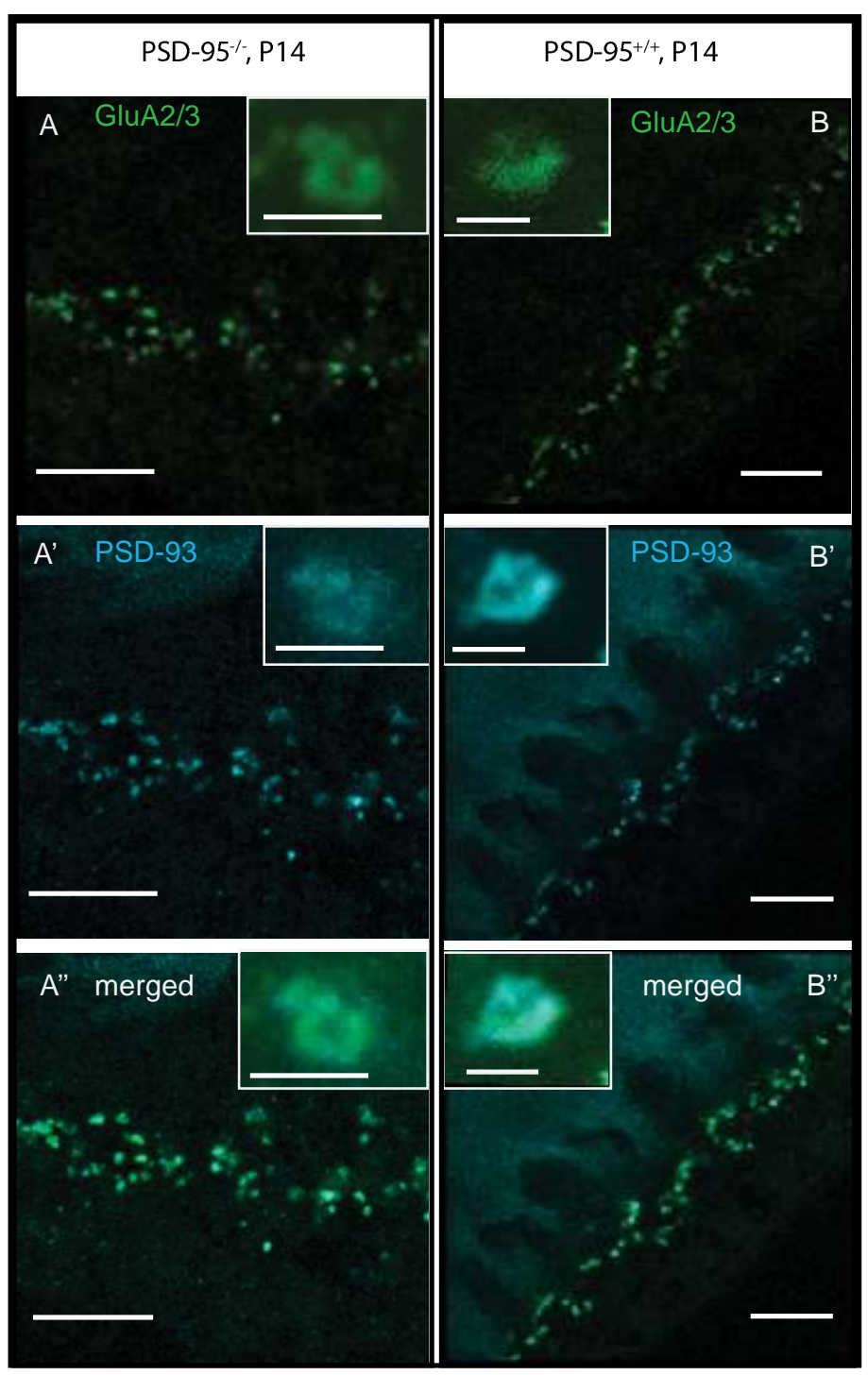

Figure 21. PSD-93 expression in PSD-95 ${ }^{-/-}$and PSD-95 ${ }^{+/+}$SGNs

A, B - GluA2/3 AMPAR subunits expressed in PSD-95 $5^{-/-}$and wild type SGNs. STED images demonstrate the ring-like shape of AMPAR cluster. 
A', B' - PSD-93 is expressed in PSD-95 ${ }^{-/-}$and PSD-95 ${ }^{+/+}$SGNs and forms clusters with a ring-like shape that overlaps with the GluA2/3 cluster.

A', B' - Merge image of GluA2/3 subunits of AMPAR cluster, colocalized with PSD-93 cluster.

Scale bars: $10 \mu \mathrm{m}$ in big panels (confocal imaging, $\mathrm{XY}$ scanning) and $300 \mathrm{~nm}$ in insets (STED imaging, z-stack, maximum intensity projection of the entire synapse volume).

Possible compensation of the PSD-95 in PSD-95 ${ }^{-/-}$SGNs was studied preforming immunostaining of PSD-93 and SAP-102 vs CtBP2 in SGNs. Both PSD-93 and SAP-102 MAGUKs were expressed in P14 SGNs. PSD-93 was organized in ring-like shape clusters and superimposed to AMPAR cluster in PSD-95 ${ }^{+/+}$and PSD-95 ${ }^{-/-}$SGNs. SAP-102 in PSD-95 ${ }^{+/+}$ SGNs was arranged in ring-like shape cluster and superimposed to AMPAR (Fig.22). Further analysis of the expression pattern and arrangement of clusters in the synapse of PSD-95 ${ }^{-/-}$SGNs might help to understand compensatory impact of PSD-93 and SAP-102 on AMPAR clustering.

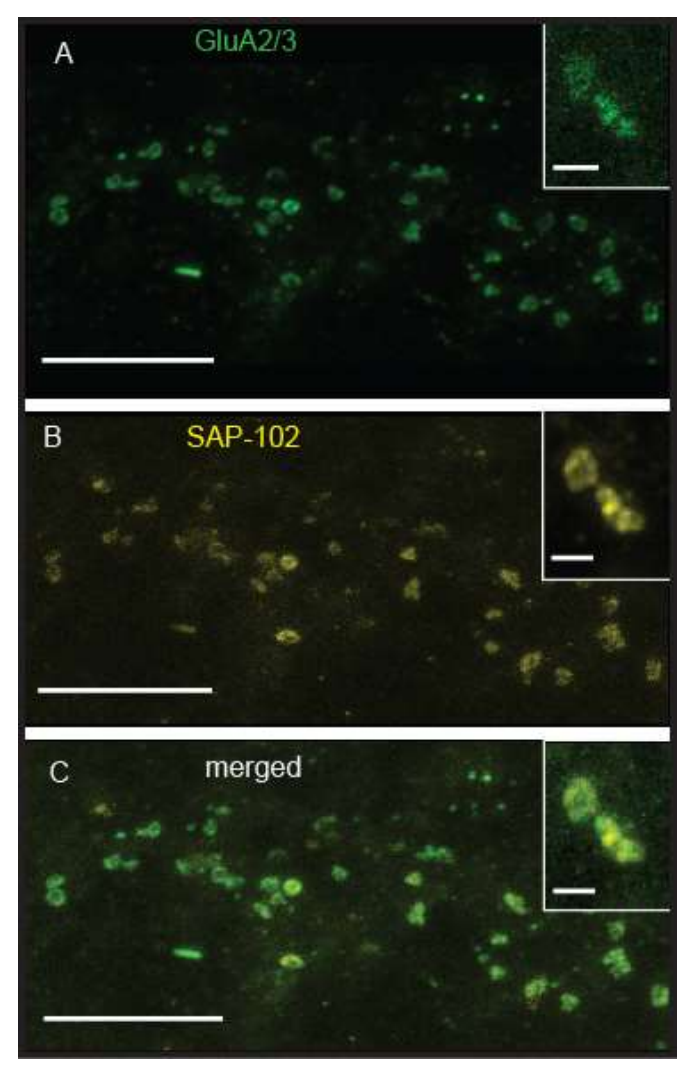

Figure 22. STED imaging of SAP-102 expression at SGNs of C57B1/6 mouse at P14 
A - GluA2/3 subunits of AMPARs.

B - SAP-102 is expressed in SGNs of P14 wild type mouse and organized in ring-like clusters.

C - SAP-102 is colocalized with AMPAR cluster.

Scale bars: $7 \mu \mathrm{m}$ in big panels (STED imaging, XY scanning) and $300 \mathrm{~nm}$ in insets (STED imaging, z-stack, maximum intensity projection of the entire synapse volume).

\subsection{Auditory phenotype of $\mathrm{Qv}^{3 \mathrm{~J}}$ mutant mice}

\subsubsection{ABRs in $\mathrm{Qv}^{3 \mathrm{~J}}$ mutant mice}

ABRs were recorded by Nadine Hermann in $8 \mathrm{Qv}^{3 \mathrm{~J}}$ mutants and in 9 wild type littermates with an average age of $61.6 \pm 12.8$ and 92.6 \pm 16.2 days respectively. Figure 23A demonstrates delayed and broadened ABR waves in response to click stimulation ( $80 \mathrm{~dB}$ SPL, stimulus frequency $20 \mathrm{~Hz}$ ). Although amplitude of ABR wave I was not reduced, its latency was increased, as well as latencies of the following waves (Fig.23B, C). ABR thresholds upon different frequencies were moderately elevated. These findings suggested that $\mathrm{Qv}^{3 \mathrm{~J}}$ mutant mice might have impaired synaptic sound encoding in SGNs as well as in cochlear nucleus neurons.

A
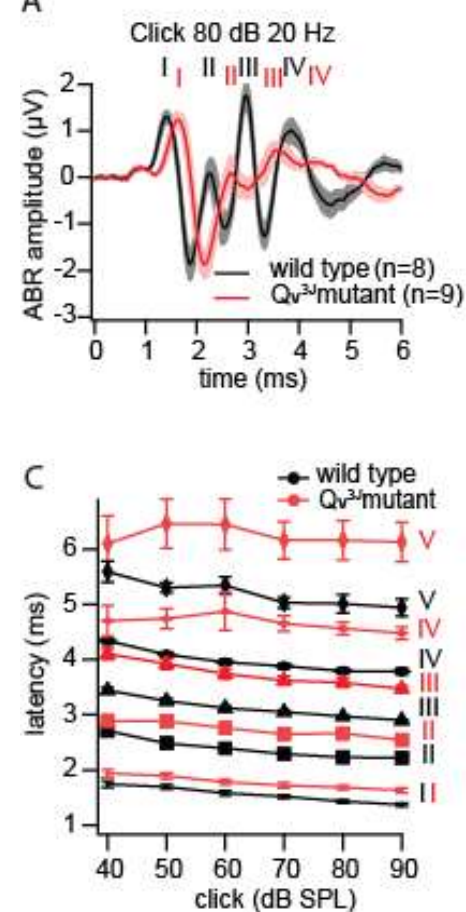

B

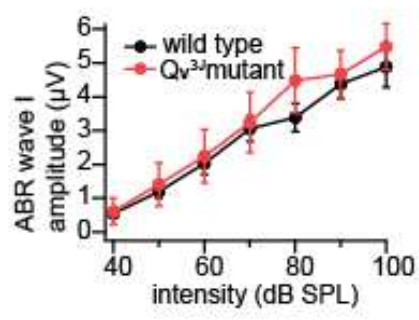

D

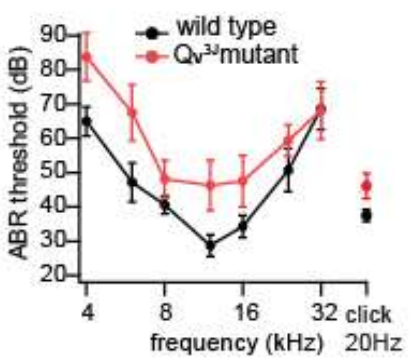

Figure 23. ABRs in $\mathrm{Qv}^{3 \mathrm{~J}}$ mutant and wild type mice 
$\mathrm{A}$ - Broadened and delayed ABR waves in $\mathrm{Qv}^{3 \mathrm{~J}}$ mutant mice.

B - ABR wave I amplitude in mutant mice, compared with wild type.

$\mathrm{C}$ - Delayed ABR waves of $\mathrm{Qv}^{3 \mathrm{~J}}$ mutant mice (red traces $-\mathrm{Qv}^{3 \mathrm{~J}}$ mutants, black traces $-\mathrm{Qv}^{3 \mathrm{~J}}$ wild types).

$\mathrm{D}$ - Elevated ABR thresholds of $\mathrm{Qv}^{3 \mathrm{~J}}$ mice at 4, 8 and $16 \mathrm{kHz}$, and not significant increase at 24 and $32 \mathrm{kHz}$ of tone burst stimulation.

\subsubsection{Sound encoding in $\mathrm{Qv}^{3 \mathrm{~J}}$ mutant mice}

Extracellular single unit in vivo recordings from SGNs and cochlear nucleus neurons were performed to study primary mechanism, underlying defined ABRs impairments. $\mathrm{Qv}^{3 \mathrm{~J}}$ wild types were $11 \pm 0.5$ weeks old and $\mathrm{Qv}^{3 \mathrm{~J}}$ mutant mice were $10 \pm 0.6$ weeks old.

SRs were recorded in silence. $\mathrm{Qv}^{3 \mathrm{~J}}$ mutant SGNs showed lower SRs (Fig24A). Figure 24B and C show that SGNs of $\mathrm{Qv}^{3 \mathrm{~J}}$ mutant mice have well preserved acoustic thresholds.

Sound evoked responses of SGNs were recorded under $50 \mathrm{~ms}$ tone burst stimulation at CF $30 \mathrm{~dB}$ above threshold. $\mathrm{Qv} \mathrm{v}^{3 \mathrm{~J}}$ mutant mice have reduced onset and steady-state spike rates at various stimulation frequencies (Fig. 24D, D, D' and E, E', E'). Peak and steady-state rates in wild type vs $\mathrm{Qv}^{3 \mathrm{~J}}$ mutant $\mathrm{SGNs}$ were respectively (mean $\pm \mathrm{SEM}$, p-value, t-test): $965.88 \pm 71.10$ vs $604.17 \pm 93.87$ and $279.61 \pm 16.94$ vs $204.41 \pm 20.40$ at $2 \mathrm{~Hz}$ stimulation ( $<0.01$ and $\mathrm{p}=0.01$ respectively); $871.17 \pm 71.35$ vs $665.36 \pm 58.45$ and $272.84 \pm 14.00$ vs $198.18 \pm 11.38$ at $5 \mathrm{~Hz}$ stimulation ( $\mathrm{p}=0.03$ vs $\mathrm{p}<0.01$ respectively); $660 \pm 59.42$ vs $439.17 \pm 61.62$ and $206.24 \pm 14.13$ vs $149.84 \pm 15.66$ at $10 \mathrm{~Hz}$ stimulation ( $\mathrm{p}=0.02$ and $\mathrm{p}=0.01$ respectively).

Increased ABR wave I latency indicated a possible impairment in temporal precision of spike generation. To estimate accuracy of coding, FSL of recorded PSTHs were analysed. $\mathrm{Qv}^{3 \mathrm{~J}}$ mutant mice exhibited no significant delay in onset responses and had no greater jitter (Fig.24F). Median FSL (ms) and variance of FSL $\left(\mathrm{ms}^{2}\right)$ in wild type vs $\mathrm{Qv}^{3 \mathrm{~J}}$ mutant SGNs were respectively (mean \pm SEM): $4.31 \pm 0.26$ vs $4.66 \pm 0.26$ ( $\mathrm{p}=0.37$, t-test $)$ and $1.93 \pm 0.49$ vs $2.20 \pm 0.33$ ( $\mathrm{p}=0.08$, Mann-Whitney U-test).

Synaptic recovery from depression was estimated as a recovery from forward masker stimulation in a forward masking paradigm. A $100 \mathrm{~ms}$ CF masker tone burst was presented, followed by another $15 \mathrm{~ms}$ probe tone by different silent intervals (4, 16. 64 and $256 \mathrm{~ms}$ ). The ratio between onset responses to the masker and tone was then calculated at various silent intervals. This calculated ratio as a function of recovery from synaptic depression was normal in $\mathrm{Qv}^{3 \mathrm{~J}}$ mutant SGNs (Fig.24G). 
The temporal precision of spike generation was evaluated as the ability for phase locking to transposed amplitude modulated $\mathrm{CF}$ tones. $\mathrm{Qv}^{3 \mathrm{~J}}$ mutant mice were comparable in their ability to phase lock, calculated as SI (Fig.24H).

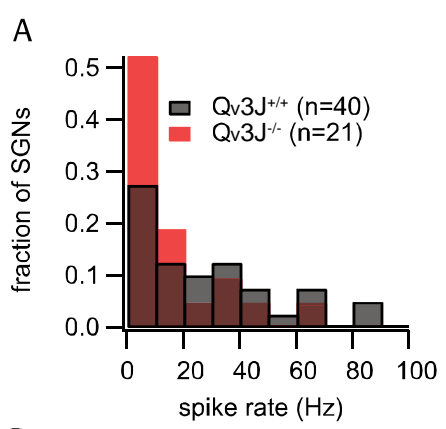

$\mathrm{D}$

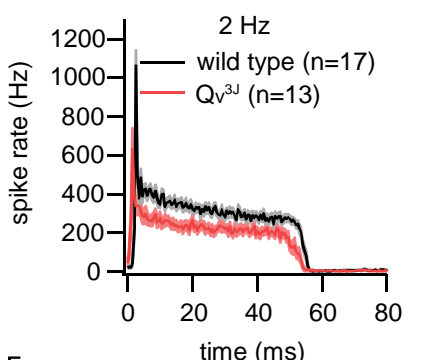

E

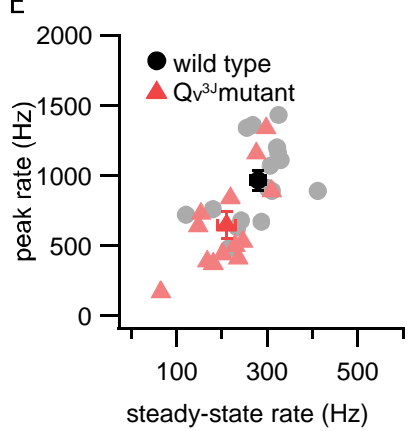

F

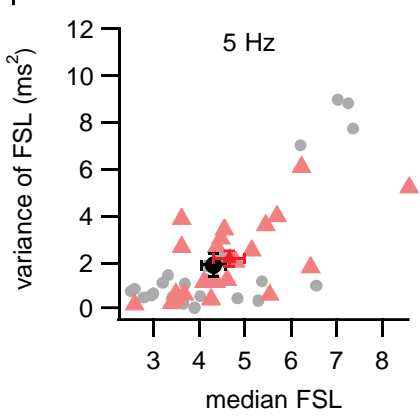

B

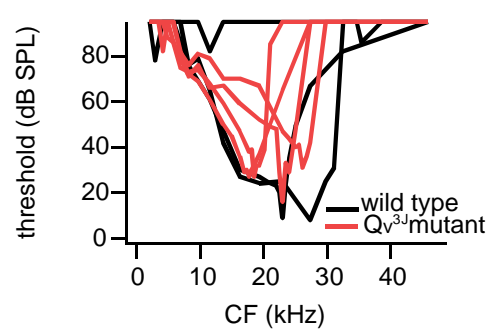

$\mathrm{D}^{\prime}$
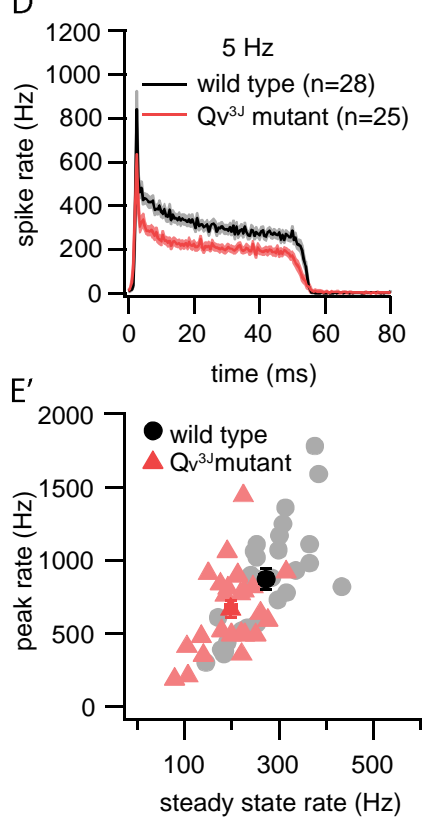

G

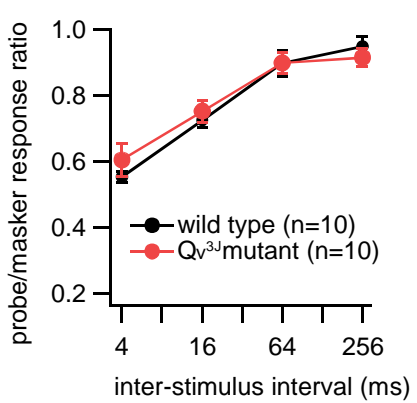

C

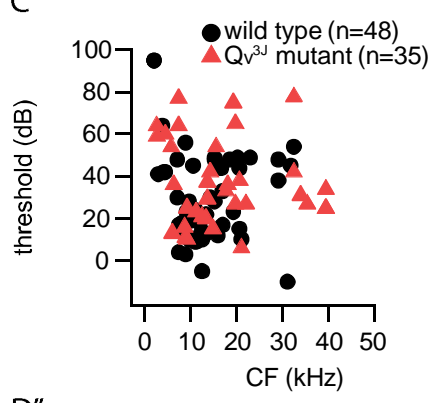

$\mathrm{D}^{\prime \prime}$

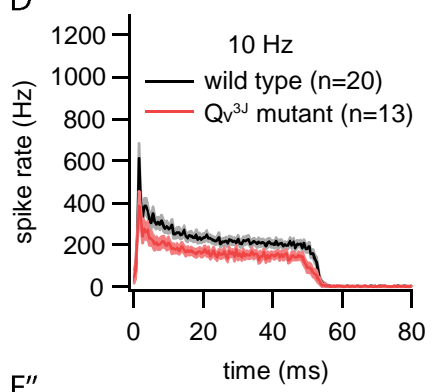

$\mathrm{E}^{\prime \prime}$

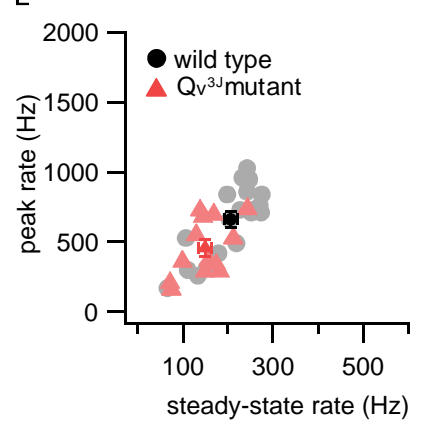

$\mathrm{H}$

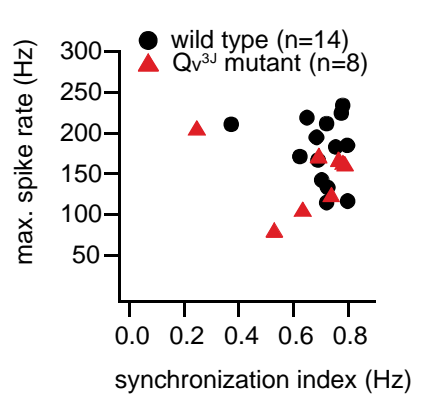

Figure 24. Sound encoding in $\mathrm{Qv}^{3 \mathrm{~J}}$ mutant and wild type SGNs

$\mathrm{A}$ - Lower SRs in $\mathrm{Qv}^{3 \mathrm{~J}}$ mutant mice.

$\mathrm{B}, \mathrm{C}$ - Tuning curves and defined thresholds at $\mathrm{CFs}$ well preserved in $\mathrm{Qv}^{3 \mathrm{~J}}$ mutant mice.

D, D', D' - Mean PSTH \pm SEM of wild types and $\mathrm{Qv}^{3 \mathrm{~J}}$ mutants in response to $50 \mathrm{~ms}$ tone bursts presented at CF, $30 \mathrm{~dB}$ above threshold at stimulus rates of $2 \mathrm{~Hz}$ (D), $5 \mathrm{~Hz}$ (D') or 10 
$\mathrm{Hz}$ (D'). While the general response pattern was well preserved, $\mathrm{Qv} \mathrm{v}^{3 \mathrm{~J}}$ mutants had reduced spike rates, especially at higher stimulus rates.

E, E', E' - Spike rates in response to sound onset. Peak rate in PSTH with $0.5 \mathrm{~ms}$ binwidth) and steady-state rates (averaged between 35 and $45 \mathrm{~ms}$ after stimulus onset) were lower in $\mathrm{Qv}^{3 \mathrm{~J}}$ mutant SGNs.

F - In consistence with the reduction in spike rates, FSL following stimulus onset was increased compared to wild type littermates, especially at higher stimulus rates. $\mathrm{Qv}^{3 \mathrm{~J}}$ mutant SGNs greater jitter ( $\mathrm{p}=0.03$, Mann-Whitney U-test).

$\mathrm{G}$ - Forward masking experiment: a $100 \mathrm{~ms}$ masker $\mathrm{CF}$ tone, $30 \mathrm{~dB}$ above threshold was followed by an inter-stimulus interval of variable duration and $15 \mathrm{~ms}$ probe tone $(\mathrm{CF}, 30 \mathrm{~dB}$ above threshold). $\mathrm{Qv}^{3 \mathrm{~J}}$ mutant SGNs recover normally from forward masking stimulation. $\mathrm{H}$ - Amplitude modulated by a half wave rectified modulator sinusoid $(500 \mathrm{~Hz})$ transposed tones with CF carrier frequency were presented. The time - varying amplitude of the carrier wave was increased in $5 \mathrm{~dB}$ steps every $2 \mathrm{~s}$. Qv ${ }^{3 \mathrm{~J}}$ mutant mice were comparable to wild type in their ability to phase lock, calculated as SI.

\subsubsection{Partial compensation in $\mathrm{Qv}^{3 \mathrm{~J}}$ mutant globular bushy cells}

Delayed ABR wave II in $\mathrm{Qv}^{3 \mathrm{~J}}$ mutant mice suggested a possible impairment in sound encoding of $\mathrm{CN}$ neurons. Therefore, globular bushy cells (neurons of AVCN) were recorded in silence and under $50 \mathrm{~ms}$ tone burst stimulation $(30 \mathrm{~dB}$ above threshold, $\mathrm{CF}, 5 \mathrm{~Hz}$ of stimulus rate). Qv ${ }^{3 \mathrm{~J}}$ mutant globular bushy cells had lower SRs (Fig.25A). The thresholds at CFs were normal (Fig.25B). Recorded under tone burst stimulation, PSTHs exhibited normal peak rates at the stimulus onset, and reduced adapted rates indicating partial compensation for the impaired synaptic input from $\mathrm{Qv}^{3 \mathrm{~J}}$ mutant SGNs (Fig.25C, D): wild types vs $\mathrm{Qv}^{3 \mathrm{~J}}$ mutant globular bushy cells onset and steady-state rates were respectively (mean \pm SEM, p-value, $\mathrm{t}$ test): $1241.36 \pm 58.84$ vs $1122.59 \pm 37.78$ and $247.20 \pm 9.71$ vs $201.26 \pm 7.49$ ( $\mathrm{p}=0.08$ and $\mathrm{p}=2.15^{*} 10^{-4}$ respectively). There was no delay or greater jitter of the FSLs in wild type vs $\mathrm{Qv}^{3 \mathrm{~J}}$ mutant median FSL and variance FSL at $5 \mathrm{~Hz}$ stimulation respectively (mean \pm SEM, p-value, Mann-Whitney $U$ - test): $4.03 \pm 0.19$ vs $3.85 \pm 0.11$ and $2.99 \pm 1.63$ vs $2.52 \pm 0.96$ (p=0.39 and $\mathrm{p}=0.8$ respectively). 
A

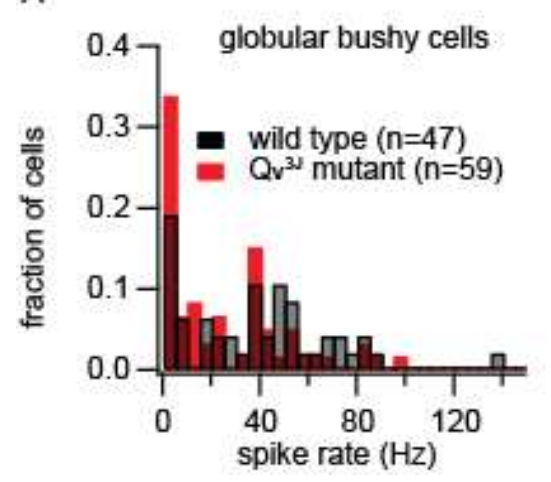

C

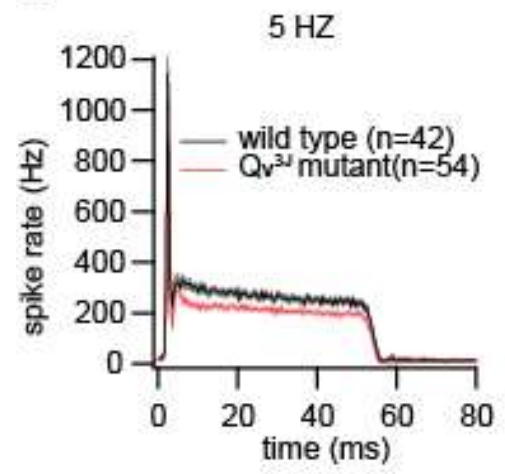

B

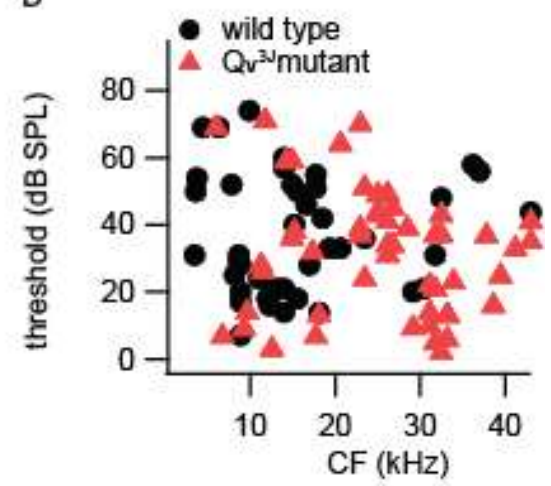

D

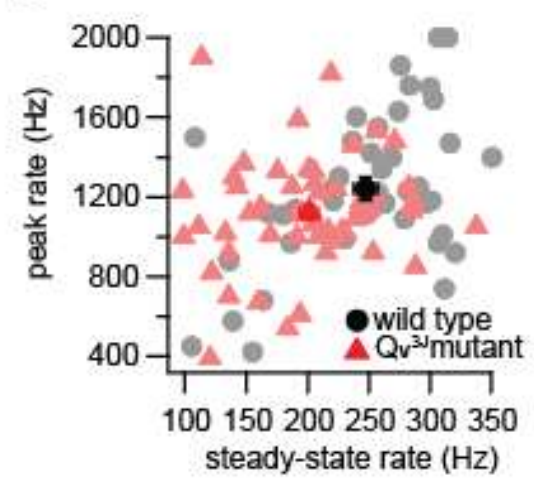

Figure 25. Sound encoding in $\mathrm{Qv}^{3 \mathrm{~J}}$ mutant and wild type globular bushy cells A - Globular bushy cells of $\mathrm{Qv}^{3 \mathrm{~J}}$ mutant mice had lower spontaneous rates.

$\mathrm{B}$ - Normal thresholds at the $\mathrm{CF}$ in $\mathrm{Qv}^{3 \mathrm{~J}}$ mutant globular bushy cells.

$\mathrm{C}-$ Mean PSTHs \pm SEM of wild types and $\mathrm{Qv}^{3 \mathrm{~J}}$ mutant globular bushy cells in response to $50 \mathrm{~ms}$ tone bursts presented at $\mathrm{CF}, 30 \mathrm{~dB}$ above threshold at stimulus rate $5 \mathrm{~Hz}$. While peak rate of $\mathrm{Qv}^{3 \mathrm{~J}}$ mutant globular bushy cells was normal, steady-state rate only partially compensated.

D - Spike rates in response to sound onset. Peak rate (maximum rate in PSTH with $0.5 \mathrm{~ms}$ binwidth) and steady-state rates (averaged between 35 and $45 \mathrm{~ms}$ after stimulus onset).

\subsubsection{Full compensation in $Q v^{3 J}$ mutant stellate cells}

In $\mathrm{Qv}^{3 \mathrm{~J}}$ mutant stellate cells, SRs recorded in silence were similar to wild type (Fig.26A). They showed normal thresholds (Fig.26B) and normal peak and steady-state rates, defined after recording PSTHs at $50 \mathrm{~ms}$ tone burst stimulation, $30 \mathrm{~dB}$ above threshold at CF (Fig.26C,D): wild types vs $\mathrm{Qv}^{3 \mathrm{~J}}$ mutant onset and steady-state rates were respectively (mean \pm SEM): $801.78 \pm 71.45$ vs $803.85 \pm 62.67$ and $226.75 \pm 14.55$ vs $213.74 \pm 13.90$ ( $\mathrm{p}=0.98$ and $\mathrm{p}=0.52$ respectively, t-test).There was also no delay or impaired precision of the spike 
generation at the stimulus onset (wild type vs $\mathrm{Qv}^{3 \mathrm{~J}}$ median FSL and variance FSL at $5 \mathrm{~Hz}$ stimulation, respectively (mean \pm SEM): $7.29 \pm 0.51$ vs $7.54 \pm 0.71$ and $2.85 \pm 0.50$ vs $2.31 \pm 0.57$ ( $\mathrm{p}=0.78$ and $\mathrm{p}=0.48$ respectively, Mann-Whitney U-test ). Thus, $\mathrm{Qv} \mathrm{v}^{3 \mathrm{~J}}$ mutant stellate neurons fully compensate for the impaired synaptic transmission in $\mathrm{Qv}^{3 \mathrm{~J}}$ mutant $\mathrm{SGNs}$.

A

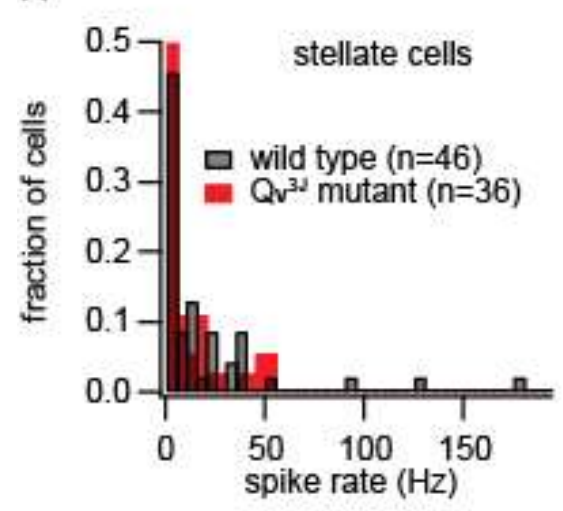

C

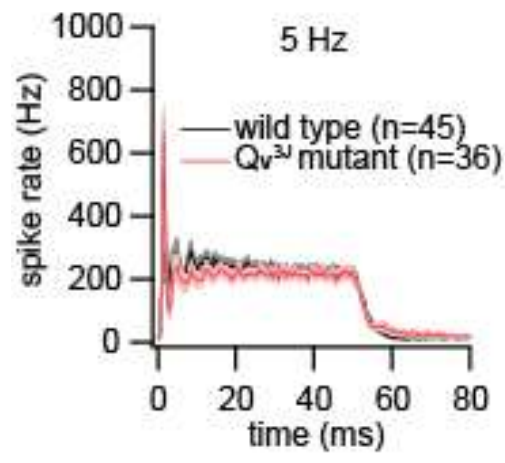

B

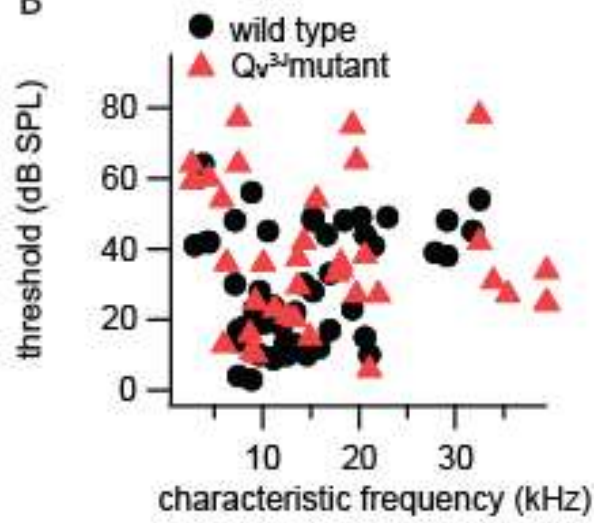

D

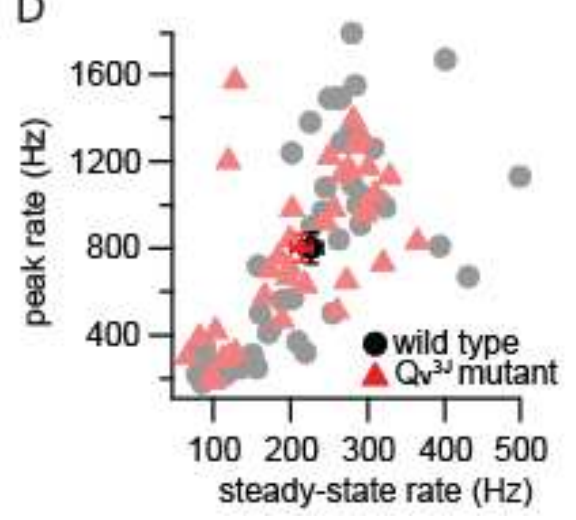

Figure 26. Sound encoding in $\mathrm{Qv}^{3 \mathrm{~J}}$ mutant and wild type stellate cells

$\mathrm{A}$ - Stellate cells of $\mathrm{Qv}^{3 \mathrm{~J}}$ mutant mice had normal SRs, recorded in silence.

$\mathrm{B}$ - Normal thresholds at the $\mathrm{CF}$ in $\mathrm{Qv}^{3 \mathrm{~J}}$ mutant stellate cells.

$\mathrm{C}-$ Mean PSTH \pm SEM of wild type and $\mathrm{Qv}^{3 \mathrm{~J}}$ stellate cells in response to $50 \mathrm{~ms}$ tone bursts presented at $\mathrm{CF}, 30 \mathrm{~dB}$ above threshold at stimulus rate $5 \mathrm{~Hz}$. Both, peak and steady-state rates were normal, indicating full compensation of impaired synaptic input from SGN of $\mathrm{Qv}^{3 \mathrm{~J}}$ mutant mice.

D - Spike rates in response to sound onset. Mean values are black for wild type and red for $\mathrm{Qv}^{3 \mathrm{~J}}$ mutant. 


\subsection{Sound perception in Otof ${ }^{515 T / 1515 T}$ mice}

Otof ${ }^{515 T / 1515 T}$ mice were studied to reveal the role of multi-C2 domain protein otoferlin in IHC synaptic function, in sound encoding of SGNs and temperature-sensitive deafness in humans carrying the Ile515Zhr mutation in otoferlin (Strenzke et al., 2016). They studied sound perception in Otof ${ }^{515 T / 1515 T}$ mice.

Two key aspects of perception - discrimination and generalization - were studied in threshold discrimination and gap detection ability, respectively.

In the first experiment for the gap detection ability, we conditioned mice to attempt to drink water only in continuous broadband noise. If noise was interrupted by conditioning 90 ms silence gaps, access to water was forbidden (doors in the corner were closed), and trials to drink were punished by 1 Bar air puff (de Hoz and Nelken, 2014b). When discrimination performance was more than $30 \%$, shorter gaps were introduced in a total of $8 \%$ of the attempts. Otof ${ }^{1515 T / 1515 T}$ attempted to drink at the trials with short gaps, whereas Otof ${ }^{\text {wt/wt }}$ mice avoided drinking when gaps were longer than $3 \mathrm{~ms}$ (Fig.27A). This is consistent with the previously studied gap thresholds, which were near $2 \mathrm{~ms}$ in CBA/J mice (Radziwon et al., 2009). The interpolated $50 \%$ value of the normalized discrimination function was used to estimate approximate gap thresholds, which were in wild type and Otof ${ }^{515 T / 1515 T}$ mice respectively: $2.7 \pm 0.4 \mathrm{~ms}$ and $17.2 \pm 4.9 \mathrm{~ms}$.

In the second experiment mice were conditioned to drink in silence and to avoid drinking when $12 \mathrm{kHz}$ tone bursts were presented. Otof ${ }^{\text {I515T/I515T }}$ showed comparable hearing thresholds in two Otof ${ }^{515 T / 1515 T}$ mice and one Otof ${ }^{\text {vt/wt }}$ mouse.

The impaired gap detection ability and normal sound pressure sensitivity in Otof ${ }^{1515 T / 515 T}$ mice are consistent with the result of in vivo recordings from SGNs demonstrated impaired recovery from adaptation but normal sound sensitivity. 

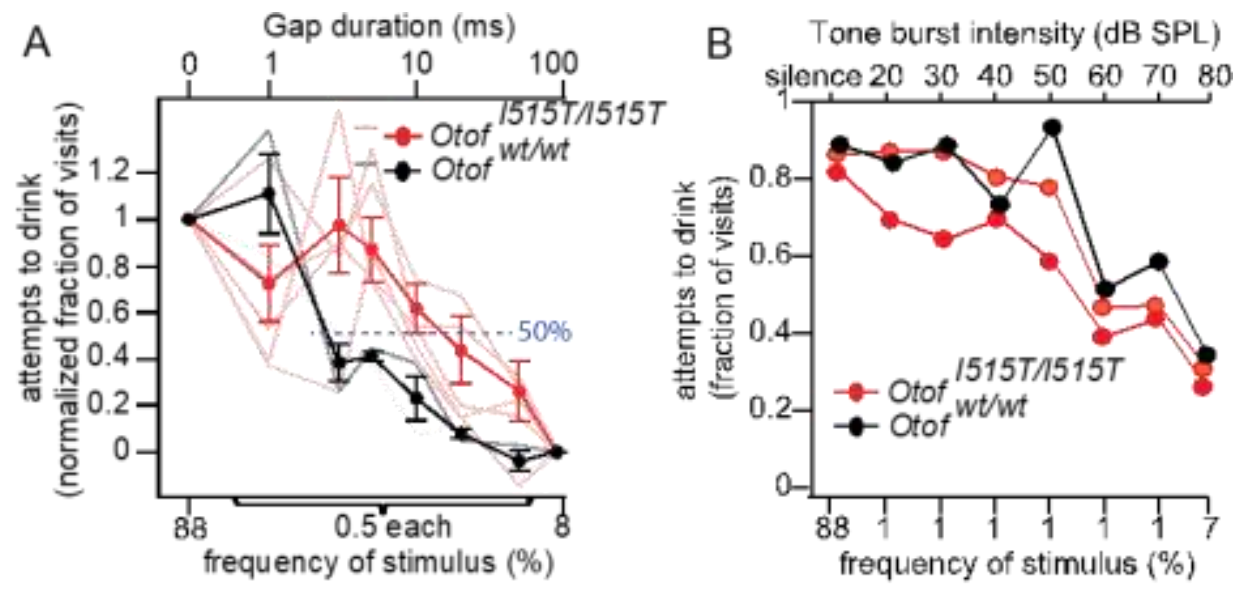

Figure 27. Gap detection and threshold sensitivity in Otof ${ }^{515 T / I 515 T}$ and wild type mice (modified from Strenzke et al., 2016)

A - Left axis - attempts to drink as a normalized fraction of visits. While hearing a continuous noise ( $88 \%$ of visits, lower axis) mice were allowed to drink. In $8 \%$ of visits, the noise was interrupted by $90 \mathrm{~ms}$ gaps and drink attempts were punished by air puffs. Similarly, for experimental stimuli $(0.5 \%$ of visits each; mice were not allowed to drink and drink attempts were punished by air puffs. While for the wild type mice gap detection threshold was between 1 and $3 \mathrm{~ms}$, it was greatly increased in Otof ${ }^{1515 T / 1515 T}$ mice.

B - Threshold discrimination in Otof ${ }^{1515 T / 1515 T}$ mice (Strenzke et al., 2016).

On the left axis - fraction of attempts to drink, experimental protocol similar to (A) but testing discrimination between silence and tone bursts of varying intensities. All three mice had a detection threshold between 50 and $60 \mathrm{~dB}$ SPL. 


\section{Discussions}

\subsection{PSD-95 and synaptic AMPA receptors in sound encoding}

\subsubsection{Reduction of ABR wave I amplitude in PSD-95\% ${ }^{-/-}$mice}

The first evidence suggesting that PSD- $95^{-/-}$mice have auditory phenotype was study of the ABRs reflecting synchronized response activity across the auditory brainstem. PSD-95I- mice showed reduced ABR wave I amplitude, whereas the other ABR peaks were well preserved and neither $\mathrm{ABR}$ waves latencies nor $\mathrm{ABR}$ thresholds were changed compared to control littermates. Such specific reduction in amplitude wave I across different stimulus intensities suggested a sound encoding synaptic deficit in SGNs and central compensation of it in the auditory brainstem. The idea about compensation in the central synapses is consistent with the previous findings in PSD-95 deficient mice showed normal synaptic transmission in acute hippocampal slices (Elias et al., 2006b). Elias et al. (2006) found that the genetic lack of either PSD-95 or PSD-93 have almost no effect on the synaptic transmission in hippocampal neurons of adult mice, whereas PSD-95 $5^{-/} / \mathrm{PSD}-93^{-/-}$mice have a clear synaptic deficiency. Our finding of a reduced ABR wave I amplitude suggested that, in contrast the central synapses, the peripheral IHC ribbon synapses may still have impaired synaptic transmission. An alternative explanation of the reduction of ABR wave I amplitude could in principle be the loss of ribbon synapses (Roux et al., 2006), but preliminary immunohistochemistry and confocal microscopy data suggest a normal number of ribbon synapses in PSD-95 $5^{-/-}$mice. Therefore, in order to explain a primary synaptic mechanism underlying the reduction of ABR wave I amplitude we set out to study the response properties of single SGNs of PSD-95 ${ }^{-/-}$mice.

\subsubsection{Impaired sound encoding in PSD-95 $\%$ afferent IHC ribbon synapses}

\section{Reduction of spontaneous and evoked spike rates in PSD-95\%- SGNs}

Recorded in silence, spontaneous activity in PSD-95 ${ }^{-/}$SGNs was significantly reduced, whereas single unit sound thresholds were normal. In consequence to reduced SRs, evoked activity of PSD-95/- SGNs was also significantly reduced in both onset and adapted spike rates, detecting a clear synaptic sound encoding deficit. Thus, suggested in ABR study synaptic deficit in PSD-95 ${ }^{-/-}$SGNs was confirmed on the single neuron level. In its turn, reduced spikes 
rates in PSD-95 ${ }^{-/-}$SGNs may contribute to the decreased ABR wave I amplitude of PSD-95 ${ }^{-/-}$ mice.

\section{Impaired accuracy of coding of first spike generation in PSD-95/- SGNs}

Accurate sound onset encoding is necessary for important auditory tasks, such as sound localization in space. It requires precise timing and reliable occurrence of first spikes in SGNs (Buran et al., 2010b). Analysis of FSLs of recorded PSTHs revealed significantly delayed first spikes in PSD-95 ${ }^{-/-}$SGNs and larger first spike jitter indicating impaired temporal precision and reliability of sound encoding. It has been suggested by Kopp-Scheinpflug and Thempel (2015) that the loss of temporal precision rather than the loss of threshold sensitivity might contribute to the lack of the ABR waves amplitudes (Kopp-Scheinpflug and Tempel, 2015b; Moser and Starr, 2016). Additional contribution to the reduced ABR wave I amplitude might be due to the reduction of spike rates in this knockout.

\section{Is presynaptic site contributing to the auditory phenotype of PSD-95/- mice?}

To address the question about possible presynaptic contribution to impaired synaptic transmission in PSD-95 ${ }^{-/-}$SGNs, a forward-masking paradigm (Harris and Dallos, 1979) was applied to analyse synaptic depression and recovery from it. While spike rate adaptation is considered to reflect partial depletion of the readily releasable pool of synaptic vesicles (RRP, (Westerman and Smith, 1984b; Yates et al., 1985a)), recovery from adaptation likely reflects RRP replenishment (Moser and Beutner, 2000b; Spassova et al., 2004; Goutman and Glowatzki, 2007b; Frank et al., 2010b). It has been shown previously that impaired recovery from synaptic depression is linked to impaired RRP vesicle depletion and replenishment in $\mathrm{WRB}^{\mathrm{f} / \mathrm{fl}}: \mathrm{Cre}^{\mathrm{A}}$ (Vogl et al., 2016) and Otof ${ }^{515 T / 1515 T}$ mice (Strenzke et al., 2016) leads to the lower vesicular turnover at the active zone in vivo and reduced exocytosis, resulting in the impaired sound encoding. Nevertheless, PSD-95 ${ }^{-1-}$ SGNs showed normal recovery from synaptic depression suggesting the intact presynaptic function. To clarify certainly most probable intact IHC exocytosis, patch-clamp recordings from IHCs (Lindau and Neher, 1988; Moser and Beutner, 2000b) would be required.

\section{Faster spike rate adaptation in PSD-95/- SGNs}

For in vivo recordings, the fast form of the sound-evoked spike rate adaptation in the auditory nerve is mostly attributed to the depletion of the RRP (Westerman and Smith, 1984b; Yates et al., 1985b). PSD-95 ${ }^{-/-}$SGNs evoked responses showed faster spike rate adaptation 
compared to wild type control, suggesting that postsynaptic mechanisms are also involved in modulation of the synaptic time course of spike rate adaptation in PSD-95 ${ }^{-/-}$mice. The idea about a role of the postsynaptic contribution to the short-term plasticity of AMPA-ergic synapses in neuronal cultures has been considered by Constals et al. (2015). By quantum dots fluorescent labelling they showed that the short-term plasticity of AMPA receptors during high-frequency stimulation depends not only on presynaptic neurotransmitter release and postsynaptic AMPA receptor activation and recovery from desensitization, but also on fast AMPA receptor lateral diffusion (Constals et al., 2015b). Desensitized AMPA receptors are more mobile due to the reduced affinity to the auxiliary TARP stargazin, which is important for AMPA receptors stabilization at the synaptic site (Schnell et al., 2002b; Kessels et al., 2009; Constals et al., 2015b). During AMPA receptor recycling desensitized receptors are removed from synaptic site and newly exocytosed receptors stabilized at the synaptic surface by binding to the C-terminus of the auxiliary protein stargazin to PSD-95 (Bats et al., 2007; Opazo et al., 2010; Anggono and Huganir, 2012). The recycling might be impaired in the absence of PSD95 that may lead to reduced internalization of the laterally diffused AMPA receptors. Lower AMPA receptors stabilization at the synaptic site may causes lowlier replacement of desensitized AMPA receptors from subclusters (Petrini et al., 2009; Opazo et al., 2012), which could lead to the faster spike rate adaptation in PSD-95 $5^{-/-}$SGNs.

\subsubsection{Immunohistochemical, confocal and STED microscopy studies of AMPA receptor}

In order to explain the impairment in sound encoding in the SGNs of PSD-95 $5^{-/-}$mice we next studied the AMPA receptors shape of a cluster and number of subclusters (or nanodomains,(Nair et al., 2013)) per synapse.

PSD-95, PSD-93 and SAP-102 were expressed in mature (8-12 weeks old) IHC ribbon synapses and superimposed to the AMPA receptor clusters as described by other authors (Meyer et al., 2009; Rutherford, 2015). The postsynaptic AMPA receptor cluster has a ringlike shape which surrounds the release face of the presynaptic active zone, indicated by the presence of the ribbon. AMPA receptors arrays are on average $\sim 900 \mathrm{~nm}$ in diameter (Meyer et al., 2009). We now used STED microscopy to reveal distinct AMPA receptor subclusters and define that in PSD-95 ${ }^{-/-}$SGNs the number of subclusters was reduced from 8 to 6 on average. Thus, it seems likely the number of available AMPA receptors is also reduced in PSD-95 ${ }^{-/}$ 
SGNs and that it might explain the reduction of the AP rates. This idea might be supported by recent studies in central synapses showing that the AMPA receptor surface regulates the synaptic strength (Migaud et al., 1998; Schnell et al., 2002b; Ehrlich, 2004; Elias et al., 2006b; Carlisle et al., 2008; Zhang and Lisman, 2012). Reduction of AMPA receptor surface expression plays a role in protection of auditory nerve fibers against excitotoxic damage (Chen et al., 2009).

There is a large heterogeneity in the amplitude and shape of the SGN EPSCs which have been described by Glowatzki and Fuchs (2002). Maintained synaptic transmission in PSD-95 ${ }^{-/-}$SGNs might be due to the compensatory function of the expressed PSD-93 and/or SAP-102 proteins. In hippocampal synapses it has been shown that in the absence of PSD-95 other MAGUKs may compensate for its function of targeting AMPA receptors at the postsynaptic membrane: PSD-93 in mature synapses and SAP-102 in immature synapses. Our data shows that both - PSD-93 and SAP-102 proteins - are expressed in mature SGNs of wild type as well as PSD-95 ${ }^{-/}$mice. A further investigation of the compensatory function for the disrupted PSD-95 would require a study PSD-93 and SAP-102 knockouts as well as their double knockouts.

\subsubsection{Central compensation of SGNs synaptic deficit in AVCN neurons}

Despite reduced spike generation and impaired accuracy of sound encoding in PSD-95 ${ }^{-/-}$SGNs, stellate and globular bushy cells demonstrated normal onset and adapted spike rates indicating central compensation in the cochlear nucleus neurons. This was consistent with well-preserved ABR wave II and wave III reflecting responses of globular bushy and stellate cells in the AVCN, respectively. Normal spike generation in central neurons of auditory brainstem of PSD$95^{-/-}$mice might be explained by compensation of the PSD-93 or/and SAP-102 for the absence of PSD-95 in deficient neurons (Elias et al., 2006b).

\subsection{Impaired sound encoding in $Q v^{3 \mathrm{~J}}$ mutant mice}

Loss-of-function mutations in the mouse ßIV-spectrin gene cause reduced voltagegated sodium channel densities at the AIS and nodes of Ranvier, where AP are generated (Komada and Soriano, 2002; Yang, 2004; Hossain, 2005). Functional studies of ßIV-mutants have revealed abnormal ABRs (Parkinson et al., 2001; Lacas-Gervais et al., 2004). Whereas $\mathrm{Qv}, \mathrm{Qv}^{4 \mathrm{~J}}$ and $\mathrm{Qv}{ }^{\operatorname{lnd} 2 \mathrm{~J}}$ mutants demonstrate substantial alterations in $\mathrm{ABR}$ waveforms morphology, including a general absence of later peaks, broadened and delayed wave peaks, 
and reduced amplitudes (Parkinson et al., 2001), which makes them the model of central deafness caused by central nervous system not cochlear dysfunction (Bock et al., 1983; Horner and Bock, 1984; Parkinson et al., 2001). In the present study $\mathrm{Qv}^{3 \mathrm{~J}}$ mutant mice showed broadened and delayed ABR wave I as well as other waves indicating that in this quivering mutant would have hearing impairment originated from peripheral and central neuropathy. Taken together with moderately elevated ABR thresholds in $\mathrm{Qv}^{3 \mathrm{~J}}$ mutant mice, the waveform changes suggested a sound encoding impairment in the SGNs as well as successive cochlear nucleus neurons in these mutants.

Extracellular single unit in vivo recordings from mature (6-12 weeks old) $\mathrm{Qv}^{3 \mathrm{~J}}$ mutant mice revealed lower SRs and evoked spike rates. Both the onset and adapted spike rates were significantly reduced, indicating an impairment of AP generation, which may explain moderately elevated ABR thresholds. Interestingly, the single unit thresholds were better preserved, and a sharpness of the TCs was comparable to the wild types indirectly suggesting normal cochlear amplification. Synaptic recovery from depression was assessed in the forwardmasking paradigm (Harris and Dallos, 1979). Qv $v^{3 J}$ mutant SGNs demonstrated normal recovery from synaptic depression suggesting normal vesicle pool depletion and recovery at IHC ribbon synapses.

Impaired voltage-gated sodium channels clustering at the AIS and nodes of Ranvier (Komada and Soriano, 2002; Yang, 2004; Hossain, 2005), the ABR changes, and the impairment of accuracy of the spike coding is more severely affected in $\mathrm{Qv}^{4 \mathrm{~J}}$ mutants (KoppScheinpflug and Tempel, 2015a). However, $Q v^{3 \mathrm{~J}}$ mutant SGNs showed only slightly increased median FSLs compared to wild types and not significantly greater jitter. Moreover, a temporal precision of the spike generation evaluated as ability for phase locking to transposed amplitude modulated $\mathrm{CF}$ tones was precise in $\mathrm{Qv}^{3 \mathrm{~J}}$ mutant SGNs. Thus, delayed ABR waves and moderately elevated ABR thresholds most likely reflect the reduced spike rates in $\mathrm{Qv}^{3 \mathrm{~J}}$ mutant SGNs.

Extracellular in vivo recordings from AVCN neurons revealed almost intact response properties of globular bushy cells and stellate cells in $\mathrm{Qv}^{3 \mathrm{~J}}$ mutant mice. Stellate cells had normal SRs, single unit thresholds and both onset and adapted evoked spike rate. Globular bushy cells had lower SRs, normal thresholds sensitivity and onset evoked spike rate, but reduced adapted spike rate. These findings suggest a presence of mechanism possibly compensating for the reduced input from primary auditory afferents. Thus, the contribution of 
the AVCN stellate and globular bushy cells to the longer ABR latencies and moderately elevated $\mathrm{ABR}$ thresholds in $\mathrm{Qv}^{3 \mathrm{~J}}$ mice seems to be minor. Further study of the temporal precision of the spike generation in stellate and globular bushy cells might reveal comparable changes to the previously defined reduced synchrony of coding in $\mathrm{Qv}^{4 \mathrm{~J}} \mathrm{AVCN}$ neurons (KoppScheinpflug and Tempel, 2015a).

\subsection{Auditory synaptopathy phenotype of $\mathrm{WRB}^{\mathrm{fl} / \mathrm{fl}}: \mathrm{Cre}^{\mathrm{A}}$ mice}

Auditory function of $\mathrm{WRB}^{\mathrm{fl} / \mathrm{fl}}: \mathrm{Cre}^{\mathrm{A}}$ mice was studied in three age groups in order to detect early onset of a hearing impairment: P14-17, P21-26, P>29. In all age groups $\mathrm{WRB}^{\mathrm{fl} / \mathrm{fl}}: \mathrm{Cre}^{\mathrm{A}}$ mice showed a progressive reduction of the ABR wave I amplitude and an elevation of ABR thresholds. Cochlear amplification function of these mice was normal indicating intact $\mathrm{OHCs}$ amplification function. Mechanoelectrical transduction measurement of the hair bundle of IHC revealed normal morphological changes and maintenance of IHC hair bundle (Vogl et al., 2016).

$\mathrm{WRB}^{\mathrm{fl} / \mathrm{fl}}: \mathrm{Cre}^{\mathrm{A}}$ mice displayed normal numbers of afferent synapses, $\mathrm{Ca}^{2+}$ channels, and membrane-proximal vesicles, but contained less ribbon-associated vesicles. Patch-camp of IHCs showed impaired sustained exocytosis, e.g. impaired synaptic vesicle replenishment (Vogl et al., 2016). Thus, impaired ABRs of $\mathrm{WRB}^{\mathrm{fl} / \mathrm{fl}}: \mathrm{Cre}^{\mathrm{A}}$ mice based on perturbed sound encoding at the IHC synapse and classified as auditory synaptopathy phenotype (Moser and Starr, 2016). Indeed, extracellular single unit in vivo recordings revealed severely reduced sound-evoked onset and adapted spike rates in $\mathrm{WRB}^{\mathrm{fl} / \mathrm{fl}}: \mathrm{Cre}^{\mathrm{A}} \mathrm{SGNs}$ which caused by reduced neurotransmitter exocytosis of $\mathrm{WRB}^{\mathrm{fl} / \mathrm{fl} l}: \mathrm{Cre}^{\mathrm{A}} \mathrm{IHC}$. Sound-evoked spike rates of $\mathrm{WRB}^{\mathrm{fl} / \mathrm{fl} l}: \mathrm{Cre}^{\mathrm{A}}$ SGNs were profoundly reduced when faster stimulus rates were applied showed a usedependent reduction of AP generation. Consistent with the onset spike rate reduction, median of FSL in response to the stimulus onset was dramatically increased in $\mathrm{WRB}^{+/+}: \mathrm{Cre}^{\mathrm{A}} \mathrm{SGNs}$ and showed larger jitter. Together with the reduced evoked spike rates and impaired accuracy of coding likely explains the severe ABR phenotype in $\mathrm{WRB}^{\mathrm{fl} / \mathrm{fl}}: \mathrm{Cre}^{\mathrm{A}}$ mice.

Since sustained exocytosis and, thus, vesicles replenishment of RRP seemed to be impaired at the $\mathrm{WRB}^{\mathrm{fl} / \mathrm{fl}}: \mathrm{Cre}^{\mathrm{A}}$ IHCs active zones, it has been necessary to confirm this hypothesis by studying the recovery of onset spiking from forward masking (Harris and Dallos, 1979). Consistent with a slowed vesicle replenishment at the active zones of $\mathrm{WRB}^{\mathrm{fl} / \mathrm{fl}}: \mathrm{Cre}^{\mathrm{A}}$ 
IHCs, knockout SGNs revealed a stronger adaptation and slower recovery from it. This results show that the reduced vesicles replenishment rate in $\mathrm{WRB}^{\mathrm{fl} / \mathrm{fl}}: \mathrm{Cre}^{\mathrm{A}} \mathrm{IHCs}$ lowers the size of the standing RRP in vivo, resulting in impaired sound encoding in $\mathrm{WRB}^{\mathrm{fl} / \mathrm{fl} l}: \mathrm{Cre}^{\mathrm{A}}$ mice.

In addition, all $\mathrm{WRB}^{\mathrm{fl} / \mathrm{fl}}: \mathrm{Cre}^{\mathrm{A}} \mathrm{SGNs}$ had SRs below $20 \mathrm{~Hz}$ and were not significantly different from wild type control. TCs and acoustic thresholds were also not significantly changed in $\mathrm{WRB}^{\mathrm{fl} / \mathrm{fl}}: \mathrm{Cre}^{\mathrm{A}} \mathrm{SGNs}$.

Taken together, our SGN recordings contribute to the multidisciplinary study which demonstrates that TRC40 pathway is necessary for the efficient insertion of the tail-anchored protein otoferlin to the endoplasmic reticulum and that disruption of the WRB protein reduces otoferlin level in IHCs and corrupts sound encoding in mouse cochleae (see chapter 1.4 of Introduction). The observed reduction of the poorly inserted otoferlin limits the rate of vesicle replenishment at the IHC synapse and therefore impairs sound encoding in WRBfl/fl:CreA mice.

\subsection{Impaired gap detection in Otof $f^{515 T / 1515 T}$ mice}

The multi-C2 domain protein otoferlin (Pangršič et al., 2012) is required for hearing and essential for exocytosis at the IHC ribbon synapse (Roux et al., 2006; Pangrsic et al., 2010; Strenzke et al., 2016). Mutations in otoferlin cause profound prelingual deafness DFNB9 (Yasunaga et al., 1999; Varga et al., 2003). Otof ${ }^{515 T / 1515 T}$ mutant mouse showed strongly reduced sustained exocytosis during prolonged stimulation (Strenzke et al., 2016), indicating that otoferlin is essential for replenishment of RRP at IHC ribbon synapse. Correspondingly, sound evoked spike rates were profoundly reduced in onset and adapted rates, and Otof $515 T / 1515 T$ SGNs revealed enhanced spike rate adaptation and slowed recovery from it (Strenzke et al., 2016).

Patients with otoferlin mutations demonstrate auditory fatigue when challenged with continuous tones, as well as speech comprehension difficulties (Wynne et al., 2013). Sound perception of the Otof ${ }^{515 T / 1515 T}$ mice was studied by psychophysiological assessment of gap detection ability and thresholds sensitivity. Otof ${ }^{515 T / I 515 T}$ mice showed impaired perception of the silent gaps in noise. The impairment might be explained by the reduction of the adapted spike rate in combination to the slower recovery of the sound onset response. The gap detection impairment in Otof ${ }^{515 T / 1515 T}$ mice is consistent with the speech recognition difficulties in patients with otoferlin mutation. Those patients would demonstrate normal sound sensitivity, 
and similarly, Otof $f^{515 T / 1515 T}$ mice showed normal behavioural sound thresholds sensitivity. Based on positive reward, psychophysiological assessment of gap detection ability and sound thresholds sensitivity in Otof $f^{515 T / 1515 T}$ mice, allowed to detect speech perception disability in humans carrying otoferlin mutation. 


\section{References}

Abbas AI, Yadav PN, Yao W-D, Arbuckle MI, Grant SGN, Caron MG, Roth BL (2009) PSD95 Is Essential for Hallucinogen and Atypical Antipsychotic Drug Actions at Serotonin Receptors. Journal of Neuroscience 29:7124-7136.

Altrock WD et al. (2003) Functional inactivation of a fraction of excitatory synapses in mice deficient for the active zone protein bassoon. Neuron 37:787-800.

Amsterdam A, Nissen RM, Sun Z, Swindell EC, Farrington S, Hopkins N (2004) Identification of 315 genes essential for early zebrafish development. PNAS 101:12792-12797.

Anggono V, Huganir RL (2012) Regulation of AMPA receptor trafficking and synaptic plasticity. Current Opinion in Neurobiology 22:461-469.

Ashmore J (2008) Cochlear Outer Hair Cell Motility. Physiol Rev 88:173-210.

Barnes AP, Polleux F (2009) Establishment of axon-dendrite polarity in developing neurons. Annu Rev Neurosci 32:347-381.

Bats C, Groc L, Choquet D (2007) The Interaction between Stargazin and PSD-95 Regulates AMPA Receptor Surface Trafficking. Neuron 53:719-734.

Battefeld A, Tran BT, Gavrilis J, Cooper EC, Kole MHP (2014) Heteromeric Kv7.2/7.3 Channels Differentially Regulate Action Potential Initiation and Conduction in Neocortical Myelinated Axons. Journal of Neuroscience 34:3719-3732.

Bender KJ, Trussell LO (2009) Axon Initial Segment Ca2+ Channels Influence Action Potential Generation and Timing. Neuron 61:259-271.

Bennett V, Baines AJ (2001a) Spectrin and Ankyrin-Based Pathways: Metazoan Inventions for Integrating Cells Into Tissues. Physiological Reviews 81:1353-1392.

Bennett V, Baines AJ (2001b) Spectrin and ankyrin-based pathways: metazoan inventions for integrating cells into tissues. Physiol Rev 81:1353-1392.

Berghs S, Aggujaro D, Dirkx R, Maksimova E, Stabach P, Hermel JM, Zhang JP, Philbrick W, Slepnev V, Ort T, Solimena M (2000) betaIV spectrin, a new spectrin localized at axon initial segments and nodes of ranvier in the central and peripheral nervous system. $\mathrm{J}$ Cell Biol 151:985-1002.

Beurg M, Michalski N, Safieddine S, Bouleau Y, Schneggenburger R, Chapman ER, Petit C, Dulon D (2010) Control of exocytosis by synaptotagmins and otoferlin in auditory hair cells. J Neurosci 30:13281-13290.

Beurg M, Safieddine S, Roux I, Bouleau Y, Petit C, Dulon D (2008) Calcium- and otoferlindependent exocytosis by immature outer hair cells. J Neurosci 28:1798-1803. 
Beutner D, Voets T, Neher E, Moser T (2001) Calcium dependence of exocytosis and endocytosis at the cochlear inner hair cell afferent synapse. Neuron 29:681-690.

Bock GR, Frank MP, Steel KP, Deol MS (1983) The quivering mutant mouse: hereditary deafness of central origin. Acta Otolaryngol 96:371-377.

Boiko T, Van Wart A, Caldwell JH, Levinson SR, Trimmer JS, Matthews G (2003) Functional specialization of the axon initial segment by isoform-specific sodium channel targeting. J Neurosci 23:2306-2313.

Borgdorff AJ, Choquet D (2002) Regulation of AMPA receptor lateral movements. Nature 417:649-653.

Boucrot E, Saffarian S, Zhang R, Kirchhausen T (2010) Roles of AP-2 in clathrin-mediated endocytosis. PLoS ONE 5:e10597.

Bozkurt G, Stjepanovic G, Vilardi F, Amlacher S, Wild K, Bange G, Favaloro V, Rippe K, Hurt E, Dobberstein B, Sinning I (2009) Structural insights into tail-anchored protein binding and membrane insertion by Get3. Proc Natl Acad Sci USA 106:21131-21136.

Brachet A, Leterrier C, Irondelle M, Fache M-P, Racine V, Sibarita J-B, Choquet D, Dargent B (2010) Ankyrin G restricts ion channel diffusion at the axonal initial segment before the establishment of the diffusion barrier. The Journal of Cell Biology 191:383-395.

Brackenbury WJ, Calhoun JD, Chen C, Miyazaki H, Nukina N, Oyama F, Ranscht B, Isom LL (2010) Functional reciprocity between $\mathrm{Na}+$ channel Nav1.6 and 1 subunits in the coordinated regulation of excitability and neurite outgrowth. Proceedings of the National Academy of Sciences 107:2283-2288.

Brackenbury WJ, Djamgoz MBA, Isom LL (2008) An Emerging Role for Voltage-Gated Na+ Channels in Cellular Migration: Regulation of Central Nervous System Development and Potentiation of Invasive Cancers. The Neuroscientist 14:571-583.

Brandstätter JH, Wässle H, Betz H, Morgans CW (1996) The plasma membrane protein SNAP25 , but not syntaxin, is present at photoreceptor and bipolar cell synapses in the rat retina. Eur J Neurosci 8:823-828.

Brandt A, Khimich D, Moser T (2005) Few CaV1. 3 channels regulate the exocytosis of a synaptic vesicle at the hair cell ribbon synapse. J Neurosci 25:11577.

Brandt A, Striessnig J, Moser T (2003) CaV1. 3 channels are essential for development and presynaptic activity of cochlear inner hair cells. J Neurosci 23:10832-10840.

Bronson RT, Sweet HO, Spencer CA, Davisson MT (1992) Genetic and age related models of neurodegeneration in mice: dystrophic axons. J Neurogenet 8:71-83.

Bryda EC, Johnson NT, Ohlemiller KK, Besch-Williford CL, Moore E, Bram RJ (2012) Conditional deletion of calcium-modulating cyclophilin ligand causes deafness in mice. Mamm Genome 23:270-276. 
Buffington SA, Rasband MN (2011) The axon initial segment in nervous system disease and injury: The AIS in nervous system disease. European Journal of Neuroscience 34:16091619.

Buran BN, Strenzke N, Neef A, Gundelfinger ED, Moser T, Liberman MC (2010a) Onset coding is degraded in auditory nerve fibers from mutant mice lacking synaptic ribbons. J Neurosci 30:7587-7597.

Buran BN, Strenzke N, Neef A, Gundelfinger ED, Moser T, Liberman MC (2010b) Onset Coding Is Degraded in Auditory Nerve Fibers from Mutant Mice Lacking Synaptic Ribbons. Journal of Neuroscience 30:7587-7597.

Cais O, Herguedas B, Krol K, Cull-Candy SG, Farrant M, Greger IH (2014) Mapping the Interaction Sites between AMPA Receptors and TARPs Reveals a Role for the Receptor N-Terminal Domain in Channel Gating. Cell Reports 9:728-740.

Cant NB, Benson CG (2003) Parallel auditory pathways: projection patterns of the different neuronal populations in the dorsal and ventral cochlear nuclei. Brain Res Bull 60:457474.

Carlisle HJ, Fink AE, Grant SGN, O’Dell TJ (2008) Opposing effects of PSD-93 and PSD-95 on long-term potentiation and spike timing-dependent plasticity: Membrane-associated guanylate kinases and synaptic plasticity. The Journal of Physiology 586:5885-5900.

Cestele S, Schiavon E, Rusconi R, Franceschetti S, Mantegazza M (2013) Nonfunctional $\mathrm{NaV} 1.1$ familial hemiplegic migraine mutant transformed into gain of function by partial rescue of folding defects. Proceedings of the National Academy of Sciences 110:17546-17551.

Chen Z, Kujawa SG, Sewell WF (2007) Auditory sensitivity regulation via rapid changes in expression of surface AMPA receptors. Nat Neurosci 10:1238-1240.

Chen Z, Peppi M, Kujawa SG, Sewell WF (2009) Regulated expression of surface AMPA receptors reduces excitotoxicity in auditory neurons. J Neurophysiol 102:1152-1159.

Chiu Y-H, Wu C-C, Lu Y-C, Chen P-J, Lee W-Y, Liu AY-Z, Hsu C-J (2010) Mutations in the OTOF gene in Taiwanese patients with auditory neuropathy. Audiol Neurootol 15:364374.

Ciuman RR (2011) Auditory and vestibular hair cell stereocilia: relationship between functionality and inner ear disease. The Journal of Laryngology \& Otology 125:9911003.

Claes L, Del-Favero J, Ceulemans B, Lagae L, Van Broeckhoven C, De Jonghe P (2001) De Novo Mutations in the Sodium-Channel Gene SCN1A Cause Severe Myoclonic Epilepsy of Infancy. The American Journal of Human Genetics 68:1327-1332.

Constals A, Penn AC, Compans B, Toulmé E, Phillipat A, Marais S, Retailleau N, Hafner A-S, Coussen F, Hosy E, Choquet D (2015a) Glutamate-Induced AMPA Receptor 
Desensitization Increases Their Mobility and Modulates Short-Term Plasticity through Unbinding from Stargazin. Neuron 85:787-803.

Constals A, Penn AC, Compans B, Toulmé E, Phillipat A, Marais S, Retailleau N, Hafner A-S, Coussen F, Hosy E, Choquet D (2015b) Glutamate-Induced AMPA Receptor Desensitization Increases Their Mobility and Modulates Short-Term Plasticity through Unbinding from Stargazin. Neuron 85:787-803.

Dallos P, Wu X, Cheatham MA, Gao J, Zheng J, Anderson CT, Jia S, Wang X, Cheng WHY, Sengupta S, He DZZ, Zuo J (2008) Prestin-Based Outer Hair Cell Motility Is Necessary for Mammalian Cochlear Amplification. Neuron 58:333-339.

Davis RL, Crozier RA (2015a) Dynamic firing properties of type I spiral ganglion neurons. Cell and Tissue Research 361:115-127.

Davis RL, Crozier RA (2015b) Dynamic firing properties of type I spiral ganglion neurons. Cell and Tissue Research 361:115-127.

de Hoz L, Nelken I (2014a) Frequency Tuning in the Behaving Mouse: Different Bandwidths for Discrimination and Generalization Vicario DS, ed. PLoS ONE 9:e91676.

de Hoz L, Nelken I (2014b) Frequency tuning in the behaving mouse: different bandwidths for discrimination and generalization. PLoS ONE 9:e91676.

Denic V, Dötsch V, Sinning I (2013) Endoplasmic reticulum targeting and insertion of tailanchored membrane proteins by the GET pathway. Cold Spring Harb Perspect Biol 5:a013334.

Dodson PD, Barker MC, Forsythe ID (2002) Two heteromeric Kv1 potassium channels differentially regulate action potential firing. J Neurosci 22:6953-6961.

Dulon D, Safieddine S, Jones SM, Petit C (2009) Otoferlin Is Critical for a Highly Sensitive and Linear Calcium-Dependent Exocytosis at Vestibular Hair Cell Ribbon Synapses. The Journal of Neuroscience 29:10474-10487.

Duncker SV, Franz C, Kuhn S, Schulte U, Campanelli D, Brandt N, Hirt B, Fakler B, Blin N, Ruth P, Engel J, Marcotti W, Zimmermann U, Knipper M (2013) Otoferlin Couples to Clathrin-Mediated Endocytosis in Mature Cochlear Inner Hair Cells. J Neurosci 33:9508-9519.

Ehrlich I (2004) Postsynaptic Density 95 controls AMPA Receptor Incorporation during LongTerm Potentiation and Experience-Driven Synaptic Plasticity. Journal of Neuroscience 24:916-927.

El Mestikawy S, Wallén-Mackenzie Å, Fortin GM, Descarries L, Trudeau L-E (2011) From glutamate co-release to vesicular synergy: vesicular glutamate transporters. Nature Reviews Neuroscience 12:204-216.

Elias GM, Funke L, Stein V, Grant SG, Bredt DS, Nicoll RA (2006a) Synapse-Specific and 
Developmentally Regulated Targeting of AMPA Receptors by a Family of MAGUK Scaffolding Proteins. Neuron 52:307-320.

Elias GM, Funke L, Stein V, Grant SG, Bredt DS, Nicoll RA (2006b) Synapse-Specific and Developmentally Regulated Targeting of AMPA Receptors by a Family of MAGUK Scaffolding Proteins. Neuron 52:307-320.

Favaloro V, Spasic M, Schwappach B, Dobberstein B (2008) Distinct targeting pathways for the membrane insertion of tail-anchored (TA) proteins. Journal of Cell Science 121:1832-1840.

Frank T, Rutherford MA, Strenzke N, Neef A, Pangršič T, Khimich D, Fejtova A, Gundelfinger ED, Liberman MC, Harke B, Bryan KE, Lee A, Egner A, Riedel D, Moser T (2010a) Bassoon and the synaptic ribbon organize $\mathrm{Ca}^{2}+$ channels and vesicles to add release sites and promote refilling. Neuron 68:724-738.

Frank T, Rutherford MA, Strenzke N, Neef A, Pangršič T, Khimich D, Fejtova A, Gundelfinger ED, Liberman MC, Harke B, Bryan KE, Lee A, Egner A, Riedel D, Moser T (2010b) Bassoon and the Synaptic Ribbon Organize Ca2+ Channels and Vesicles to Add Release Sites and Promote Refilling. Neuron 68:724-738.

Frischknecht R, Seidenbecher CI (2012) Brevican: A key proteoglycan in the perisynaptic extracellular matrix of the brain. The International Journal of Biochemistry \& Cell Biology 44:1051-1054.

Fuchs PA, Glowatzki E, Moser T (2003) The afferent synapse of cochlear hair cells. Current Opinion in Neurobiology 13:452-458.

Furukawa T, Matsuura S (1978) Adaptive rundown of excitatory post-synaptic potentials at synapses between hair cells and eight nerve fibres in the goldfish. J Physiol (Lond) 276:193-209.

Gacek RR, Rasmussen GL (1961) Fiber analysis of the statoacoustic nerve of guinea pig, cat, and monkey. Anat Rec 139:455-463.

Gardoni F, Marcello E, Di Luca M (2009) Postsynaptic density-membrane associated guanylate kinase proteins (PSD-MAGUKs) and their role in CNS disorders. Neuroscience 158:324-333.

Geisler CD (1998) From Sound to Synapse. New York: Oxford University Press.

Glowatzki E, Fuchs PA (2002) Transmitter release at the hair cell ribbon synapse. Nat Neurosci 5:147-154.

Goldberg EM, Clark BD, Zagha E, Nahmani M, Erisir A, Rudy B (2008) K+ Channels at the Axon Initial Segment Dampen Near-Threshold Excitability of Neocortical Fast-Spiking GABAergic Interneurons. Neuron 58:387-400.

Goutman JD, Glowatzki E (2007a) Time course and calcium dependence of transmitter release 
at a single ribbon synapse. Proc Natl Acad Sci U S A 104:16341-16346.

Goutman JD, Glowatzki E (2007b) Time course and calcium dependence of transmitter release at a single ribbon synapse. Proceedings of the National Academy of Sciences 104:16341-16346.

Goutman JD, Glowatzki E (2011) Short-Term Facilitation Modulates Size and Timing of the Synaptic Response at the Inner Hair Cell Ribbon Synapse. J Neurosci 31:7974-7981.

Grant L, Yi E, Glowatzki E (2010) Two Modes of Release Shape the Postsynaptic Response at the Inner Hair Cell Ribbon Synapse. J Neurosci 30:4210-4220.

Greifzu F, Parthier D, Goetze B, Schlüter OM, Löwel S (2016) Ocular Dominance Plasticity after Stroke Was Preserved in PSD-95 Knockout Mice Dunaevsky A, ed. PLOS ONE 11:e0149771.

Griswold AJ, Ma D, Sacharow SJ, Robinson JL, Jaworski JM, Wright HH, Abramson RK, Lybaek H, Øyen N, Cuccaro ML, Gilbert JR, Pericak-Vance MA (2011) A de novo 1.5 $\mathrm{Mb}$ microdeletion on chromosome $14 \mathrm{q} 23.2-23.3$ in a patient with autism and spherocytosis. Autism Research 4:221-227.

Gross JM, Perkins BD, Amsterdam A, Egana A, Darland T, Matsui JI, Sciascia S, Hopkins N, Dowling JE (2005) Identification of Zebrafish Insertional Mutants With Defects in Visual System Development and Function. Genetics 170:245-261.

Harris DM, Dallos P (1979) Forward masking of auditory nerve fiber responses. Journal of Neurophysiology 42:1083-1107.

Hedstrom KL, Xu X, Ogawa Y, Frischknecht R, Seidenbecher CI, Shrager P, Rasband MN (2007) Neurofascin assembles a specialized extracellular matrix at the axon initial segment. The Journal of Cell Biology 178:875-886.

Hirose G (2013) [An overview of epilepsy: its history, classification, pathophysiology and management]. Brain Nerve 65:509-520.

Ho TS-Y, Zollinger DR, Chang K-J, Xu M, Cooper EC, Stankewich MC, Bennett V, Rasband MN (2014) A hierarchy of ankyrin-spectrin complexes clusters sodium channels at nodes of Ranvier. Nature Neuroscience 17:1664-1672.

Horner KC, Bock GR (1984) Single unit responses in the cochlear nucleus of the deaf quivering mouse. Hear Res 13:63-72.

Hossain WA (2005) Where Is the Spike Generator of the Cochlear Nerve? Voltage-Gated Sodium Channels in the Mouse Cochlea. Journal of Neuroscience 25:6857-6868.

Hossain WA, Antic SD, Yang Y, Rasband MN, Morest DK (2005) Where is the spike generator of the cochlear nerve? Voltage-gated sodium channels in the mouse cochlea. J Neurosci $25: 6857-6868$ 
Hsu W-CJ, Nilsson CL, Laezza F (2014) Role of the Axonal Initial Segment in Psychiatric Disorders: Function, Dysfunction, and Intervention. Frontiers in Psychiatry 5 Available at: http://journal.frontiersin.org/article/10.3389/fpsyt.2014.00109/abstract [Accessed June 12, 2018].

Hu D, Barajas-Martinez H, Burashnikov E, Springer M, Wu Y, Varro A, Pfeiffer R, Koopmann TT, Cordeiro JM, Guerchicoff A, Pollevick GD, Antzelevitch C (2009) A Mutation in the 3 Subunit of the Cardiac Sodium Channel Associated With Brugada ECG Phenotype. Circulation: Cardiovascular Genetics 2:270-278.

Huang X, Stodieck SK, Goetze B, Cui L, Wong MH, Wenzel C, Hosang L, Dong Y, Löwel S, Schlüter OM (2015a) Progressive maturation of silent synapses governs the duration of a critical period. PNAS:201506488.

Huang X, Stodieck SK, Goetze B, Cui L, Wong MH, Wenzel C, Hosang L, Dong Y, Löwel S, Schlüter OM (2015b) Progressive maturation of silent synapses governs the duration of a critical period. Proceedings of the National Academy of Sciences 112:E3131-E3140.

Hudspeth AJ, Lewis RS (1988) Kinetic analysis of voltage- and ion-dependent conductances in saccular hair cells of the bull-frog, Rana catesbeiana. J Physiol (Lond) 400:237-274.

Hüttenbrink KB (1989) [Movement of the ear ossicles by middle ear muscle contraction]. Laryngorhinootologie 68:614-621.

Isaac JT, Nicoll RA, Malenka RC (1995) Evidence for silent synapses: implications for the expression of LTP. Neuron 15:427-434.

Jahn R, Fasshauer D (2012) Molecular machines governing exocytosis of synaptic vesicles. Nature 490:201-207.

Jenkins SM, Bennett V (2001) Ankyrin-G coordinates assembly of the spectrin-based membrane skeleton, voltage-gated sodium channels, and L1 CAMs at Purkinje neuron initial segments. The Journal of Cell Biology 155:739-746.

Jing Z, Rutherford MA, Takago H, Frank T, Fejtova A, Khimich D, Moser T, Strenzke N (2013) Disruption of the presynaptic cytomatrix protein bassoon degrades ribbon anchorage, multiquantal release, and sound encoding at the hair cell afferent synapse. J Neurosci $33: 4456-4467$.

Johnson CP, Chapman ER (2010) Otoferlin is a calcium sensor that directly regulates SNAREmediated membrane fusion. J Cell Biol 191:187-197.

Johnston J, Forsythe ID, Kopp-Scheinpflug C (2010) SYMPOSIUM REVIEW: Going native: voltage-gated potassium channels controlling neuronal excitability: $\mathrm{K}^{+}$channels and auditory processing. The Journal of Physiology 588:3187-3200.

Jones SL, Svitkina TM (2016) Axon Initial Segment Cytoskeleton: Architecture, Development, and Role in Neuron Polarity. Neural Plasticity 2016:1-19. 
Jung S, Maritzen T, Wichmann C, Jing Z, Neef A, Revelo NH, Al-Moyed H, Meese S, Wojcik SM, Panou I, Bulut H, Schu P, Ficner R, Reisinger E, Rizzoli SO, Neef J, Strenzke N, Haucke V, Moser T (2015) Disruption of adaptor protein $2 \mu$ (AP-2 $\mu$ ) in cochlear hair cells impairs vesicle reloading of synaptic release sites and hearing. EMBO J 34:26862702.

Kapitein LC, Hoogenraad CC (2011) Which way to go? Cytoskeletal organization and polarized transport in neurons. Molecular and Cellular Neuroscience 46:9-20.

Kessels HW, Kopec CD, Klein ME, Malinow R (2009) Roles of stargazin and phosphorylation in the control of AMPA receptor subcellular distribution. Nature Neuroscience 12:888896.

Keyel PA, Thieman JR, Roth R, Erkan E, Everett ET, Watkins SC, Heuser JE, Traub LM (2008) The AP-2 adaptor beta2 appendage scaffolds alternate cargo endocytosis. Mol Biol Cell 19:5309-5326.

Khimich D, Nouvian R, Pujol R, tom Dieck S, Egner A, Gundelfinger ED, Moser T (2005) Hair cell synaptic ribbons are essential for synchronous auditory signalling. Nature 434:889-894.

Kiang NY, Liberman MC, Sewell WF, Guinan JJ (1986) Single unit clues to cochlear mechanisms. Hear Res 22:171-182.

Kiang NY, Pfeiffer RR, Warr WB, Backus AS (1965) Stimulus coding in the cochlear nucleus. Trans Am Otol Soc 53:35-58.

Kiang NY, Rho JM, Northrop CC, Liberman MC, Ryugo DK (1982) Hair-cell innervation by spiral ganglion cells in adult cats. Science 217:175-177.

Kim KX, Rutherford MA (2016a) Maturation of NaV and KV Channel Topographies in the Auditory Nerve Spike Initiator before and after Developmental Onset of Hearing Function. J Neurosci 36:2111-2118.

Kim KX, Rutherford MA (2016b) Maturation of NaV and KV Channel Topographies in the Auditory Nerve Spike Initiator before and after Developmental Onset of Hearing Function. Journal of Neuroscience 36:2111-2118.

Kole MHP, Ilschner SU, Kampa BM, Williams SR, Ruben PC, Stuart GJ (2008) Action potential generation requires a high sodium channel density in the axon initial segment. Nature Neuroscience 11:178-186.

Kole MHP, Letzkus JJ, Stuart GJ (2007) Axon Initial Segment Kv1 Channels Control Axonal Action Potential Waveform and Synaptic Efficacy. Neuron 55:633-647.

Komada M, Soriano P (2002) BIV-spectrin regulates sodium channel clustering through ankyrin-G at axon initial segments and nodes of Ranvier. The Journal of Cell Biology $156: 337-348$. 
Kopp-Scheinpflug C, Tempel BL (2015a) Decreased temporal precision of neuronal signaling as a candidate mechanism of auditory processing disorder. Hearing Research 330:213220.

Kopp-Scheinpflug C, Tempel BL (2015b) Decreased temporal precision of neuronal signaling as a candidate mechanism of auditory processing disorder. Hearing Research 330:213220.

Kordeli E, Lambert S, Bennett V (1995) AnkyrinG. A new ankyrin gene with neural-specific isoforms localized at the axonal initial segment and node of Ranvier. J Biol Chem 270:2352-2359.

Lacas-Gervais S, Guo J, Strenzke N, Scarfone E, Kolpe M, Jahkel M, De Camilli P, Moser T, Rasband MN, Solimena M (2004) $\beta I V \Sigma 1$ spectrin stabilizes the nodes of Ranvier and axon initial segments. The Journal of Cell Biology 166:983-990.

Lenzi D, Crum J, Ellisman MH, Roberts WM (2002) Depolarization redistributes synaptic membrane and creates a gradient of vesicles on the synaptic body at a ribbon synapse. Neuron 36:649-659.

Lenzi D, Runyeon JW, Crum J, Ellisman MH, Roberts WM (1999) Synaptic Vesicle Populations in Saccular Hair Cells Reconstructed by Electron Tomography. J Neurosci 19:119-132.

Lenzi D, von Gersdorff H (2001) Structure suggests function: the case for synaptic ribbons as exocytotic nanomachines. Bioessays 23:831-840.

Leterrier C, Potier J, Caillol G, Debarnot C, Rueda Boroni F, Dargent B (2015) Nanoscale Architecture of the Axon Initial Segment Reveals an Organized and Robust Scaffold. Cell Reports 13:2781-2793.

Leterrier C, Vacher H, Fache M-P, d'Ortoli SA, Castets F, Autillo-Touati A, Dargent B (2011) End-binding proteins EB3 and EB1 link microtubules to ankyrin $\mathrm{G}$ in the axon initial segment. Proceedings of the National Academy of Sciences 108:8826-8831.

Liao D, Hessler NA, Malinow R (1995) Activation of postsynaptically silent synapses during pairing-induced LTP in CA1 region of hippocampal slice. Nature 375:400-404.

Liberman M (1982) Single-neuron labeling in the cat auditory nerve. Science 216:1239-1241.

Liberman MC (1980) Morphological differences among radial afferent fibers in the cat cochlea: an electron-microscopic study of serial sections. Hear Res 3:45-63.

Liberman MC, Oliver ME (1984) Morphometry of intracellularly labeled neurons of the auditory nerve: Correlations with functional properties. The Journal of Comparative Neurology 223:163-176.

Lindau M, Neher E (1988) Patch-clamp techniques for time-resolved capacitance measurements in single cells. Pflugers Arch 411:137-146. 
Lisman J, Raghavachari S (2006) A Unified Model of the Presynaptic and Postsynaptic Changes During LTP at CA1 Synapses. Science's STKE 2006:re11-re11.

Liu Q, Lee E, Davis RL (2014) Heterogeneous intrinsic excitability of murine spiral ganglion neurons is determined by Kv1 and HCN channels. Neuroscience 257:96-110.

Longo-Guess C, Gagnon LH, Bergstrom DE, Johnson KR (2007) A missense mutation in the conserved C2B domain of otoferlin causes deafness in a new mouse model of DFNB9. Hear Res 234:21-28.

Lorincz A, Nusser Z (2008) Cell-Type-Dependent Molecular Composition of the Axon Initial Segment. Journal of Neuroscience 28:14329-14340.

Luo L (2002) Actin Cytoskeleton Regulation in Neuronal Morphogenesis and Structural Plasticity. Annual Review of Cell and Developmental Biology 18:601-635.

MacGillavry HD, Kerr JM, Blanpied TA (2011) Lateral organization of the postsynaptic density. Mol Cell Neurosci 48:321-331.

Magupalli VG, Schwarz K, Alpadi K, Natarajan S, Seigel GM, Schmitz F (2008) Multiple RIBEYE-RIBEYE interactions create a dynamic scaffold for the formation of synaptic ribbons. J Neurosci 28:7954-7967.

Makino H, Malinow R (2009) AMPA Receptor Incorporation into Synapses during LTP: The Role of Lateral Movement and Exocytosis. Neuron 64:381-390.

Matsubara A, Laake JH, Davanger S, Usami S, Ottersen OP (1996) Organization of AMPA receptor subunits at a glutamate synapse: a quantitative immunogold analysis of hair cell synapses in the rat organ of Corti. J Neurosci 16:4457.

Matthews G, Fuchs P (2010) The diverse roles of ribbon synapses in sensory neurotransmission. Nat Rev Neurosci 11:812-822.

Merchan-Perez A, Liberman MC (1996) Ultrastructural differences among afferent synapses on cochlear hair cells: correlations with spontaneous discharge rate. J Comp Neurol 371:208-221.

Meyer AC, Frank T, Khimich D, Hoch G, Riedel D, Chapochnikov NM, Yarin YM, Harke B, Hell SW, Egner A, Moser T (2009) Tuning of synapse number, structure and function in the cochlea. Nature Neuroscience 12:444-453.

Meyer AC, Moser T (2010) Structure and function of cochlear afferent innervation. Curr Opin Otolaryngol Head Neck Surg 18:441-446.

Migaud M, Charlesworth P, Dempster M, Webster LC, Watabe AM, Makhinson M, He Y, Ramsay MF, Morris RGM, Morrison JH, O’Dell TJ, Grant SGN (1998) Enhanced longterm potentiation and impaired learning in mice with mutant postsynaptic density-95 protein. Nature 396:433-439. 
Mohler PJ, Gramolini AO, Bennett V (2002) The Ankyrin-B C-terminal Domain Determines Activity of Ankyrin-B/G Chimeras in Rescue of Abnormal Inositol 1,4,5-Trisphosphate and Ryanodine Receptor Distribution in Ankyrin-B (-/-) Neonatal Cardiomyocytes. Journal of Biological Chemistry 277:10599-10607.

Moser T, Beutner D (2000a) Kinetics of exocytosis and endocytosis at the cochlear inner hair cell afferent synapse of the mouse. Proc Natl Acad Sci U S A 97:883-888.

Moser T, Beutner D (2000b) Kinetics of exocytosis and endocytosis at the cochlear inner hair cell afferent synapse of the mouse. Proc Natl Acad Sci USA 97:883-888.

Moser T, Neef A, Khimich D (2006) Mechanisms underlying the temporal precision of sound coding at the inner hair cell ribbon synapse. J Physiol 576:55-62.

Moser T, Starr A (2016) Auditory neuropathy - neural and synaptic mechanisms. Nat Rev Neurol 12:135-149.

Müller M, Smolders JWT (2005) Shift in the cochlear place-frequency map after noise damage in the mouse. Neuroreport 16:1183-1187.

Nair D, Hosy E, Petersen JD, Constals A, Giannone G, Choquet D, Sibarita J-B (2013) SuperResolution Imaging Reveals That AMPA Receptors Inside Synapses Are Dynamically Organized in Nanodomains Regulated by PSD95. Journal of Neuroscience 33:1320413224.

Nayagam BA, Muniak MA, Ryugo DK (2011) The spiral ganglion: Connecting the peripheral and central auditory systems. Hearing Research Available at: http://linkinghub.elsevier.com/retrieve/pii/S0378595511001043 [Accessed June 21, 2011].

Nouvian R, Beutner D, Parsons TD, Moser T (2006) Structure and function of the hair cell ribbon synapse. The Journal of membrane biology 209:153-165.

Nouvian R, Neef J, Bulankina AV, Reisinger E, Pangršič T, Frank T, Sikorra S, Brose N, Binz T, Moser T (2011) Exocytosis at the hair cell ribbon synapse apparently operates without neuronal SNARE proteins. Nat Neurosci 14:411-413.

Oak M-H, Yi E (2014) Voltage-gated K+ channels contributing to temporal precision at the inner hair cell-auditory afferent nerve fiber synapses in the mammalian cochlea. Archives of Pharmacal Research 37:821-833.

Obholzer N, Wolfson S, Trapani JG, Mo W, Nechiporuk A, Busch-Nentwich E, Seiler C, Sidi S, Söllner C, Duncan RN, Boehland A, Nicolson T (2008a) Vesicular glutamate transporter 3 is required for synaptic transmission in zebrafish hair cells. J Neurosci 28:2110-2118.

Obholzer N, Wolfson S, Trapani JG, Mo W, Nechiporuk A, Busch-Nentwich E, Seiler C, Sidi S, Sollner C, Duncan RN, Boehland A, Nicolson T (2008b) Vesicular Glutamate Transporter 3 Is Required for Synaptic Transmission in Zebrafish Hair Cells. Journal 
of Neuroscience 28:2110-2118.

Oertel D, Wright S, Cao X-J, Ferragamo M, Bal R (2011) The multiple functions of T stellate/multipolar/chopper cells in the ventral cochlear nucleus. Hear Res 276:61-69.

Ogawa Y, Rasband MN (2008) The functional organization and assembly of the axon initial segment. Current Opinion in Neurobiology 18:307-313.

Oliva MK, McGarr TC, Beyer BJ, Gazina E, Kaplan DI, Cordeiro L, Thomas E, Dib-Hajj SD, Waxman SG, Frankel WN, Petrou S (2014) Physiological and genetic analysis of multiple sodium channel variants in a model of genetic absence epilepsy. Neurobiology of Disease 67:180-190.

Opazo P, Labrecque S, Tigaret CM, Frouin A, Wiseman PW, De Koninck P, Choquet D (2010) CaMKII Triggers the Diffusional Trapping of Surface AMPARs through Phosphorylation of Stargazin. Neuron 67:239-252.

Opazo P, Sainlos M, Choquet D (2011) Regulation of AMPA receptor surface diffusion by PSD-95 slots. Curr Opin Neurobiol Available at: http://www.ncbi.nlm.nih.gov/pubmed/22051694 [Accessed February 21, 2012].

Opazo P, Sainlos M, Choquet D (2012) Regulation of AMPA receptor surface diffusion by PSD-95 slots. Current Opinion in Neurobiology 22:453-460.

O'Roak BJ et al. (2012) Multiplex Targeted Sequencing Identifies Recurrently Mutated Genes in Autism Spectrum Disorders. Science 338:1619-1622.

Palmer AR, Russell IJ (1986) Phase-locking in the cochlear nerve of the guinea-pig and its relation to the receptor potential of inner hair-cells. Hearing Research 24:1-15.

Pan Z (2006) A Common Ankyrin-G-Based Mechanism Retains KCNQ and NaV Channels at Electrically Active Domains of the Axon. Journal of Neuroscience 26:2599-2613.

Pangrsic T, Lasarow L, Reuter K, Takago H, Schwander M, Riedel D, Frank T, Tarantino LM, Bailey JS, Strenzke N, Brose N, Müller U, Reisinger E, Moser T (2010) Hearing requires otoferlin-dependent efficient replenishment of synaptic vesicles in hair cells. Nat Neurosci 13:869-876.

Pangršič T, Reisinger E, Moser T (2012) Otoferlin: a multi-C2 domain protein essential for hearing. Trends in Neurosciences 35:671-680.

Parkinson NJ, Olsson CL, Hallows JL, McKee-Johnson J, Keogh BP, Noben-Trauth K, Kujawa SG, Tempel BL (2001) Mutant $\beta$-spectrin 4 causes auditory and motor neuropathies in quivering mice. Nature Genetics 29:61-65.

Parsons TD (2006) Auditory fidelity. Nature 444:1013-1014.

Petrini EM, Lu J, Cognet L, Lounis B, Ehlers MD, Choquet D (2009) Endocytic Trafficking and Recycling Maintain a Pool of Mobile Surface AMPA Receptors Required for 
Synaptic Potentiation. Neuron 63:92-105.

Platzer J, Engel J, Schrott-Fischer A, Stephan K, Bova S, Chen H, Zheng H, Striessnig J (2000) Congenital deafness and sinoatrial node dysfunction in mice lacking class D L-type Ca2+ channels. Cell 102:89-97.

Radziwon KE, June KM, Stolzberg DJ, Xu-Friedman MA, Salvi RJ, Dent ML (2009) Behaviorally measured audiograms and gap detection thresholds in $\mathrm{CBA} / \mathrm{CaJ}$ mice. Journal of Comparative Physiology A 195:961-969.

Regus-Leidig H, Fuchs M, Löhner M, Leist SR, Leal-Ortiz S, Chiodo VA, Hauswirth WW, Garner CC, Brandstätter JH (2014) In vivo knockdown of Piccolino disrupts presynaptic ribbon morphology in mouse photoreceptor synapses. Front Cell Neurosci $8: 259$.

Regus-Leidig H, Ott C, Löhner M, Atorf J, Fuchs M, Sedmak T, Kremers J, Fejtová A, Gundelfinger ED, Brandstätter JH (2013) Identification and Immunocytochemical Characterization of Piccolino, a Novel Piccolo Splice Variant Selectively Expressed at Sensory Ribbon Synapses of the Eye and Ear. PLoS ONE 8:e70373.

Reisinger E, Bresee C, Neef J, Nair R, Reuter K, Bulankina A, Nouvian R, Koch M, Bückers J, Kastrup L, Roux I, Petit C, Hell SW, Brose N, Rhee J-S, Kügler S, Brigande JV, Moser T (2011) Probing the functional equivalence of otoferlin and synaptotagmin 1 in exocytosis. J Neurosci 31:4886-4895.

Riederer BM, Zagon IS, Goodman SR (1986) Brain spectrin(240/235) and brain spectrin(240/235E): two distinct spectrin subtypes with different locations within mammalian neural cells. J Cell Biol 102:2088-2097.

Robles L, Ruggero MA (2001) Mechanics of the Mammalian Cochlea. Physiol Rev 81:13051352.

Roos MJ, May BJ (2012a) Classification of unit types in the anteroventral cochlear nucleus of laboratory mice. Hearing Research 289:13-26.

Roos MJ, May BJ (2012b) Classification of unit types in the anteroventral cochlear nucleus of laboratory mice. Hearing Research 289:13-26.

Rothman JS, Young ED, Manis PB (1993) Convergence of auditory nerve fibers onto bushy cells in the ventral cochlear nucleus: implications of a computational model. Journal of neurophysiology 70:2562-2583.

Roux I, Safieddine S, Nouvian R, Grati M, Simmler M-C, Bahloul A, Perfettini I, Le Gall M, Rostaing P, Hamard G, Triller A, Avan P, Moser T, Petit C (2006) Otoferlin, defective in a human deafness form, is essential for exocytosis at the auditory ribbon synapse. Cell 127:277-289.

Ruel J, Chabbert C, Nouvian R, Bendris R, Eybalin M, Leger CL, Bourien J, Mersel M, Puel J-L (2008) Salicylate Enables Cochlear Arachidonic-Acid-Sensitive NMDA Receptor 
Responses. Journal of Neuroscience 28:7313-7323.

Russell IJ, Sellick PM (1978) Intracellular studies of hair cells in the mammalian cochlea. J Physiol (Lond) 284:261-290.

Rutherford MA (2015) Resolving the structure of inner ear ribbon synapses with STED microscopy: Molecular Nanoanatomy of Inner Ear Ribbon Synapses. Synapse 69:242255.

Rutherford MA, Roberts WM (2006) Frequency selectivity of synaptic exocytosis in frog saccular hair cells. Proc Natl Acad Sci U S A 103:2898.

Sachs MB, Abbas PJ (1974) Rate versus level functions for auditory-nerve fibers in cats: toneburst stimuli. J Acoust Soc Am 56:1835-1847.

Sachs MB, Winslow RL, Sokolowski BH (1989a) A computational model for rate-level functions from cat auditory-nerve fibers. Hear Res 41:61-69.

Sachs MB, Winslow RL, Sokolowski BH (1989b) A computational model for rate-level functions from cat auditory-nerve fibers. Hear Res 41:61-69.

Safieddine S, El-Amraoui A, Petit C (2012) The auditory hair cell ribbon synapse: from assembly to function. Annu Rev Neurosci 35:509-528.

Safieddine S, Eybalin M (1992) Co-expression of NMDA and AMPA/kainate receptor mRNAs in cochlear neurones. Neuroreport 3:1145-1148.

Safieddine S, Wenthold RJ (1999) SNARE complex at the ribbon synapses of cochlear hair cells: analysis of synaptic vesicle- and synaptic membrane-associated proteins. European Journal of Neuroscience 11:803-812.

Sanders SJ et al. (2012) De novo mutations revealed by whole-exome sequencing are strongly associated with autism. Nature 485:237-241.

Schlüter OM, Xu W, Malenka RC (2006) Alternative N-Terminal Domains of PSD-95 and SAP97 Govern Activity-Dependent Regulation of Synaptic AMPA Receptor Function. Neuron 51:99-111.

Schmitz F, Königstorfer A, Südhof TC (2000) RIBEYE, a component of synaptic ribbons: a protein's journey through evolution provides insight into synaptic ribbon function. Neuron 28:857-872.

Schnee ME, Lawton DM, Furness DN, Benke TA, Ricci AJ (2005) Auditory hair cell-afferent fiber synapses are specialized to operate at their best frequencies. Neuron 47:243-254.

Schnell E, Sizemore M, Karimzadegan S, Chen L, Bredt DS, Nicoll RA (2002a) Direct interactions between PSD-95 and stargazin control synaptic AMPA receptor number. Proceedings of the National Academy of Sciences 99:13902-13907.

Schnell E, Sizemore M, Karimzadegan S, Chen L, Bredt DS, Nicoll RA (2002b) Direct 
interactions between PSD-95 and stargazin control synaptic AMPA receptor number. Proceedings of the National Academy of Sciences 99:13902-13907.

Schnupp J (2011) Auditory Neuroscience: How to Stop Tinnitus by Buzzing the Vagus. Current Biology 21:R263-R265.

Schwander M, Sczaniecka A, Grillet N, Bailey JS, Avenarius M, Najmabadi H, Steffy BM, Federe GC, Lagler EA, Banan R, Hice R, Grabowski-Boase L, Keithley EM, Ryan AF, Housley GD, Wiltshire T, Smith RJH, Tarantino LM, Müller U (2007) A Forward Genetics Screen in Mice Identifies Recessive Deafness Traits and Reveals That Pejvakin Is Essential for Outer Hair Cell Function. J Neurosci 27:2163-2175.

Seal RP, Akil O, Yi E, Weber CM, Grant L, Yoo J, Clause A, Kandler K, Noebels JL, Glowatzki E, Lustig LR, Edwards RH (2008) Sensorineural Deafness and Seizures in Mice Lacking Vesicular Glutamate Transporter 3. Neuron 57:263-275.

Sewell WF (1984) The effects of furosemide on the endocochlear potential and auditory-nerve fiber tuning curves in cats. Hear Res 14:305-314.

Shah MM, Migliore M, Valencia I, Cooper EC, Brown DA (2008) Functional significance of axonal Kv7 channels in hippocampal pyramidal neurons. Proceedings of the National Academy of Sciences 105:7869-7874.

Shu Y, Yu Y, Yang J, McCormick DA (2007) Selective control of cortical axonal spikes by a slowly inactivating $\mathrm{K}+$ current. Proceedings of the National Academy of Sciences 104:11453-11458.

Simpson PJ, Schwappach B, Dohlman HG, Isaacson RL (2010) Structures of Get3, Get4, and Get5 provide new models for TA membrane protein targeting. Structure 18:897-902.

Singer JH, Diamond JS (2006) Vesicle Depletion and Synaptic Depression at a Mammalian Ribbon Synapse. Journal of Neurophysiology 95:3191-3198.

Sobkowicz HM, Rose JE, Scott GE, Slapnick SM (1982) Ribbon synapses in the developing intact and cultured organ of Corti in the mouse. J Neurosci 2:942-957.

Spassova MA, Avissar M, Furman AC, Crumling MA, Saunders JC, Parsons TD (2004) Evidence that rapid vesicle replenishment of the synaptic ribbon mediates recovery from short-term adaptation at the hair cell afferent synapse. J Assoc Res Otolaryngol 5:376-390.

Spoendlin H (1969) Innervation patterns in the organ of corti of the cat. Acta Otolaryngol 67:239-254.

Spoendlin H (1975) Neuroanatomical basis of cochlear coding mechanisms. Audiology $14: 383-407$.

Strenzke N, Chakrabarti R, Al-Moyed H, Müller A, Hoch G, Pangrsic T, Yamanbaeva G, Lenz C, Pan K-T, Auge E, Geiss-Friedlander R, Urlaub H, Brose N, Wichmann C, Reisinger 
E (2016) Hair cell synaptic dysfunction, auditory fatigue and thermal sensitivity in otoferlin Ile515Thr mutants. EMBO J 35:2519-2535.

Strenzke N, Chanda S, Kopp-Scheinpflug C, Khimich D, Reim K, Bulankina AV, Neef A, Wolf F, Brose N, Xu-Friedman MA, Moser T (2009) Complexin-I Is Required for HighFidelity Transmission at the Endbulb of Held Auditory Synapse. J Neurosci 29:79918004.

Taberner AM, Liberman MC (2005a) Response Properties of Single Auditory Nerve Fibers in the Mouse. J Neurophysiol 93:557-569.

Taberner AM, Liberman MC (2005b) Response Properties of Single Auditory Nerve Fibers in the Mouse. Journal of Neurophysiology 93:557-569.

Tomita S (2004) Dynamic Interaction of Stargazin-like TARPs with Cycling AMPA Receptors at Synapses. Science 303:1508-1511.

Touma M, Joshi M, Connolly MC, Ellen Grant P, Hansen AR, Khwaja O, Berry GT, Kinney HC, Poduri A, Agrawal PB (2013) Whole genome sequencing identifies SCN2A mutation in monozygotic twins with Ohtahara syndrome and unique neuropathologic findings. Epilepsia 54:e81-e85.

Triller A, Choquet D (2008) New Concepts in Synaptic Biology Derived from Single-Molecule Imaging. Neuron 59:359-374.

Trudeau MM (2006) Heterozygosity for a protein truncation mutation of sodium channel SCN8A in a patient with cerebellar atrophy, ataxia, and mental retardation. Journal of Medical Genetics 43:527-530.

Typlt M, Englitz B, Sonntag M, Dehmel S, Kopp-Scheinpflug C, Ruebsamen R (2012) Multidimensional Characterization and Differentiation of Neurons in the Anteroventral Cochlear Nucleus. PLoS One 7.

Uemoto Y, Suzuki S, Terada N, Ohno N, Ohno S, Yamanaka S, Komada M (2007) Specific Role of the Truncated $\beta I V-S p e c t r i n ~ \Sigma 6$ in Sodium Channel Clustering at Axon Initial Segments and Nodes of Ranvier. Journal of Biological Chemistry 282:6548-6555.

Uthaiah RC, Hudspeth AJ (2010) Molecular Anatomy of the Hair Cell's Ribbon Synapse. J Neurosci 30:12387-12399.

Varga R, Avenarius MR, Kelley PM, Keats BJ, Berlin CI, Hood LJ, Morlet TG, Brashears SM, Starr A, Cohn ES, Smith RJH, Kimberling WJ (2006) OTOF mutations revealed by genetic analysis of hearing loss families including a potential temperature sensitive auditory neuropathy allele. J Med Genet 43:576-581.

Varga R, Kelley PM, Keats BJ, Starr A, Leal SM, Cohn E, Kimberling WJ (2003) Nonsyndromic recessive auditory neuropathy is the result of mutations in the otoferlin (OTOF) gene. J Med Genet 40:45-50. 
Vilardi F, Lorenz H, Dobberstein B (2011) WRB is the receptor for TRC40/Asna1-mediated insertion of tail-anchored proteins into the ER membrane. J Cell Sci 124:1301-1307.

Virmani T (2003) Synaptotagmin 7 splice variants differentially regulate synaptic vesicle recycling. The EMBO Journal 22:5347-5357.

Vogl C et al. (2016a) Tryptophan-rich basic protein (WRB) mediates insertion of the tailanchored protein otoferlin and is required for hair cell exocytosis and hearing. EMBO $\mathrm{J}: \mathrm{e} 201593565$.

Vogl C et al. (2016b) Tryptophan-rich basic protein (WRB) mediates insertion of the tailanchored protein otoferlin and is required for hair cell exocytosis and hearing. EMBO J 35:2536-2552.

Vogl C, Cooper BH, Neef J, Wojcik SM, Reim K, Reisinger E, Brose N, Rhee J-S, Moser T, Wichmann C (2015) Unconventional molecular regulation of synaptic vesicle replenishment in cochlear inner hair cells. J Cell Sci 128:638-644.

Volkers L, Kahlig KM, Verbeek NE, Das JHG, van Kempen MJA, Stroink H, Augustijn P, van Nieuwenhuizen O, Lindhout D, George AL, Koeleman BPC, Rook MB (2011) Nav1.1 dysfunction in genetic epilepsy with febrile seizures-plus or Dravet syndrome: Analysis of Nav1.1 missense mutations in epilepsy. European Journal of Neuroscience 34:12681275.

Weiss LA, Escayg A, Kearney JA, Trudeau M, MacDonald BT, Mori M, Reichert J, Buxbaum JD, Meisler MH (2003) Sodium channels SCN1A, SCN2A and SCN3A in familial autism. Molecular Psychiatry 8:186-194.

Westerman LA, Smith RL (1984a) Rapid and short-term adaptation in auditory nerve responses. Hear Res 15:249-260.

Westerman LA, Smith RL (1984b) Rapid and short-term adaptation in auditory nerve responses. Hear Res 15:249-260.

Wichmann C, Moser T (2015) Relating structure and function of inner hair cell ribbon synapses. Cell Tissue Res.

Winkels R, Jedlicka P, Weise FK, Schultz C, Deller T, Schwarzacher SW (2009) Reduced excitability in the dentate gyrus network of $\beta I V$-spectrin mutant mice in vivo. Hippocampus 19:677-686.

Wynne DP, Zeng F-G, Bhatt S, Michalewski HJ, Dimitrijevic A, Starr A (2013) Loudness adaptation accompanying ribbon synapse and auditory nerve disorders. Brain 136:1626-1638.

Xu X, Zhang Y, Sun H, Liu X, Jiang Y, Wu X (2012) [Genetic and phenotypic characteristics of SCN1A mutations in Dravet syndrome]. Zhonghua Yi Xue Yi Chuan Xue Za Zhi 29:625-630. 
Yamada R, Kuba H (2016) Structural and Functional Plasticity at the Axon Initial Segment. Frontiers in Cellular Neuroscience 10 Available at: http://journal.frontiersin.org/article/10.3389/fncel.2016.00250/full [Accessed June 14, 2018].

Yamamoto Y, Sakisaka T (2015) The Emerging Role of Calcium-modulating Cyclophilin Ligand (CAML) in Posttranslational Insertion of Tail-anchored Proteins into the Endoplasmic Reticulum Membrane. J Biochem.

Yang Y (2004) IV Spectrins Are Essential for Membrane Stability and the Molecular Organization of Nodes of Ranvier. Journal of Neuroscience 24:7230-7240.

Yang Y, Ogawa Y, Hedstrom KL, Rasband MN (2007) $\beta I V$ spectrin is recruited to axon initial segments and nodes of Ranvier by ankyrinG. The Journal of Cell Biology 176:509519.

Yao W-D, Gainetdinov RR, Arbuckle MI, Sotnikova TD, Cyr M, Beaulieu J-M, Torres GE, Grant SGN, Caron MG (2004) Identification of PSD-95 as a regulator of dopaminemediated synaptic and behavioral plasticity. Neuron 41:625-638.

Yasunaga S, Grati M, Cohen-Salmon M, El-Amraoui A, Mustapha M, Salem N, El-Zir E, Loiselet J, Petit C (1999) A mutation in OTOF, encoding otoferlin, a FER-1-like protein, causes DFNB9, a nonsyndromic form of deafness. Nat Genet 21:363-369.

Yates GK, Robertson D, Johnstone BM (1985a) Very rapid adaptation in the guinea pig auditory nerve. Hearing Research 17:1-12.

Yates GK, Robertson D, Johnstone BM (1985b) Very rapid adaptation in the guinea pig auditory nerve. Hear Res 17:1-12.

Yildirim-Baylan M, Bademci G, Duman D, Ozturkmen-Akay H, Tokgoz-Yilmaz S, Tekin M (2014) Evidence for genotype-phenotype correlation for OTOF mutations. Int J Pediatr Otorhinolaryngol 78:950-953.

Yu H, Xu K, Zou B, Wu M, McManus OB, Le Engers J, Cheung Y-Y, Salovich JM, Hopkins CR, Lindsley CW, Li M (2010) Identification of a novel, small molecule inhibitor of KCNQ2 channels. In: Probe Reports from the NIH Molecular Libraries Program. Bethesda (MD): National Center for Biotechnology Information (US). Available at: http://www.ncbi.nlm.nih.gov/books/NBK133432/ [Accessed June 14, 2018].

Zenisek D, Davila V, Wan L, Almers W (2003) Imaging calcium entry sites and ribbon structures in two presynaptic cells. J Neurosci 23:2538-2548.

Zhang P, Lisman JE (2012) Activity-dependent regulation of synaptic strength by PSD-95 in CA1 neurons. Journal of Neurophysiology 107:1058-1066.

Zhang-Hooks Y, Agarwal A, Mishina M, Bergles DE (2016) NMDA Receptors Enhance Spontaneous Activity and Promote Neuronal Survival in the Developing Cochlea. Neuron 89:337-350. 
Zhou D, Lambert S, Malen PL, Carpenter S, Boland LM, Bennett V (1998) AnkyrinG is required for clustering of voltage-gated $\mathrm{Na}$ channels at axon initial segments and for normal action potential firing. J Cell Biol 143:1295-1304.

Zonta B, Desmazieres A, Rinaldi A, Tait S, Sherman DL, Nolan MF, Brophy PJ (2011) A Critical Role for Neurofascin in Regulating Action Potential Initiation through Maintenance of the Axon Initial Segment. Neuron 69:945-956. 


\section{Acknowledgements}

I am immensely grateful to Dr. Nicola Strenzke for the great support and generously shared knowledge and expertise, and raising me as a scientist. Together with Prof. Dr. Tobias Moser, they introduced me to the most fascinating and important problems of current sensory neuroscience. They inspired me by their research, mentored and supported my studies throughout the years and gave me an opportunity to address exciting scientific questions. I am grateful to Dr. Nicola Strenzke for the challenging discussions, and comments about this thesis. And I am grateful to Prof. Dr. Tobias Moser for being always around and encourage, and bring luck for the most challenging experiments. It has been breathtaking, inexpressibly difficult and great, and in the very end - very romantic time spent next to the great scientists and living legends.

I thank Prof. Dr. Tim Gollisch and Prof. Dr. Siegrid Löwel for being critical during thesis committee meetings, for their advices and patience, and general support. It has been always very helpful to receive an external point of view on my research and think different, think more. I benefit a lot from their knowledge, advices and experience.

I thank Prof. Dr. Jochen Staiger, Prof. Dr. Alexander Gail and Prof. Dr. Martin Göpfert to their interest to my research and agreement to examine me as extended examination committee members.

I thank Dr. Dr. Oliver Schlüter and Dr. Man Ho Wang for the fruitful collaboration.

I thank Prof. Dr. Sang Yong Jung and Dr. Jacob Neef for teaching and helping to obtain STED microscopy data and also for their kindness, availability and coffee break discussions.

I thank Gerhard Hoch and Peter Wenig for resolving all setup issues, as well as their attentive care to all arising technical questions.

I thank Dr. Zhizi Jing for the initial support and supervision of my first single unit in vivo experiment, as well as leaving for me a small library of his most favorite relevant scientific publications.

I thank Stefan Thom and Nadine Hermann for their great ABR measurements and also for the constant optimism and great work mood.

I thank Elisabeth Auge for introducing me to the behavioral experiment and initial help with the data analysis. 
I thank for the technical assistance and keeping things organized Christiane Senger-Freitag, Sandra Gerke and Nina Dankenbrink-Werder.

I thank GGNB for the great organization of the studying process as well as providing a great platform to exchange the knowledge, experience and issues within the graduate students.

I thank administrative coordinator Susann Müller, team assistant Patricia Raeke-Kuegler and secretary of Prof. T. Moser Frau Brigitte Higazi for the great organization of administrative work.

I would like to thank Dr. Markus Jeschke and Dr. Christian Wrobel for the team spirit, science questions, discussions, support, critical and friendly advises. Their true scientific passion and work courage were so inspiring. Thanks to Dr. C. Wrobel for great years of work over the weekends, holidays and sometime night shifts in Uniklinikum Göttingen, as well as encouragement to speak German.

I would like to thank my office mates Dr. Tobias Dombrowski, Dr. Kai Bodensiek, Dennis Spormann and Maike Pelgrim for the perfect joyful work atmosphere and their help in numerous questions.

I would like to thank all members of the InnerEarLab for the excellent work atmosphere and team spirit, especially to Daniel Keppeler, Josephine T. Mintel, Mattia Nova, Dr. Nikolai M. Chapochnikov and Dr. Ellen Reisinger.

I would like to thank Dr. Mattis R. O. Bertlich and Dr. Bernhard G. Weiss for being attentive friends from my first day of coming to the Uniklinikum Göttingen till the last stage of my doctorate. I thank Dr. Bernhard G. Weiss for expanding my interest in medicine and surgery. I am grateful to my friend and mentor Dr. Renato Frischknecht for scientific discussions, work and life advises, and for the encouragement to become a scientist.

I am grateful to my previous mentors in Russia Dr. Ruslan Mukhamadeev, Dr. Vadim Fedyaev and my biology teacher in school Tatiana Nikolaevna Krivoschekova for inspiring me and believing in me.

I would like to thank my friends Andreas Kuzel, Alexei Arapov, Maria Tchistyakova, Bruno Bodenstein, Dr. Alexei Akhounov, Dr. Alexei Kascheev, Dr. Alexei Traspov and Dr. Anna Vasinskaya for being good advisers and personal inspiring examples.

Finally, I would like to thank my family for their understanding, love and care, especially to my sister Almira Yamanbaeva and my parents for their endless support and believe in me. 
Curriculum Vitae 


\section{List of Publications}

Jung, Sangyong, Tomoko Oshima-Takago, Rituparna Chakrabarti, Aaron B. Wong, Zhizi Jing, Gulnara Yamanbaeva, Maria Magdalena Picher, et al. 2015. 'Rab3-Interacting Molecules $2 \alpha$ and $2 \beta$ Promote the Abundance of Voltage-Gated CaV1.3 Ca2+ Channels at Hair Cell Active Zones'. Proceedings of the National Academy of Sciences 112 (24): E3141-49. doi:10.1073/pnas.1417207112.

Strenzke, Nicola, Rituparna Chakrabarti, Hanan Al-Moyed, Alexandra Müller, Gerhard Hoch, Tina Pangrsic, Gulnara Yamanbaeva, et al. 2016. 'Hair Cell Synaptic Dysfunction, Auditory Fatigue and Thermal Sensitivity in Otoferlin Ile515Thr Mutants'. The EMBO Journal 35 (23): 2519-35. doi:10.15252/embj.201694564.

Vogl $^{1}$, Christian, Iliana Panou ${ }^{1}$, Gulnara Yamanbaeva ${ }^{1}$, Carolin Wichmann, Sara J. Mangosing, Fabio Vilardi, Artur A. Indzhykulian, et al. 2016. 'Tryptophan-Rich Basic Protein (WRB) Mediates Insertion of the Tail-Anchored Protein Otoferlin and Is Required for Hair Cell Exocytosis and Hearing'. The EMBO Journal, July. doi:10.15252/embj.201593565. 